\title{
Assimilation of Doppler weather radar observations in a mesoscale model for the prediction of rainfall associated with mesoscale convective systems
}

\author{
S Abhilash ${ }^{1, *}$, Someshwar Das ${ }^{2}$, S R Kalsi ${ }^{3}$, M Das Gupta ${ }^{2}$, K Mohankumar ${ }^{1}$,

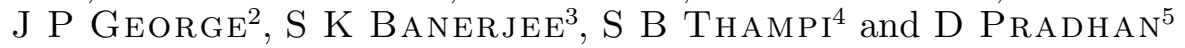 \\ ${ }^{1}$ Department of Atmospheric Sciences, Cochin University of Science and Technology, Cochin 682 016, India. \\ ${ }^{2}$ National Center for Medium Range Weather Forecasting, Noida 201 30\%, India. \\ ${ }^{3}$ India Meteorological Department, Mausam Bhavan, Lodhi Road, New Delhi 110 003, India. \\ ${ }^{4}$ Cyclone Detection Radar, India Meteorological Department, Rajaji Salai, Chennai 600 001, India. \\ ${ }^{5}$ Cyclone Detection Radar, Regional Meteorological Center, India Meteorological Department, Kolkata, India. \\ *e-mail: abhimets@yahoo.com
}

\begin{abstract}
Obtaining an accurate initial state is recognized as one of the biggest challenges in accurate model prediction of convective events. This work is the first attempt in utilizing the India Meteorological Department (IMD) Doppler radar data in a numerical model for the prediction of mesoscale convective complexes around Chennai and Kolkata. Three strong convective events both over Chennai and Kolkata have been considered for the present study. The simulation experiments have been carried out using fifth-generation Pennsylvania State University-National Center for Atmospheric Research (PSU-NCAR) mesoscale model (MM5) version 3.5.6. The variational data assimilation approach is one of the most promising tools available for directly assimilating the mesoscale observations in order to improve the initial state. The horizontal wind derived from the DWR has been used alongwith other conventional and non-conventional data in the assimilation system. The preliminary results from the three dimensional variational (3DVAR) experiments are encouraging. The simulated rainfall has also been compared with that derived from the Tropical Rainfall Measuring Mission (TRMM) satellite. The encouraging result from this study can be the basis for further investigation of the direct assimilation of radar reflectivity data in 3DVAR system. The present study indicates that Doppler radar data assimilation improves the initial field and enhances the Quantitative Precipitation Forecasting (QPF) skill.
\end{abstract}

\section{Introduction}

Mesoscale convective cloud clusters produce large amounts of rain in the tropics and consist of numerous deep cells. The structure and life cycle of Tropical Mesoscale Convective Systems (TMCS) is complex and in its mature stage, the clusters consist partly of convective towers which contain buoyant updrafts, negatively buoyant downdrafts and heavy showers of rain. The precipitation bands associated with these TMCS extend over a horizontal distance of more than $100 \mathrm{~km}$. Based on the radar reflectivity and satellite imageries obtained during Global Atmospheric Research Program (GARP)'s Atlantic Tropical Experiment (GATE) and GARP's Winter Monsoon Experiment (WMONEX), Houze (1982) summarized the detailed structure of these oceanic TMCS. Studies by Maddox (1980) had well documented many important characteristics of MCS using satellite data.

Tropical deep convection is observed to be organized on scales ranging from a few tens of kilometers to 100 s and even 1000 s of kilometers. Radar

Keywords. Tropical mesoscale convective systems; Doppler weather radar; 3DVAR; radar reflectivity. 
reflectivity and satellite observations show the detailed organization of individual cloud clusters into mesoscale convective systems, and the grouping of these cloud clusters and MCS into Mesoscale Convective Complexes (MCC) and Super Cloud Clusters (SCC) with horizontal scale up to $1000 \mathrm{~km}$ or more (Mapes and Houze 1993; Nakazawa 1988).

The updraft and downdraft motions depend on the heating associated with freezing and cooling associated with melting. Scott and Houze (1995) have shown that the strong maximum melting is found just above the position of the mean convective downdrafts. Strong heating contained within a deep vertical column nearly coincides with the convective updraft. Hence a detailed vertical structure of thermodynamical and microphysical fields is very important in the structure and intensity of parameterized convective cloud clusters.

Prediction of the timing, location, organization and structure of the MCS especially over the tropics is recognized as one of the biggest challenges in mesoscale modeling. The mesoscale and storm scale models require observations with high temporal and spatial resolution for determining the initial conditions. The variational data assimilation approach is one of the most promising techniques available for directly assimilating heterogeneous mesoscale observations in order to improve the estimate of the model initial state. Das Gupta et al (2005) made the first attempt to investigate the application of the MM5-3DVAR assimilation system on the Indian region.

Doppler radars play a key role in the high resolution convective and mesoscale data assimilation system. Despite the importance of the use of DWR data for forewarning of heavy rainfall associated with convective systems, there remains no effort to include analyzed Doppler radar data in the assimilation cycle of the operational weather prediction models in India. Therefore, a first step in the near real time application of DWR observations in the 3DVAR system is investigated in this study. The main objective of this study is to explore the role of DWR wind observations in initializing storm scale models and quantitative precipitation forecasting.

\section{Overview of the 3DVAR systems in MM5}

The mesoscale model, MM5 version 3.5.6 (Grell et al 1994) has been used for the present study. The MM5 is a non-hydrostatic model with terrain following $\sigma$ coordinate system developed at the National Center for Atmospheric Research (NCAR) and designed to simulate or predict mesoscale and regional scale atmospheric circulation (Dudhia et al 2002). The 3DVAR system developed for MM5 is flexible enough to allow a variety of research studies apart from its operational utilization. The 3DVAR system developed by Barker et al $(2003,2004)$ has been used for the present assimilation experiments. The basic goal of the 3DVAR system is to produce an 'optimal' estimate of the true atmospheric state at any desired analysis time through iterative solution of a prescribed cost function (Ide et al 1997)

$$
\begin{aligned}
J(x)= & J^{b}+J^{o}=\frac{1}{2}\left(x-x^{b}\right)^{T} B^{-1}\left(x-x^{b}\right) \\
& +\frac{1}{2}\left(y-y^{o}\right)^{T}(E+F)^{-1}\left(y-y^{o}\right) .
\end{aligned}
$$

The variational (VAR) problem can be summarized as an iterative solution of equation (1) to find an analysis state $x$ that minimizes $J(x)$. This solution represents a posteriori maximum likelihood (minimum variance) estimate of the true state of the atmosphere given the two sources of the priori data: the background (previous forecast) $x^{b}$ and observations $y^{o}$ (Lorenc 1986). The fit to individual data points is weighted by estimates of their errors; $B, E$ and $F$ are the background, observation (instrumental) and representivity error covariance matrices respectively. Representivity error is an estimate of the inaccuracies introduced in the observation operator $H$ used to transform the gridded analysis $x$ to observation space $y=H x$. Further details about the components of the 3DVAR system can be found in Barker et al (2003). Applications of the 3DVAR system have been reported in real-time analysis and forecasting (Barker et al 2004).

Statistics of the differences between the 24-h and 12-h forecast are used to estimate the background error covariances via the National Meteorological Center (NMC) method (Parish and Derber 1992). Das Gupta et al (2005) computed the background error $(B)$ of the MM5 (V3.6) model using the NMC method and studied the impact of various conventional and non-conventional data sets on the Indian region.

\section{Background motivation and experiment design}

Data from DWR provides valuable information for verification of mesoscale and cloud system resolving models such as Weather Research and Forecast (WRF), MM5 and Regional Atmospheric Modeling System (RAMS). It will also allow development and testing of advanced data assimilation techniques.

Figure 1 shows the domain configuration for the MM5 experiments. Two-way nesting is employed 
Domains of MM5 simulation

Model terrain height $(\mathrm{km})$ above sea level (shading)

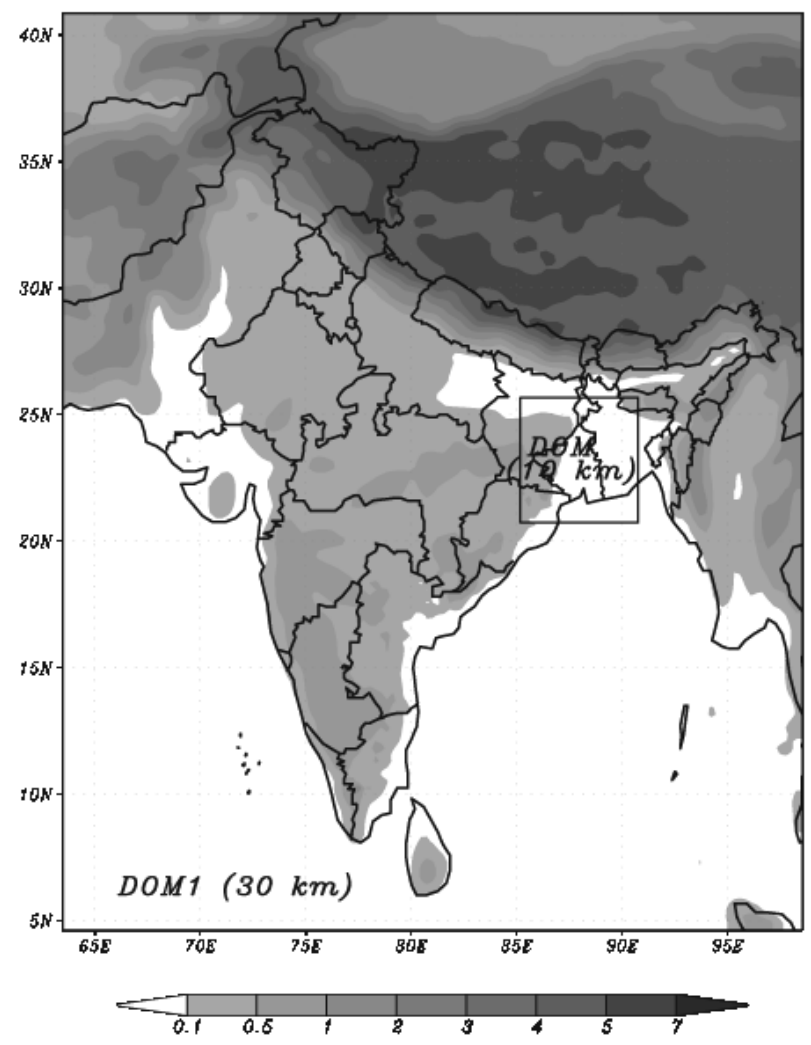

Figure 1. Domain configuration for MM5-3DVAR experiments.

with a horizontal resolution of $30 \mathrm{~km}$ for the coarse outer grid and $10 \mathrm{~km}$ for the inner fine grid. The model physics include Grell cumulus parameterization (Grell et al 1994), boundary layer parameterization of Hong and Pan (1996) as used in the Medium Range Forecast (MRF) model, explicit treatment of cloud water, rain water, snow, ice and graupel has been performed using GSFC (NASA/Goddard Space Flight Center) scheme (Tao et al 1989, 1993), cloud radiation interaction is allowed between explicit cloud and clear air.

To assess the impact of assimilating the DWR wind data into MM5-3DVAR system for predicting the mesoscale convective events, three experiments have been carried out. The initial and lateral boundary conditions are obtained from the global analysis of NCMRWF T80 model to initialize the first (CTRL/GSFC) experiment. In the second experiment (3DVAR/NoDWR), the conventional and non-conventional observations are included in the 6-h assimilation cycle in which the cold-start is at $0600 \mathrm{UTC}$ of the previous day. In this 6-h 3DVAR update cycle, the 6 - $h$ forecast from the previous cycle serves as the background for the next cycle. The third experiment (3DVAR/DWR) is the same as the second experiment, except the
Table 1. Description of data used in the assimilation experiments.

\begin{tabular}{ll}
\hline Data & Description \\
\hline SYNOP & Surface observations from land stations \\
SHIP & Voluntary observation from sea \\
BUOY & Drifting and moored buoy observations \\
TEMP & $\begin{array}{l}\text { Upper air profiles of temperature, } \\
\text { humidity and wind from radio theodolite }\end{array}$ \\
PILOT & Wind profiles from optical theodolite \\
AIREP/AMDAR & $\begin{array}{l}\text { Upper level wind and temperature } \\
\text { reported by aircrafts }\end{array}$ \\
SATOB & $\begin{array}{l}\text { Satellite observed cloud motion vectors } \\
\text { from INSAT, METEOSAT-6, GMS and } \\
\text { GOES }\end{array}$ \\
SATEM & $\begin{array}{l}\text { Satellite observed wind and total pre- } \\
\text { cipitable water from NOAA series of } \\
\text { satellites }\end{array}$ \\
\hline
\end{tabular}

Table 2. Summary of MM5 forecast experiments.

\begin{tabular}{ll}
\hline Experiment & Initialization and assimilation \\
\hline CTRL_GSFC & $\begin{array}{l}\text { Using global analysis of NCMRWF T80 } \\
\text { model without data assimilation }\end{array}$ \\
3DVAR_NoDWR & $\begin{array}{l}\text { 3DVAR 6-h assimilation cycle using } \\
\text { GTS data }\end{array}$ \\
3DVAR_DWR & 3DVAR 6-h assimilation cycle using \\
& GTS and DWR wind observations \\
\hline
\end{tabular}

horizontal wind derived from the DWR has also been used along with other conventional and nonconventional data in the assimilation system. The DWR wind fields are available at 6 levels (0.5, $1.0,1.5,2.0,2.5,3.0 \mathrm{~km}$ ) above the ground. Link software has been developed to read the DWR wind data and convert them into a format suitable for the 3DVAR data assimilation system. Table 1 gives the details of the data used for the assimilation experiments. Summary of the experiments are described in table 2. Figure 2 shows the overview of the three experiments.

Heavy rainfall occurs frequently over the Indian peninsula during pre-monsoon and monsoon season associated with Tropical Mesoscale Convective Systems (TMCS). The radar reflectivity and rainfall observations are used to select the convection days. In order to investigate the detailed structure of convection and thunderstorms and utility of DWR observations in a mesoscale model, three cases around Kolkata and four cases around Chennai have been selected for the present study. The seven cases are listed in table 3 . A detailed investigation of each case and the simulated results are presented here. Accumulated rainfall amount from the simulations are compared with TRMM 


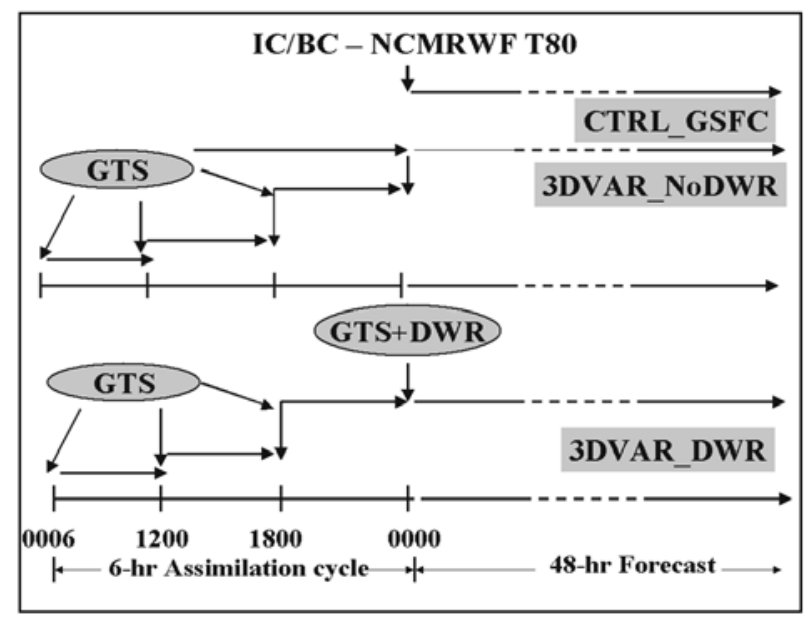

Figure 2. Experiment design for radar data assimilation.

Table 3. Cases selected for the experiments.

\begin{tabular}{llr}
\hline Case & Location & \multicolumn{1}{c}{ Date } \\
\hline 1 & Kolkata & 6 May 2005 \\
2 & Kolkata & 22 May 2005 \\
3 & Kolkata & 7 June 2005 \\
4 & Chennai & 30 April 2005 \\
5 & Chennai & 1 May 2005 \\
6 & Chennai & 2 May 2005 \\
7 & Chennai & 3 May 2005 \\
\hline
\end{tabular}

observations. The results are examined further in two aspects;

- organization of precipitation bands associated with TMCS and

- simulated structure of near surface radar reflectivity.

\section{Simulation of intense convection events around Kolkata}

We have considered three rain cases over Kolkata. Observational analysis of these cases indicates that the large-scale atmospheric features and the process of heavy rain development differ from case to case.

\subsection{Case 1: 5-6 May 2005}

A north-south oriented trough from northern states to south peninsular India dominated the weather condition over the region. The trough extended up to $0.9 \mathrm{~km}$ above mean sea level. Maximum temperature was above normal by $2-3^{\circ} \mathrm{C}$ at many places over the region. Thunderstorms were reported over the Gangetic West Bengal and sub-Himalayan West Bengal during 5-7 May.
Jalpaiguri, Cooch Behar and Malda reported $1 \mathrm{~cm}$ rainfall each on 5 May. Kolkata (Alipore) reported $5 \mathrm{~cm}$ and Kolkata (Dum Dum) reported $2 \mathrm{~cm}$ on 6 May. On 7 May, Kolkata (Dum Dum) and Digha reported $5 \mathrm{~cm}$, Canning Town and Diamond Harbour reported $1 \mathrm{~cm}$ rainfall each on 7 May.

Figure 3(a, b, c and d) presents radar reflectivity, MAX (Z) at 1148 UTC, 1648 UTC of 05 May and at 1108 and 1408 UTC of 06 May 2005. The radar reflectivity pattern also shows similar organization and movement of convective cloud clusters on 5 and 6 May 2005. Figure 4(a) shows the 6-h accumulated rainfall observed by TRMM satellite. Two rainbands were observed around Kolkata, one over the north and the other over southwest of Kolkata during 0600-1800 UTC 5 May. The major rainbands, initially originating from northwest, propagated southeastwards during 0600 UTC 5 May and 0000 UTC 6 May, which is a typical characteristic of Norwesters (the severe thunderstorms that move from northwest to southeast direction over the West Bengal region during the pre-monsoon season). A small patch of rainband is also observed over northwest of Kolkata at 1200 UTC of 6 May, which moved southward and centered around south and southeast of Kolkata at 1800 UTC 6 May. Though the intensity of precipitation was less, this precipitation band moved southeastwards.

\subsubsection{Simulated rainfall}

Six-hour accumulated rainfall from the three experiments are compared with the observations. Figure 4(b, c and d) presents simulated rainfall by the three experiments, namely CTRL_GSFC, 3DVAR_NoDWR and 3 DVAR_DWR respectively. The CTRL_GSFC simulation shows $6-8 \mathrm{~cm}$ of widespread rainfall between 0600 and 1800 UTC, 6 May and 3DVAR_NoDWR predicts rainbands with less intensity as compared to CTRL_GSFC experiment. But the TRMM does not show much rainfall at these times. The rainfall observed by TRMM may be underestimated as it depends on the pass of the satellite and the rain-gauge observations included in its analysis. The observed rainfall amount from TRMM is more during 06001800 UTC, 5 May. Both the experiments show the southeastward propagation of the precipitation bands as observed by TRMM. However, radar reflectivity (figure 3) does show clouds between 12 and 18 UTC of 6 May. The simulated rainfall from 3DVAR_DWR indicates that assimilation of DWR data has produced rainfall during 1200-1800 UTC of both 5 and 6 May, south of Kolkata as seen from TRMM observations and satellite images. The 5 May rainfall was not simulated by the experiments CTRL_GSFC and 3DVAR_NoDWR. 
(a) $\operatorname{MAX}(Z) \quad 1148 Z 050505$

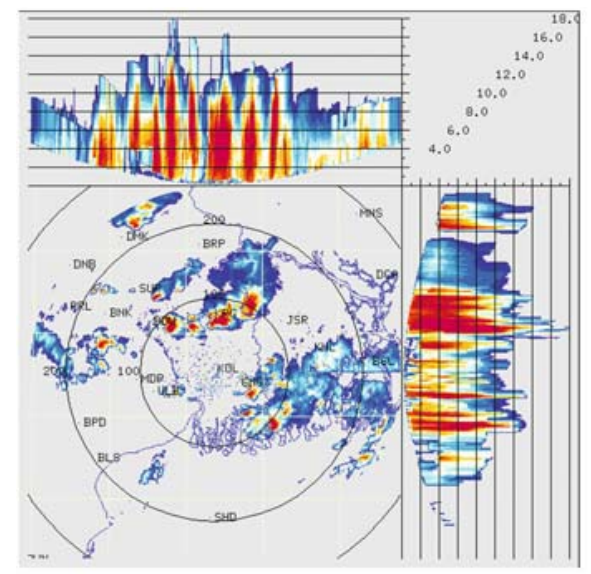

(c) $\operatorname{MAX}(Z) \quad 1108 Z 060505$

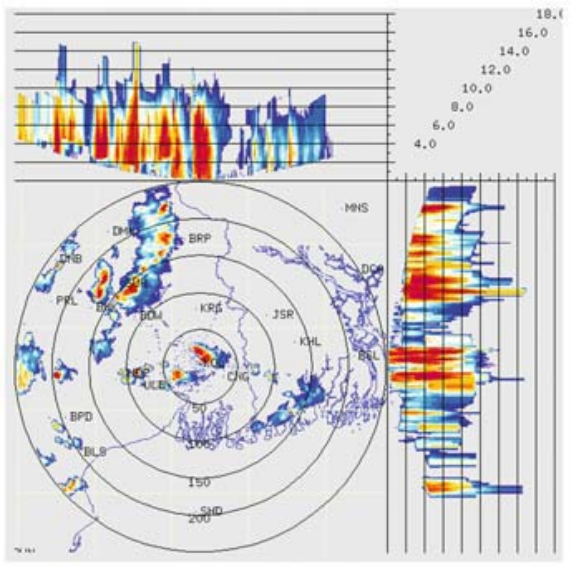

(b) $\operatorname{MAX}(Z) \quad 1648 Z 050505$

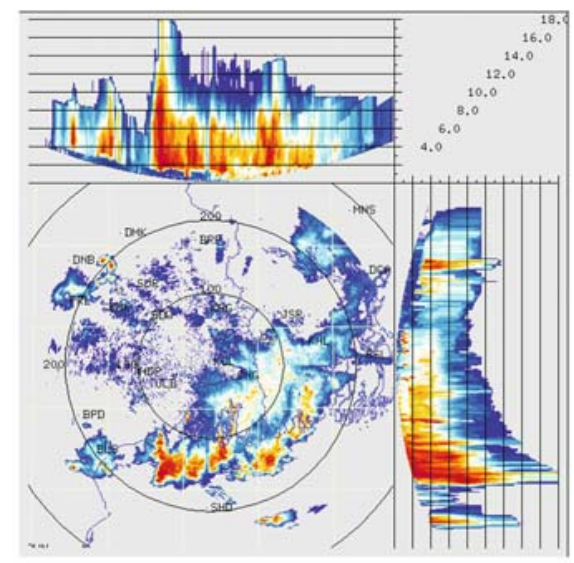

(d) $\operatorname{MAX}(\mathrm{Z}) \quad 1408 Z 060505$

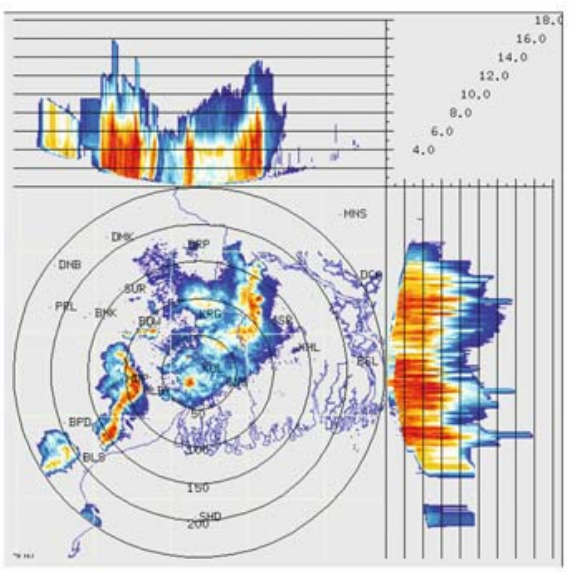

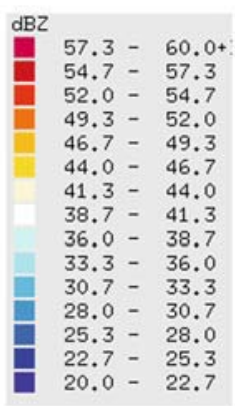

Figure 3. Radar reflectivity, MAX(Z) at (a) 1148 UTC, (b) 1648 UTC of 5 May and at (c) 1108 and (d) 1408 UTC of 6 May 2005.

The rainfall amount is further reduced in the 3DVAR_DWR experiment, making it closer to observations. The aerial extent of the precipitation band is also reduced in the 3DVAR_DWR experiment.

\subsubsection{Reflectivity}

Figure 5 shows the simulated near-surface radar reflectivity (shading) of the three experiments at 6 -h intervals. The CTRL_GSFC and 3DVAR_NoDWR experiments do not predict any reflectivity structure valid at 1200 and 1800 UTC of 5 May, while 3DVAR_DWR experiment predicts small patches of reflectivity values greater than $50 \mathrm{dBZ}$ valid at the same forecast time. All the three experiments predict regions of enhanced reflectivity patches at 1200 and 1800 UTC of 6 May. At 1800 UTC, the model-derived echoes from the CTRL_GSFC experiment is distributed over a large area with maximum reflectivity of more than $50 \mathrm{dBZ}$ over the Kolkata region, while that from the 3DVAR_NoDWR experiment showing two individual maximum in radar reflectivity over and to the west of Kolkata. The 3DVAR_DWR experiment simulates radar echoes extending from the southwest to northeast of Kolkata with three distinct maximum of reflectivities (> $50 \mathrm{dBZ}$ ) one over Kolkata, another two over southwest and northeast of Kolkata. The radar reflectivity predicted by the 3DVAR_DWR experiment is almost close to the observed low-level (elevation angle of 0.5 degree) radar reflectivity from the DWR (figure 3). The main important result from this analysis is that the intensity, location and organization of MCSs are better simulated by the 3DVAR_DWR experiment. Though the simulated reflectivity does not match exactly with the observations, their magnitudes are of the same order and range from $10-50 \mathrm{dBZ}$.

\subsubsection{Vorticity}

In this section, the wind field such as convergence in terms of vorticity has been analyzed to examine the improvements in the initial 
(a) TRMM

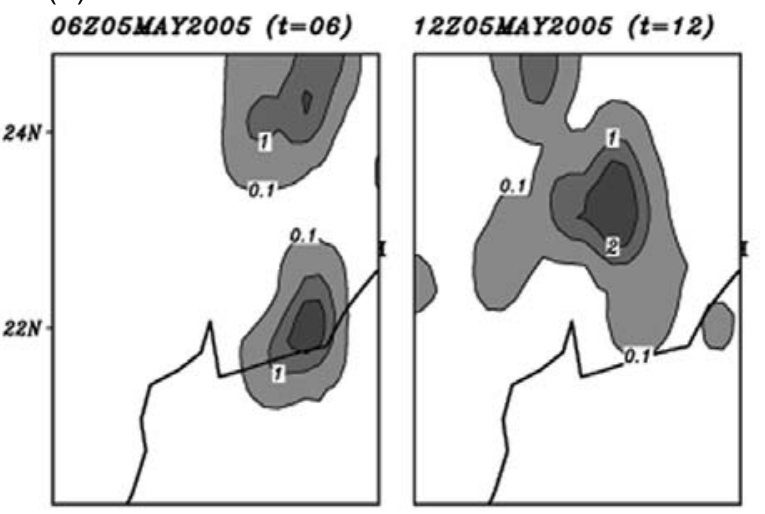

O6Z06MAY2005 $(t=30)$

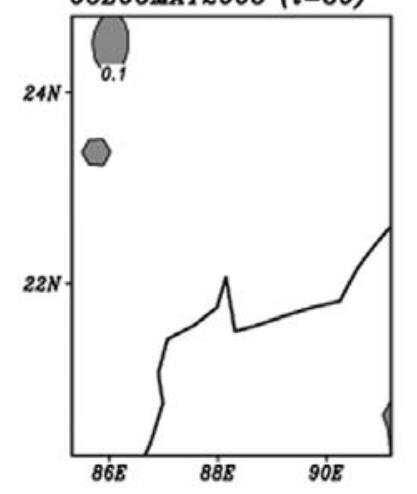

(b) CTRL_GSFC
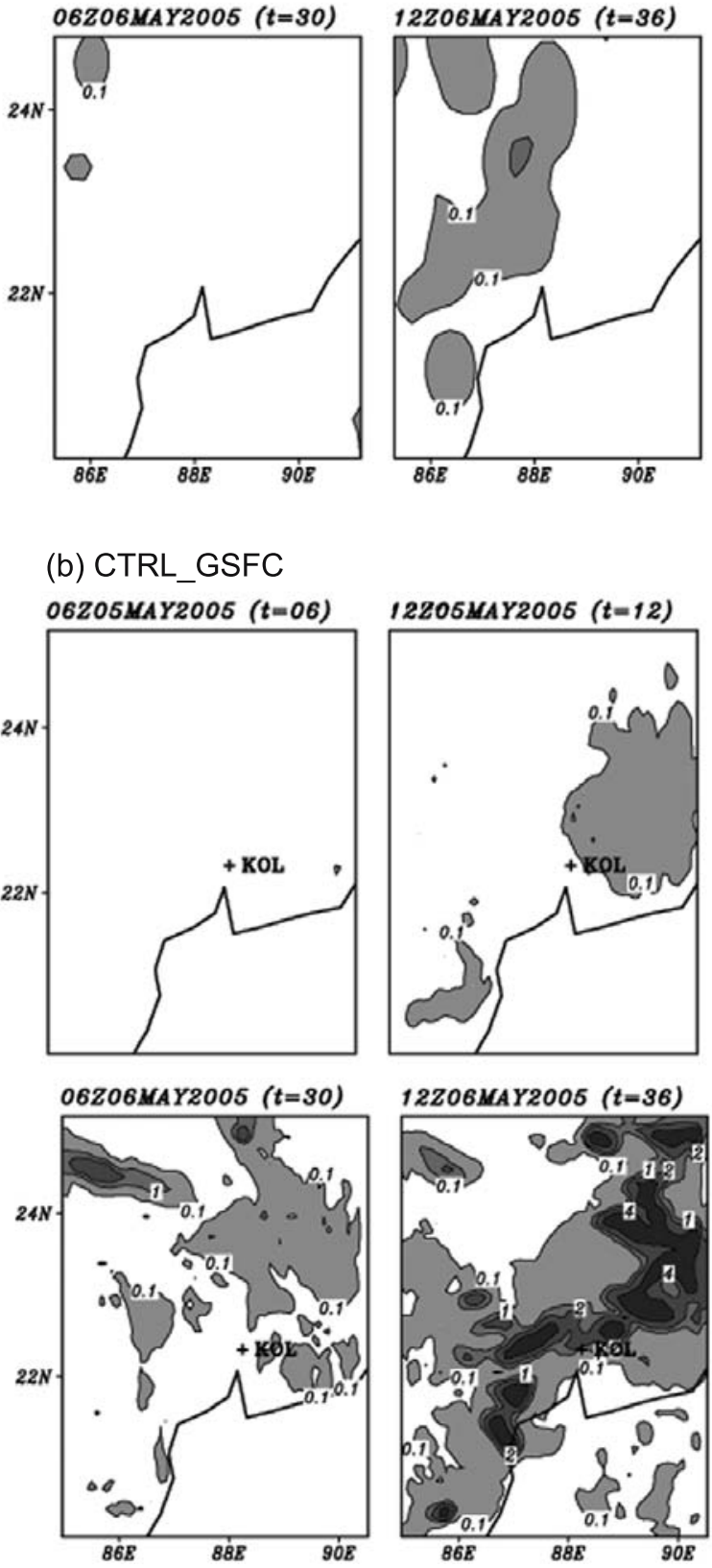

$86 \dot{8 B E} \quad 9 \dot{O B E}$

12Z05MAY2005 $(t=12)$

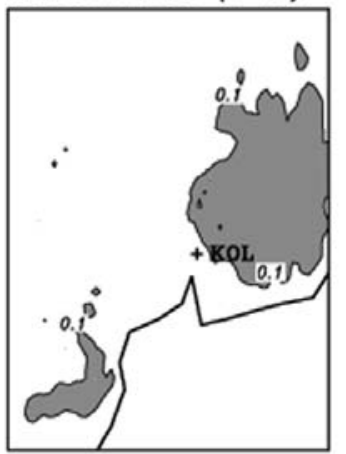

12Z06MAY2005 $(t=36)$

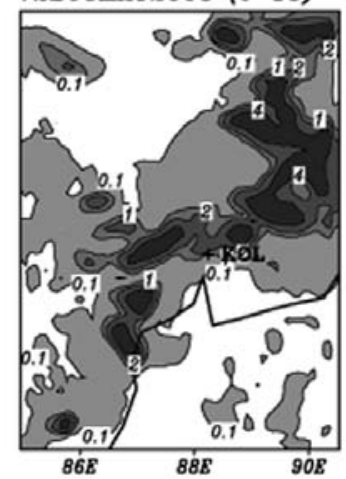

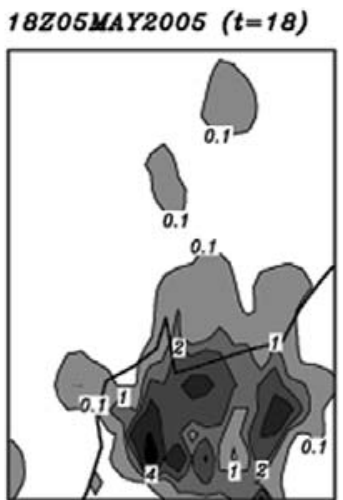

18Z06MAY2005 $(t=42)$
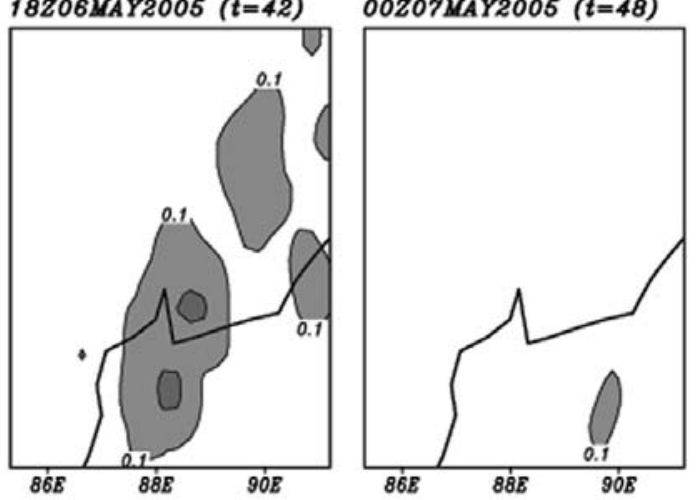

18Z05MAY2005 $(t=18)$

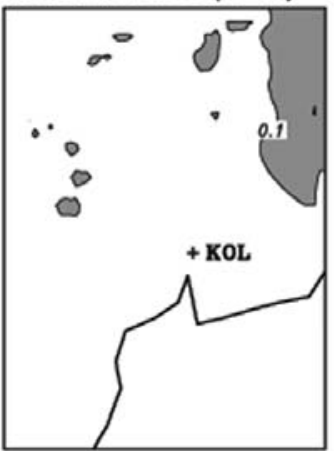

18Z06MAY2005 ( $t=42)$

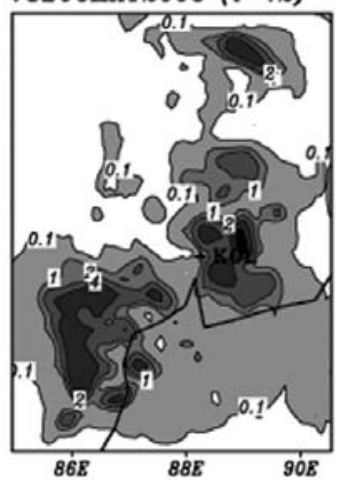

OOZ06MAY2005 $(t=24)$

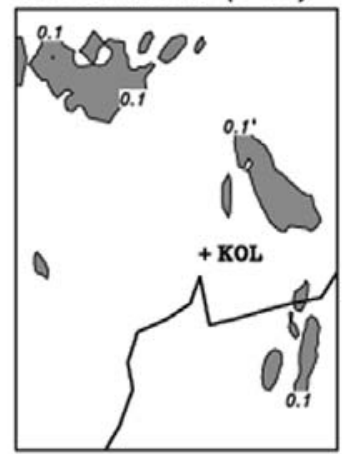

OOZ07MAY2005 $(t=48)$

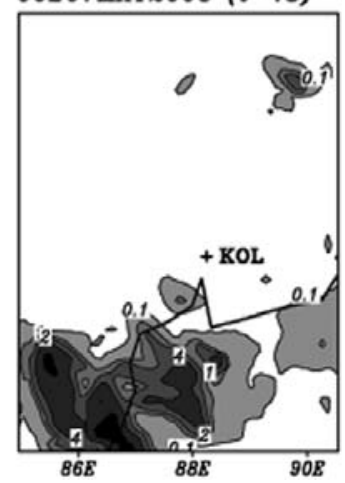

Figure 4. (Continued) 
(c) 3DVAR_NoDWR
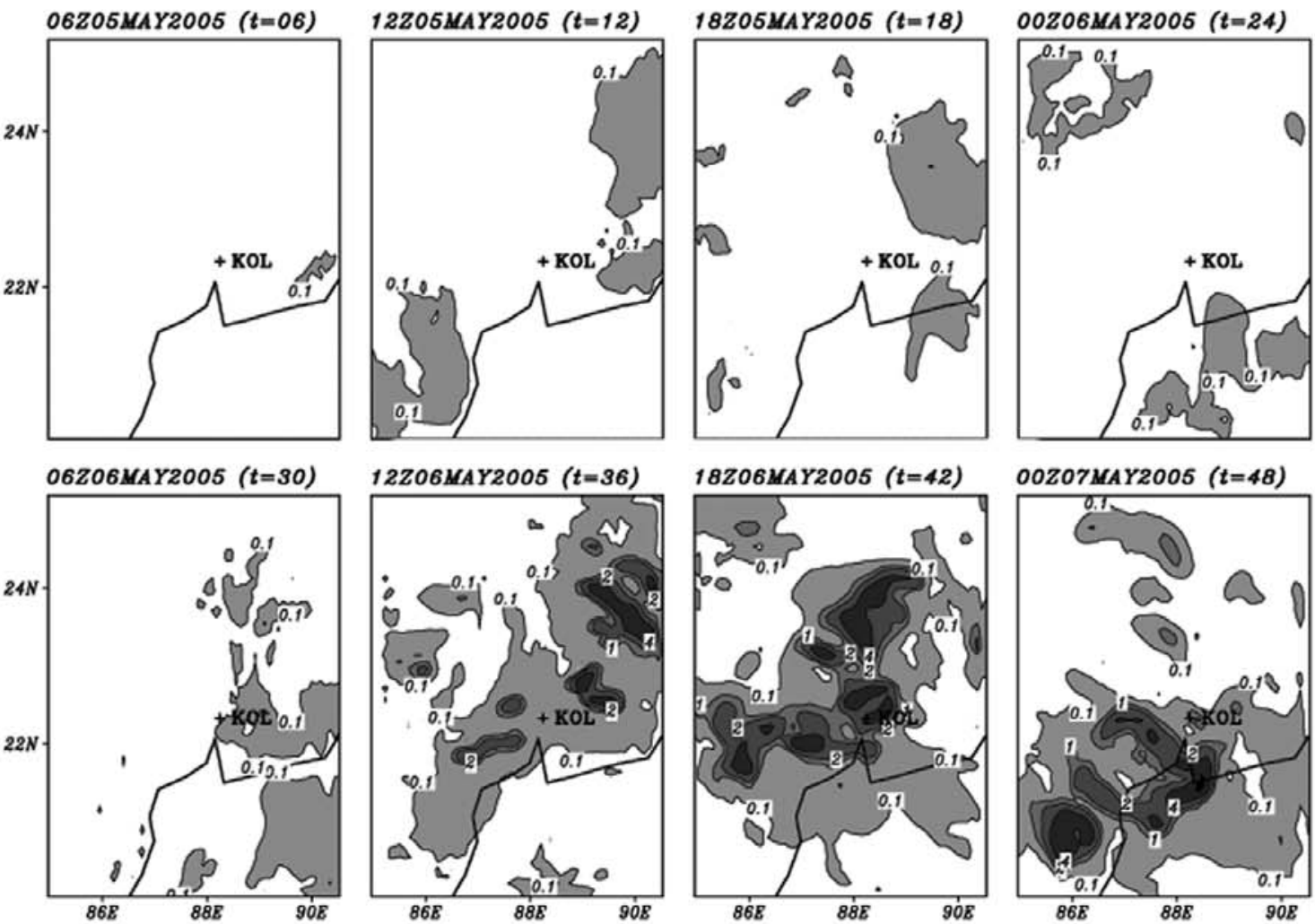

(d) 3DVAR_DWR

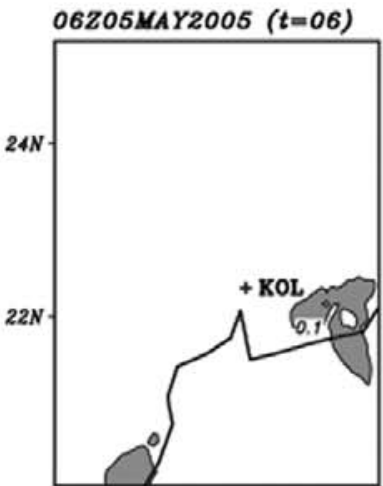

$12 Z 05 M A Y 2005(t=12)$
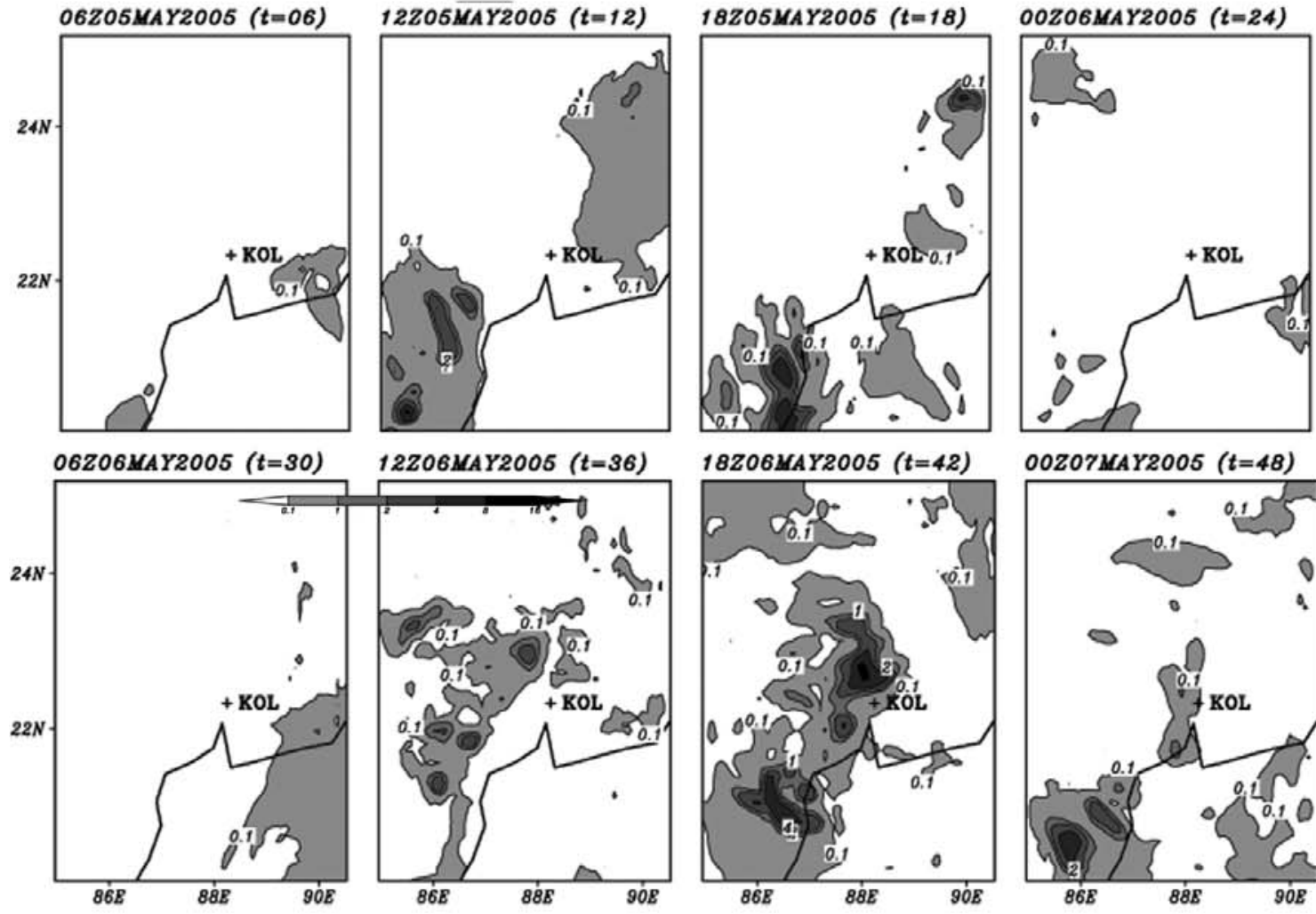

OOZOFMAYZOO5 $(t=48)$
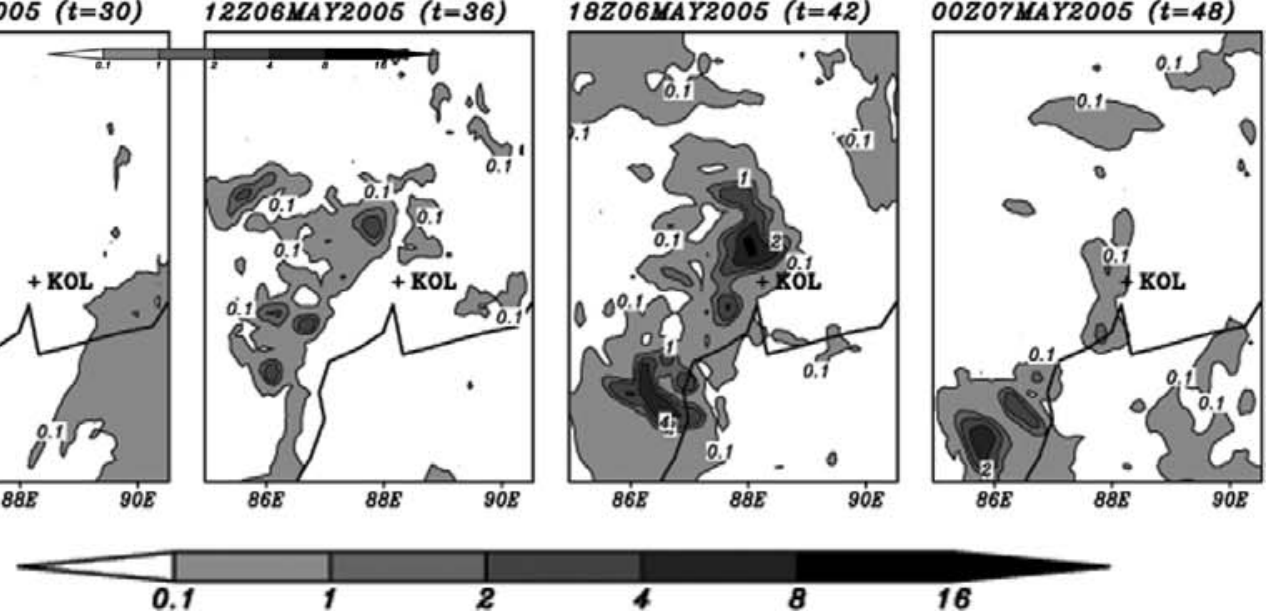

8

16

Figure 4(a-d). Six-hourly accumulated precipitation (cm) from (a) TRMM, (b) CTRL_GSFC, (c) 3DVAR_NoDWR and (d) 3DVAR_DWR experiment based on initial condition of 00 UTC, 5 May 2005. 
(a) CTRL_GSFC
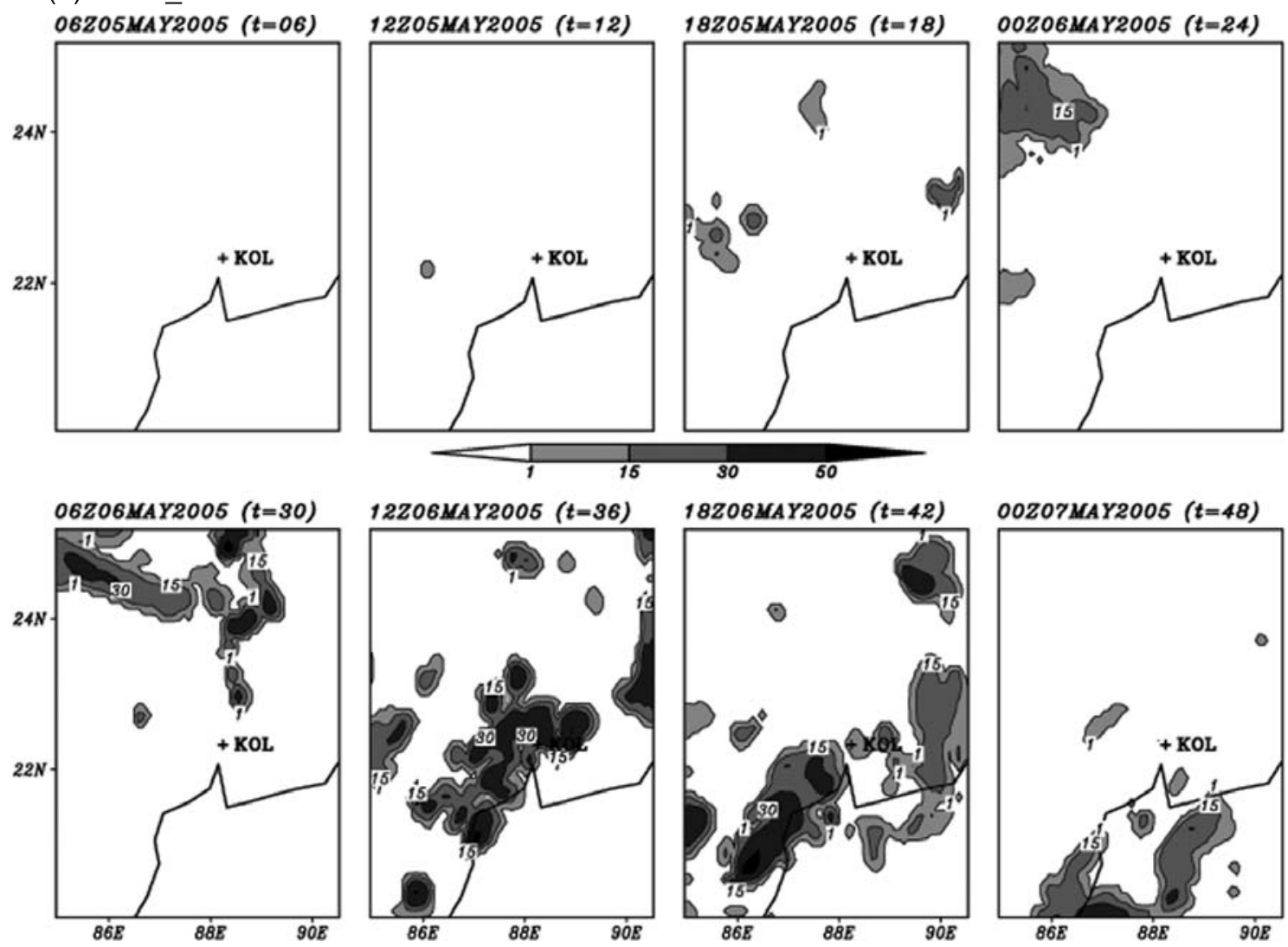

(b) 3DVAR_NoDWR
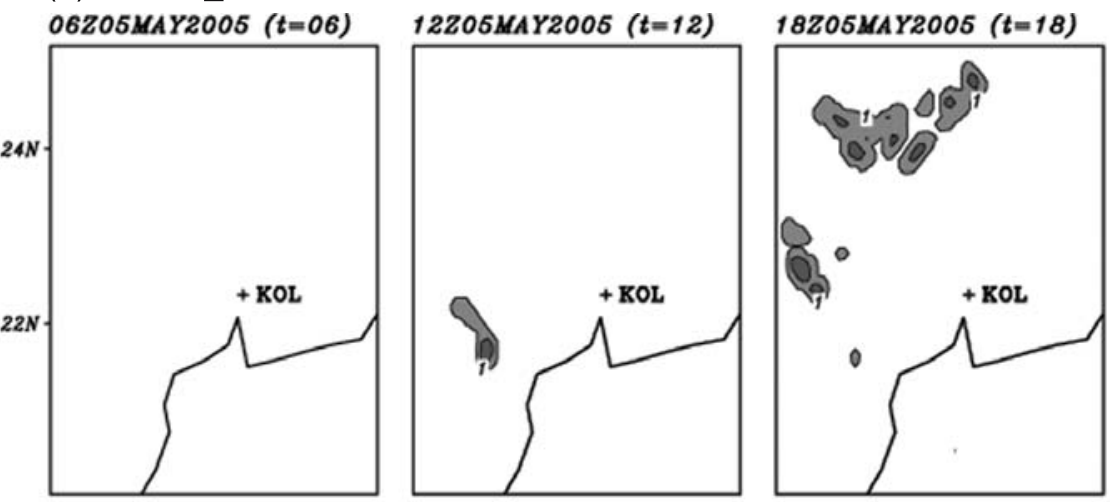

OOZ06MAY2005 $(t=24)$

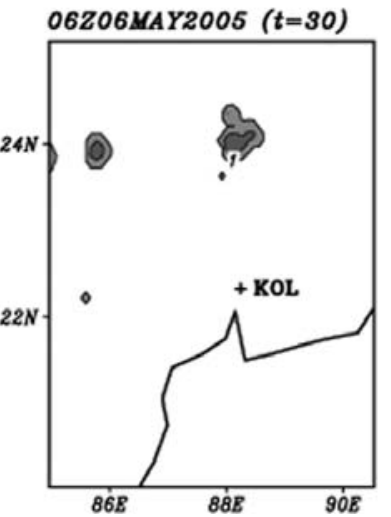

12Z06MAY2005 ( $t=36)$
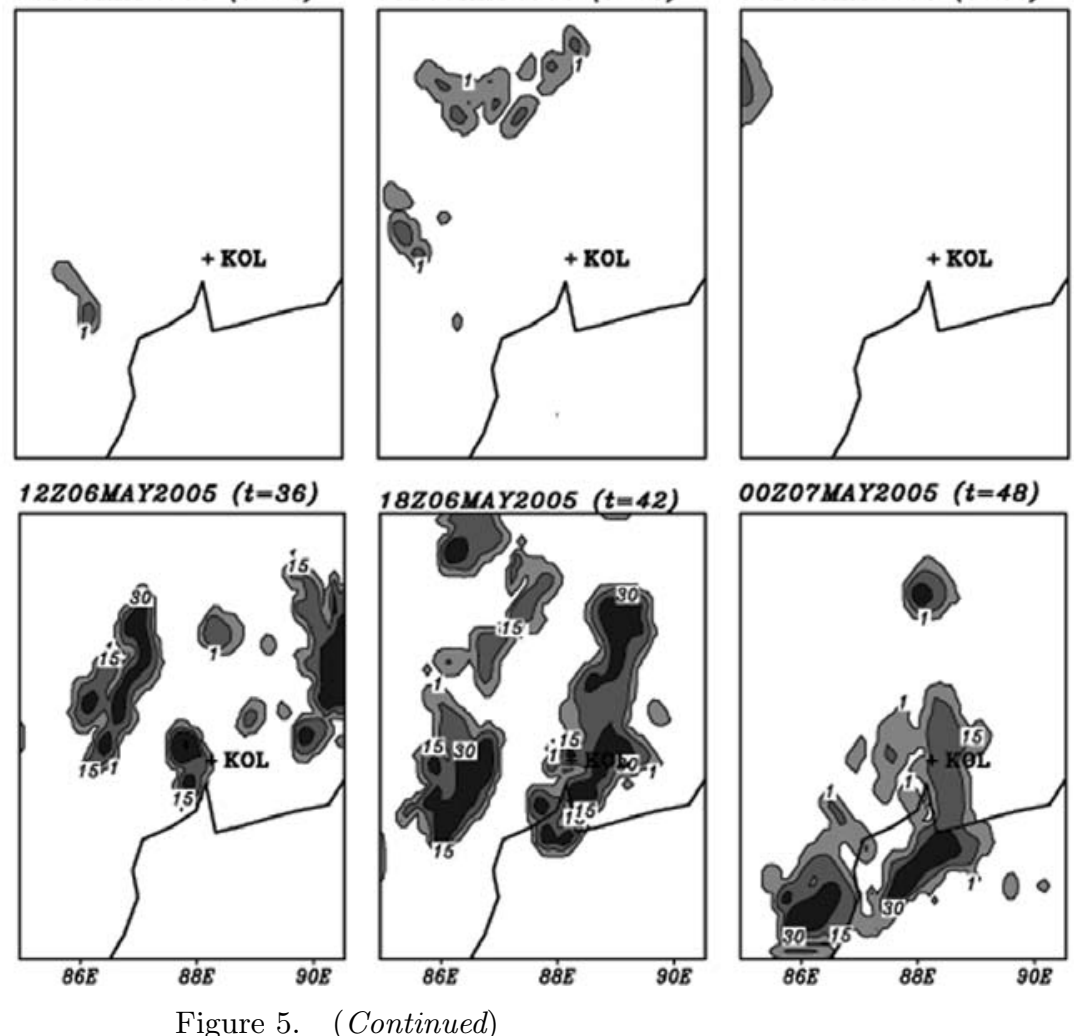

Figure 5. (Continued)

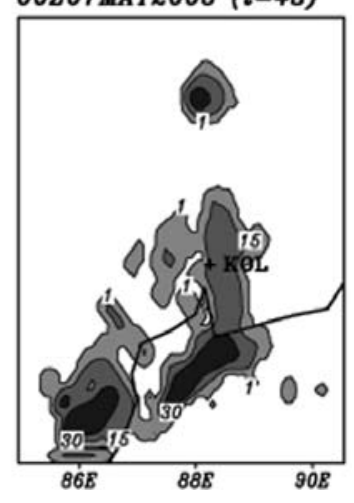


(c) 3DVAR_DWR

06Z05MAY2005 $(t=06)$

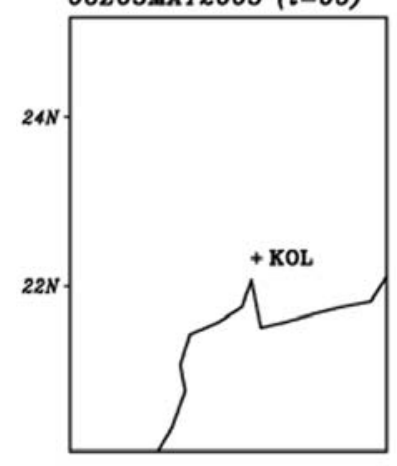

06Z06MAY2005 $(t=30)$

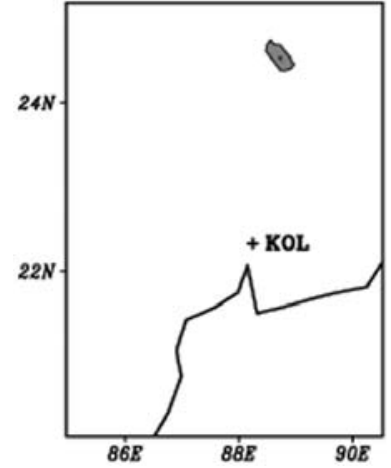

$12 Z 05 M A Y 2005(t=12)$

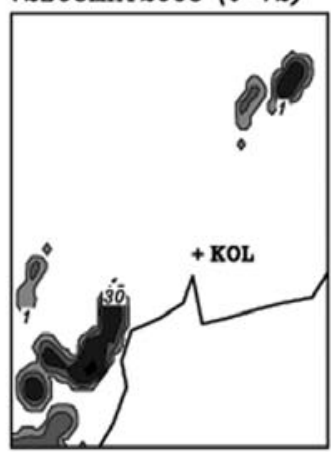

12Z06MAY2005 $(t=36)$

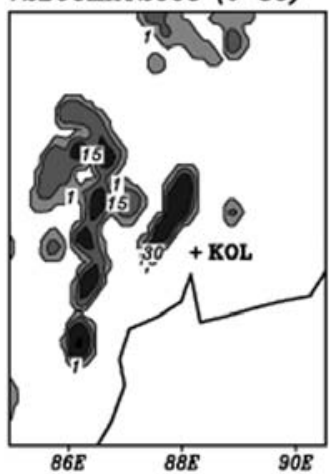

18Z05MAY2005 $(t=18)$

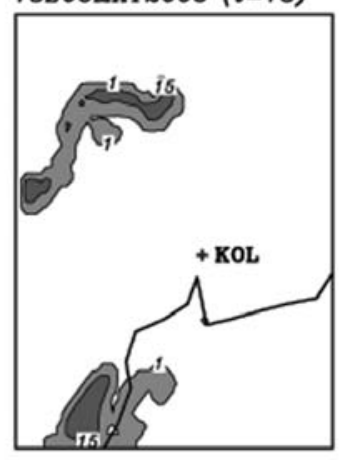

18Z06MAY2005 $(t=42)$

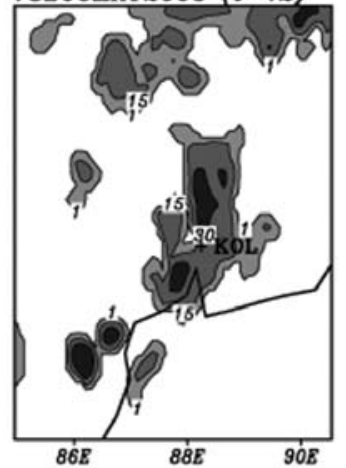

O0Z06MAY2005 $(t=24)$

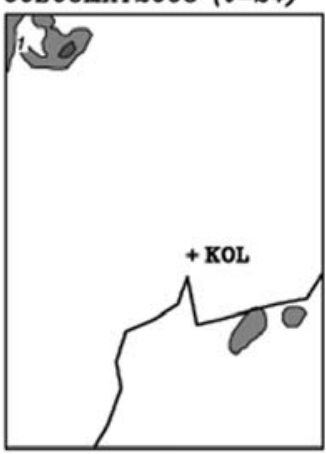

OOZ07MAY2005 $(t=48)$

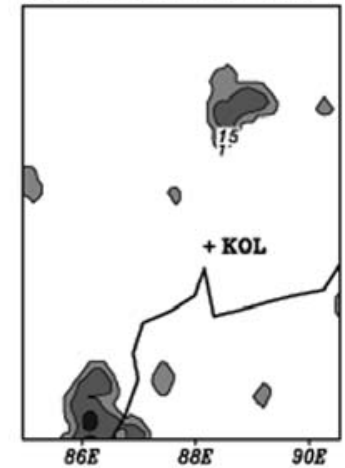

Figure $5(\mathbf{a}-\mathbf{c})$. Composite reflectivity at 6 - $\mathrm{h}$ intervals simulated by the experiment (a) CTRL_GSFC, (b) 3DVAR_NoDWR and (c) 3DVAR_DWR based on initial condition at 0000 UTC, 5 May 2005.

(a)

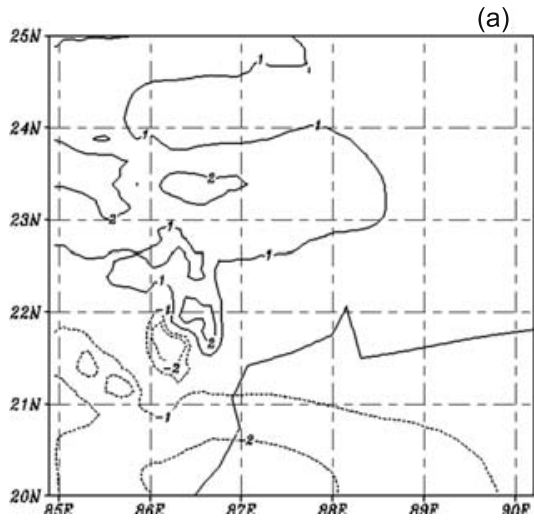

(b)

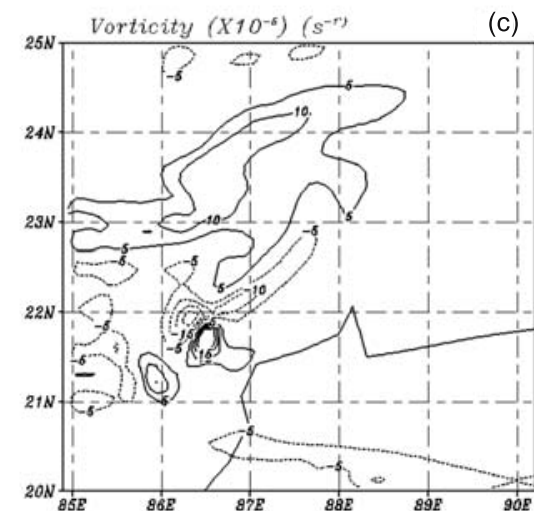

Figure 6. Vorticity at 0000 UTC of 5 May 2005 for the (a) CTRL_GSFC, (b) 3DVAR_NoDWR and (c) 3DVAR_DWR experiments.

condition on assimilating both the conventional and DWR wind observations. Figure $6(\mathrm{a}, \mathrm{b}$ and c) shows the vorticity fields at 0000 UTC 5 May 2005 (initial condition for the first case) for the experiments, CTRL_GSFC, 3DVAR_NoDWR and 3DVAR_DWR respectively. The vorticity for the CTRL_GSFC experiment is as low as $2 \times 10^{-5} \mathrm{~s}^{-1}$ over the southwest sector of the domain. After assimilating the conventional data, the initial vorticity field has been improved well in the second experiment (3DVAR_NoDWR) and shows a maximum value of $10 \times 10^{-5} \mathrm{~s}^{-1}$. After incorporating the DWR wind field to the assimilation system, the vorticity field has increased to a maximum value of $15 \times 10^{-5} \mathrm{~s}^{-1}$. This analysis signifies the impact of the DWR wind observations in creating localized convergence in the initial condition, which in turn causes development of convective clouds during the early hours of the forecast period. For brevity, the vorticity analysis has been carried out only for the first case.

\subsection{Case 2: 21-22 May 2005}

Severe thunderstorms formed over Kolkata region between 0000 and 1800 UTC, 22 May 2005 under 
(a) $\operatorname{MAX}(Z) \quad 0621 Z 220505$

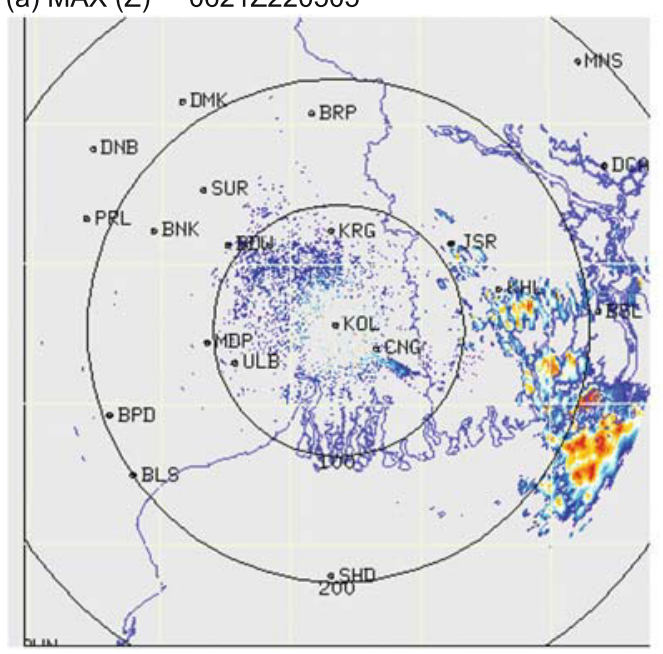

(b) MAX (Z) $1321 Z 220505$

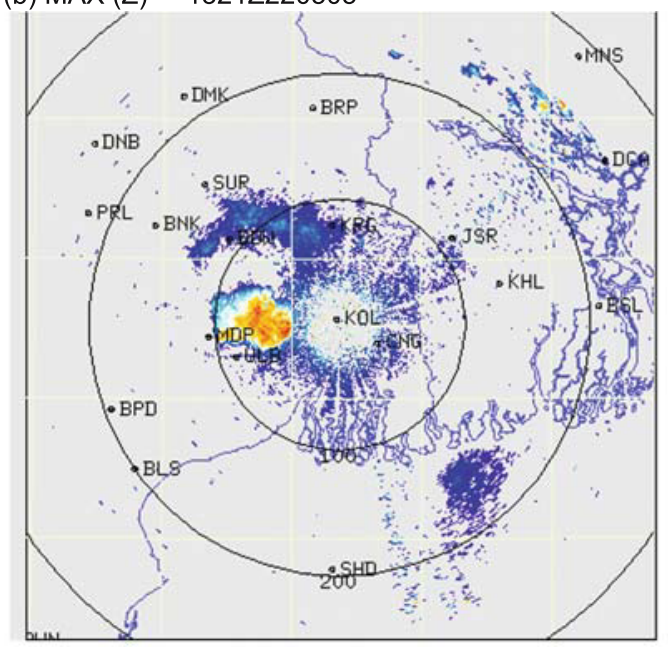

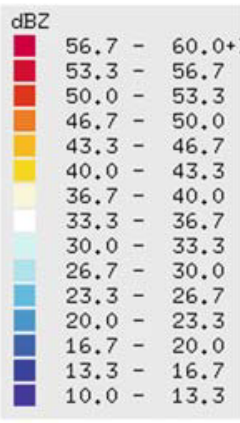

Figure 7. Reflectivity, PPI(Z) at (a) 0621 and (b) 1321 UTC, 22 May 2005.

the influence of a low-level cyclonic circulation extending up to $1.5 \mathrm{~km}$ over the sub-Himalayan West Bengal, Sikkim and neighbourhood. Figure $7(\mathrm{a}$ and $\mathrm{b})$ shows the radar reflectivity $\mathrm{PPI}(\mathrm{Z})$ at 0621 and 1321 UTC on 22 May 2005. Figure 8(a) presents the 6-h accumulated rainfall obtained from TRMM for the period 0000 UTC, 21 May to 0000 UTC, 23 May. While the maximum rainfall in the domain is about $4-8 \mathrm{~cm}$, major rainfall near Kolkata occurred between 12 and 18 UTC, 22 May. The cloud systems moved eastward and were seen over east Bangladesh and Tripura at 0600 UTC, 22 May. The radar images (figure 5) does show the organization of convection at 0621 and 1321 UTC, 22 May.

\subsubsection{Simulated rainfall}

Figure 8(b, c and d) illustrates the simulated rainfall for 48 hours based on the three experiments CTRL_GSFC, 3DVAR_NoDWR and 3 DVAR_DWR respectively. Comparing the $6-\mathrm{h}$ accumulated rainfall with TRMM observations and radar reflectivity, $3 \mathrm{DVAR} \_$DWR has been able to produce better rainfall distribution between 0000 and 0600 UTC on 22 May. The assimilation experiment with radar data is able to predict two organized regions of precipitation greater than $2 \mathrm{~cm}$ including southwest and southeast of Kolkata and head Bay region, while the other two experiments predict a single rainband over southwest of Kolkata. All the three experiments show precipitation bands during 1200 UTC, 21 May and 0000 UTC, 22 May and none of them properly simulates the rainfall distribution near Kolkata during 1200 and 1800 UTC, 22 May. The simulated rainfall from the three experiments shows large variability of rainfall in terms of quantity and location.

\subsubsection{Reflectivity}

The simulated reflectivity by the three experiments is presented in figure 9. The diagrams indicate that the observed echo distribution by DWR (figure 6) does not match exactly with the simulated echo fields. Maximum echo is simulated by the experiment 3DVAR_DWR between 0000 and 0600 UTC of 22 May corresponding to the rainfall simulated by the model during that time. The simulated reflectivity from the three experiments is of the same order of magnitude as observed reflectivity data from DWR.

\subsection{Case 3: 6-7 June 2005}

Severe thunderstorms lashed the West Bengal region on 6 and 7 June 2005. The synoptic conditions indicated sea level trough extending from west Rajasthan to coastal Orissa. Embedded cyclonic circulation was seen over Jharkhand and neighbourhood extending up to $1.5 \mathrm{~km}$. Another cyclonic circulation also existed from northeast Bay to southwest Bay. Major rainfall recorded under the influence of these systems in Ganjetic West Bengal on 6 June were at Harinkhola $(5 \mathrm{~cm})$, Kolkata-Alipore $(5 \mathrm{~cm})$, Digha $(3 \mathrm{~cm})$, Barrackpore $(2 \mathrm{~cm})$. On 7 June, major rainfall was reported at Asansol $(2 \mathrm{~cm})$, Chepan $(6 \mathrm{~cm})$, Domohani $(5 \mathrm{~cm}), \mathrm{NH}-31(4 \mathrm{~cm})$, Coochbehar $(3 \mathrm{~cm})$. On 8 June, the system moved eastward and major rainfall was reported from Assam and Meghalaya at Matunga $(11 \mathrm{~cm})$, Khowang $(5 \mathrm{~cm})$, Dillighat $(5 \mathrm{~cm})$, Diamond Harbour and Berhampore in Ganjetic West Bengal reported $2 \mathrm{~cm}$ each.

Figure 10 presents the radar reflectivity, $\mathrm{PPI}(\mathrm{Z})$ during 1312 and 1912 UTC, 6 June and 1236 
(a) TRMM

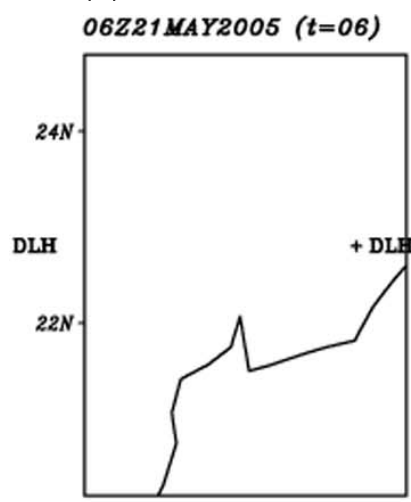

$12 Z 21$ MAY2005 $(t=12)$
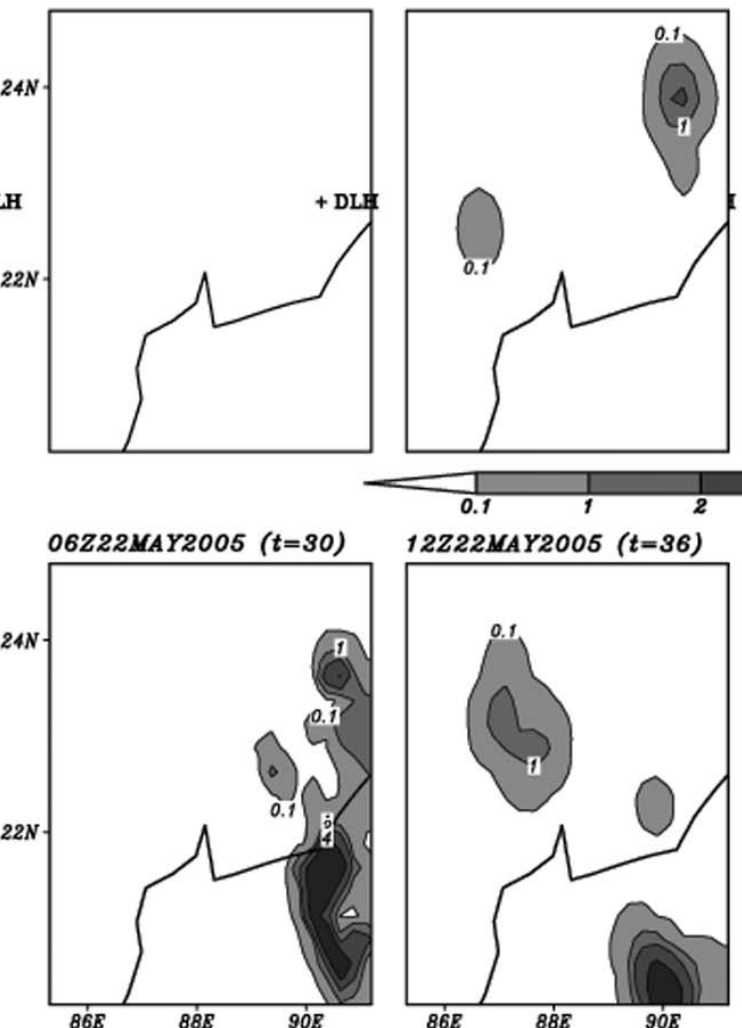

(b) CTRL_GSFC

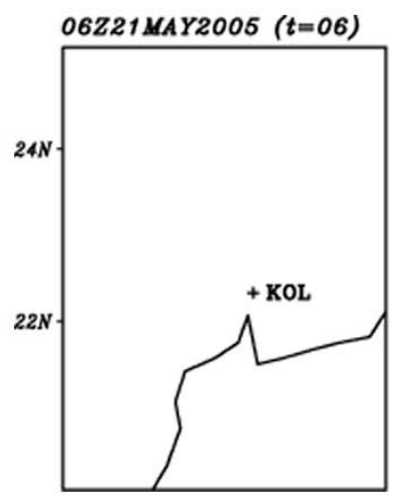

O6Z22MAY2005 ( $t=30)$

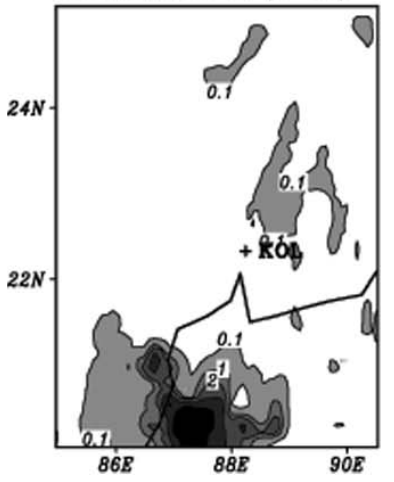

12Z21MAY2005 $(t=12)$

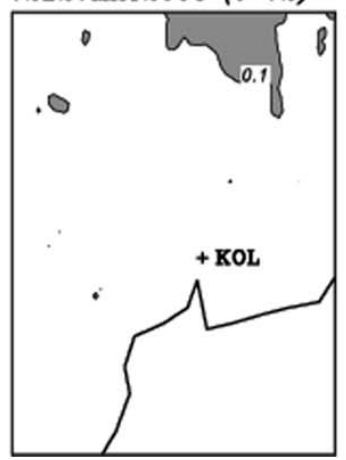

12Z22MAY2005 $(t=36)$

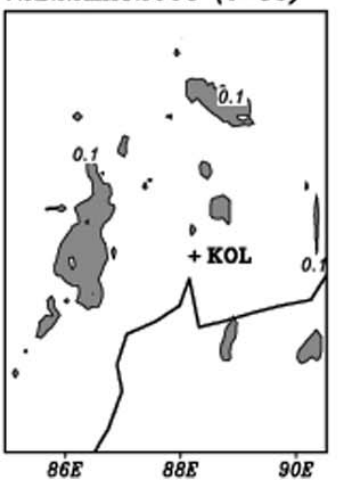

18Z21MAY2005 $(t=18)$

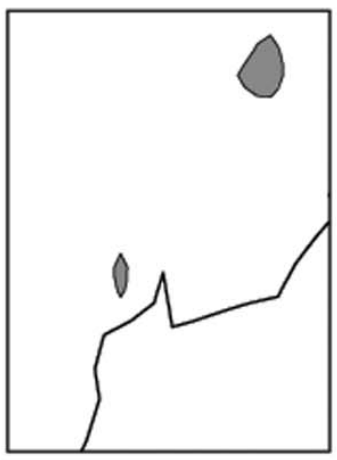

OOZ22MAY2005 $(t=24)$

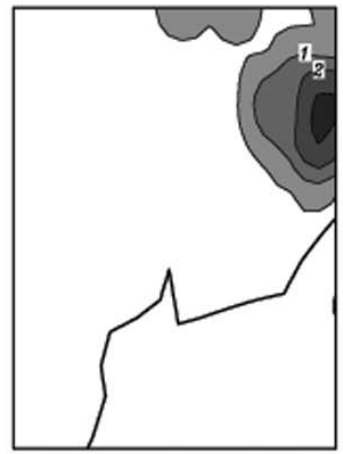

OOZ23MAY2005 $(t=48)$
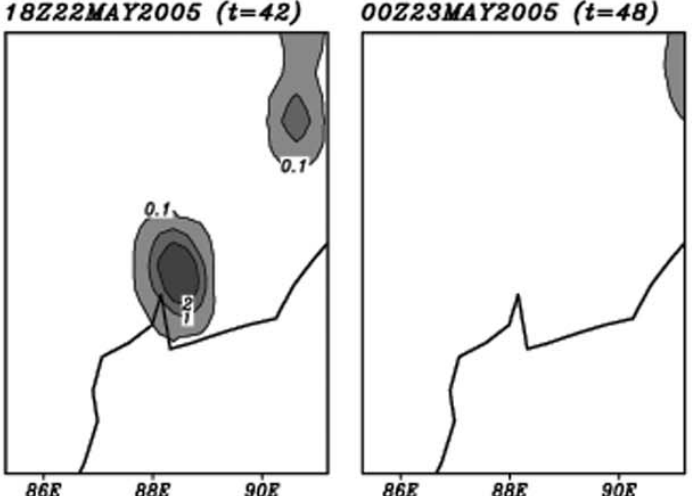

Figure 8. (Continued)

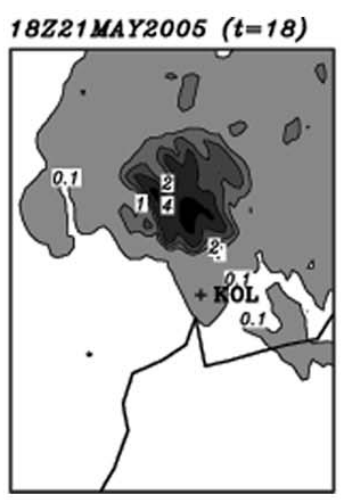

OOZ22MAY2005 $(t=24)$

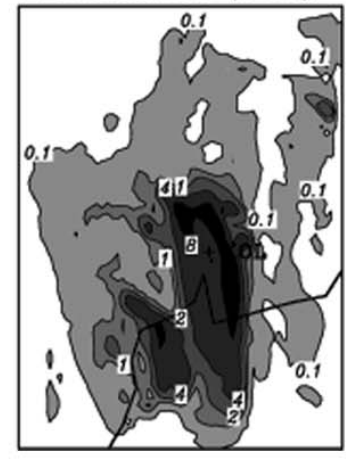

18Z22MAY2005 $(t=42)$

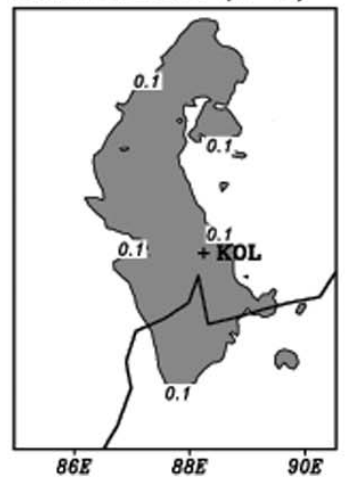

OOZ23MAY2005 $(t=48)$

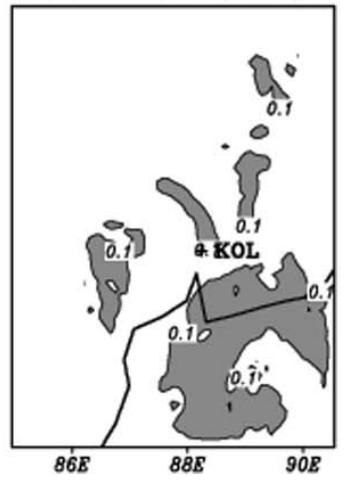


(c) 3DVAR_NoDWR

O6Z21MAY2005 $(t=06)$

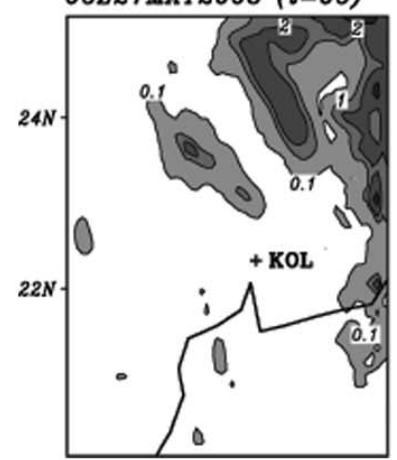

06Z22MAY2005 $(t=30)$

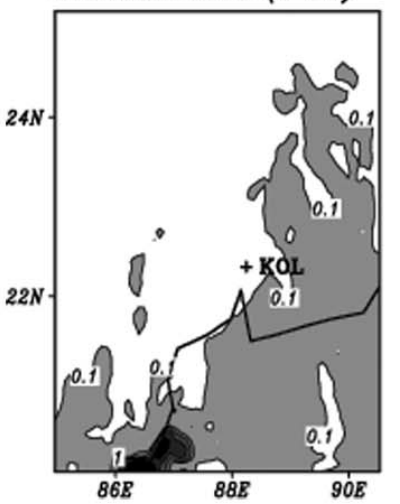

(d) 3DVAR_DWR
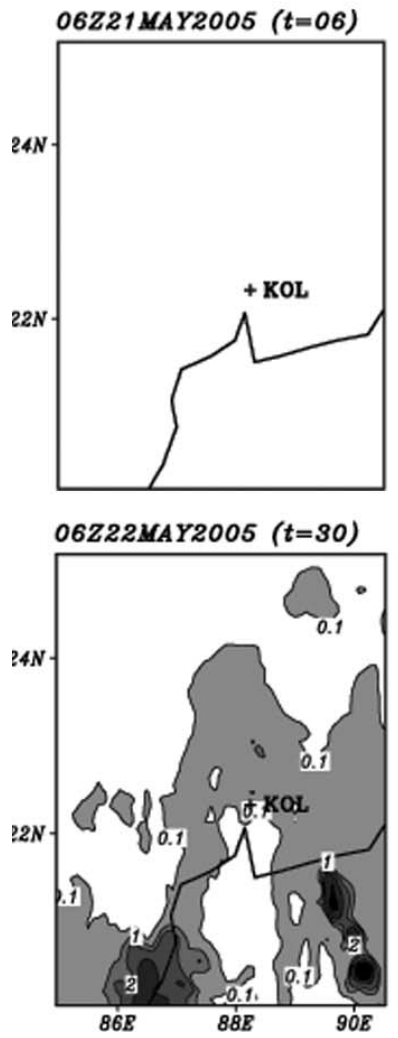

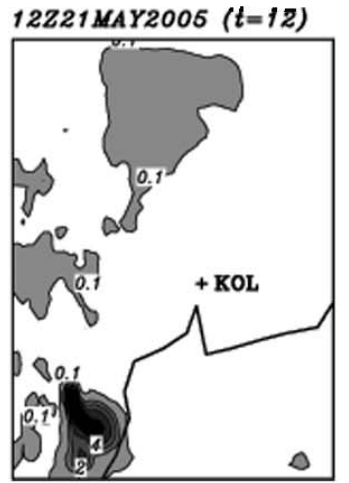

12Z22MAY2005 $(t=36)$

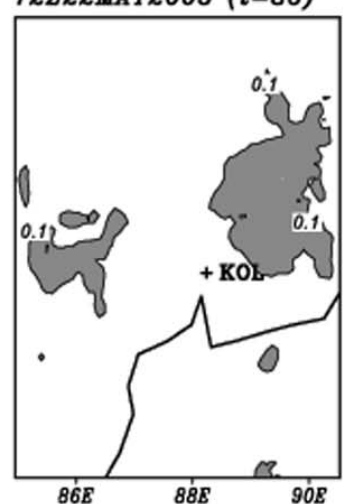

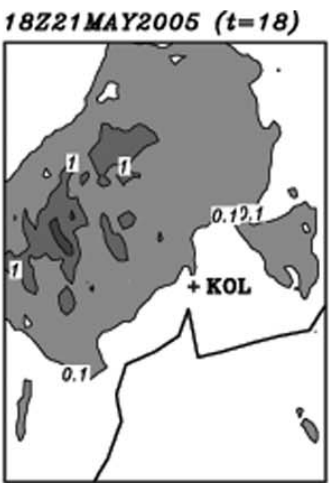

18Z2ZMAY2005 ( $t=42)$

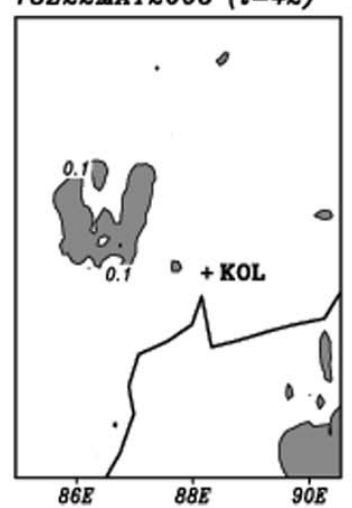

OEB
OOZ22MAY2005 $(t=24)$

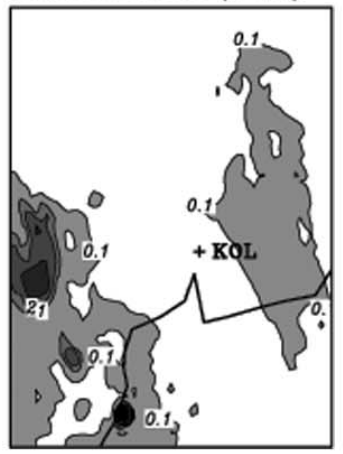

OOZ23MAY2005 ( $t=48)$

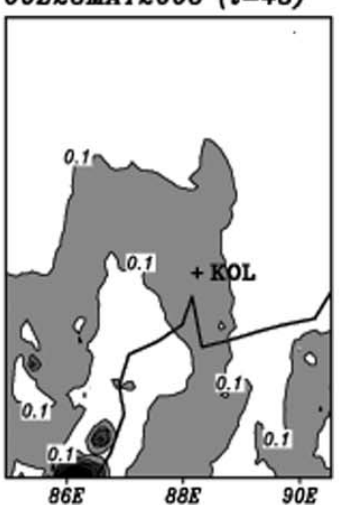

12Z21MAY2005 ( $t=12)$

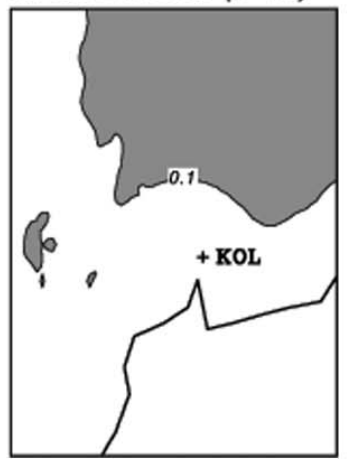

12Z22MAY2005 $(t=36)$

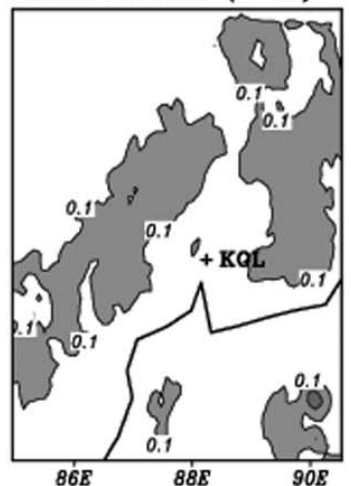

18Z21MAY2005 $(t=18)$

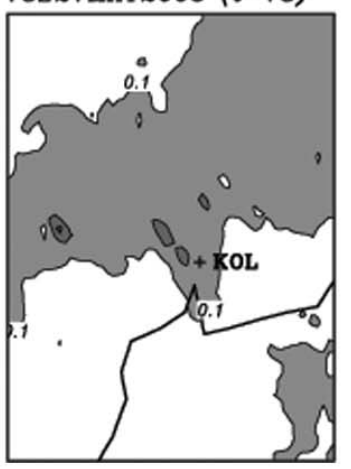

18Z2ZMAYZOO5 $(t=42)$

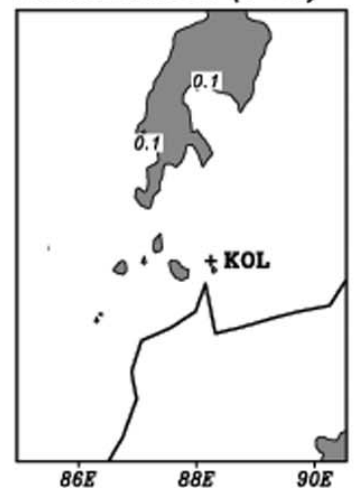

OOZ22MAY2005 $(t=24)$

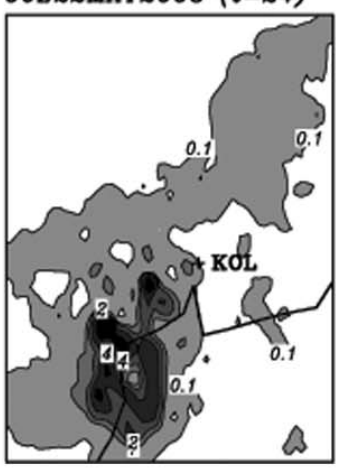

OOZ23MAY2005 $(t=48)$

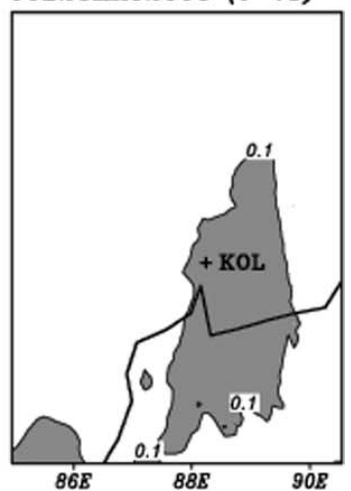

Figure $8(\mathbf{a}-\mathbf{d})$. Six-hourly accumulated precipitation $(\mathrm{cm})$ from (a) TRMM, (b) CTRL_GSFC, (c) 3DVAR_NoDWR and (d) 3DVAR_DWR experiment based on initial condition of 00 UTC, 21 May 2005. 
(a) CTRL_GSFC
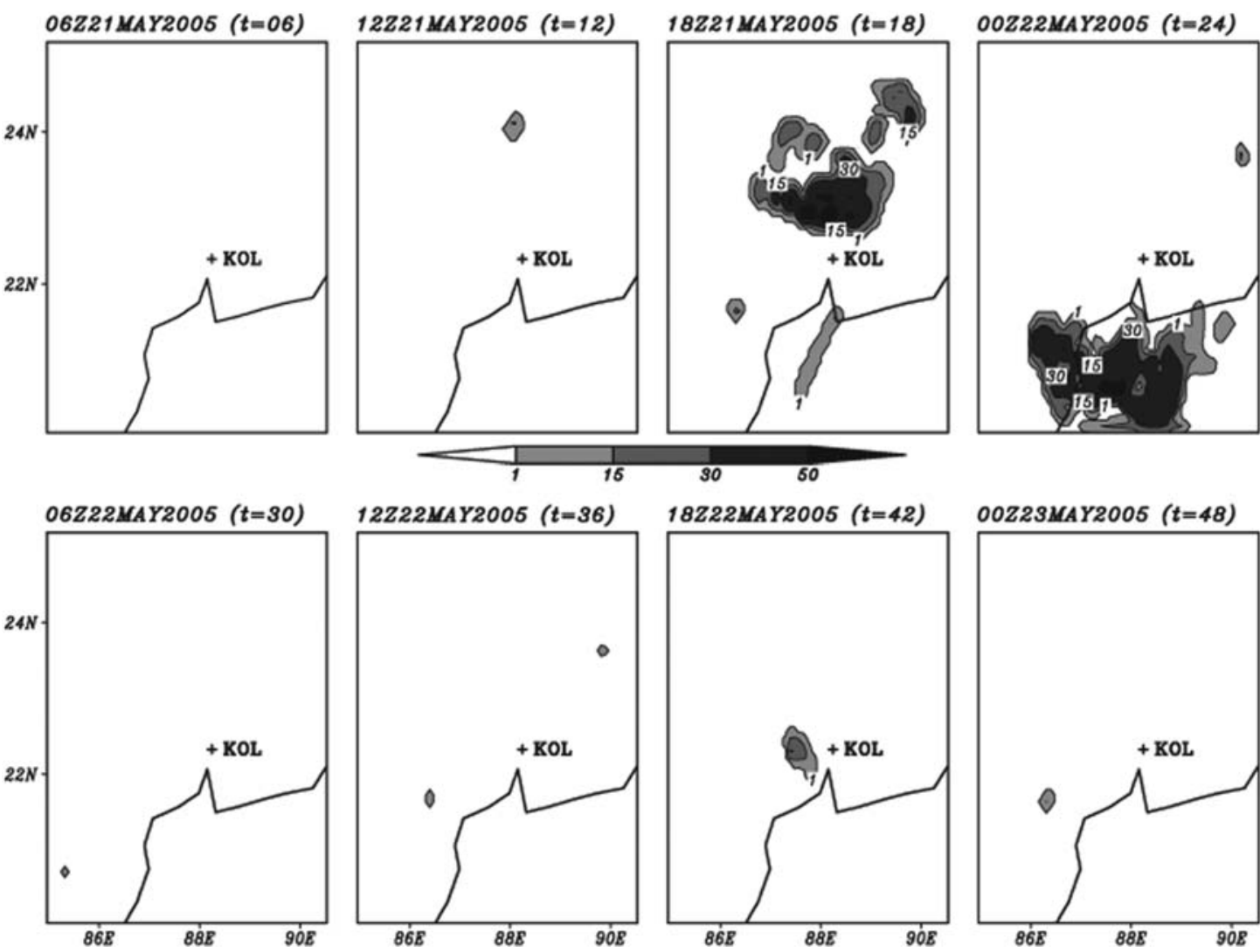

(b) 3DVAR_NoDWR
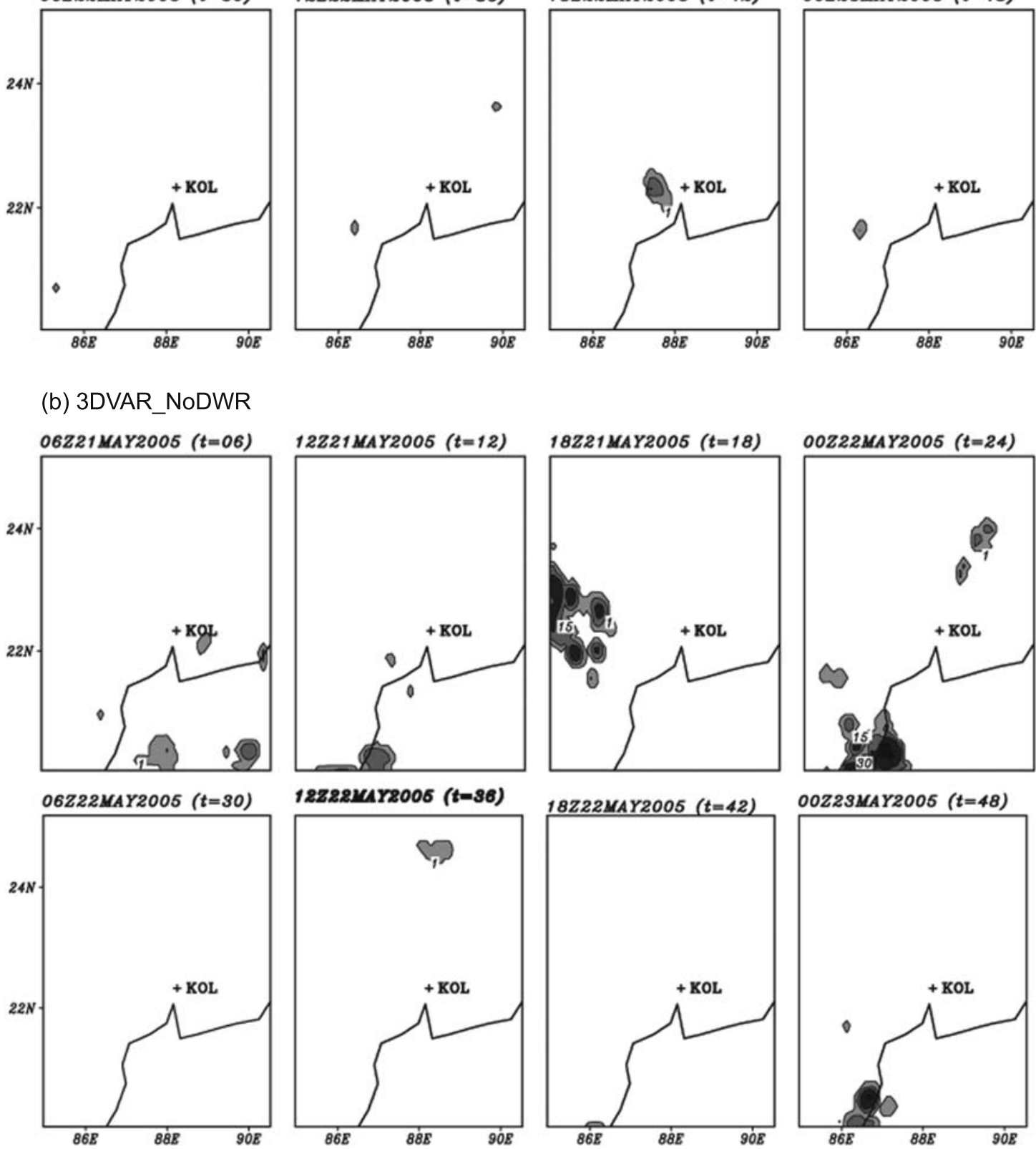

Figure 9. (Continued)

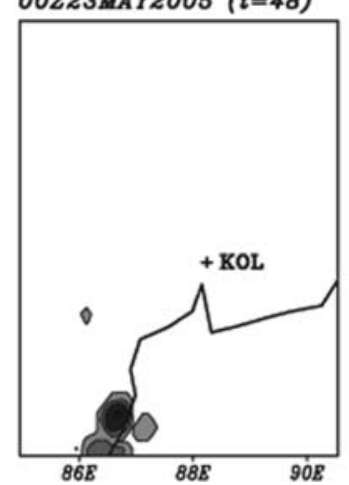


(c) 3DVAR_DWR

06221 MAY2005 $(t=06)$

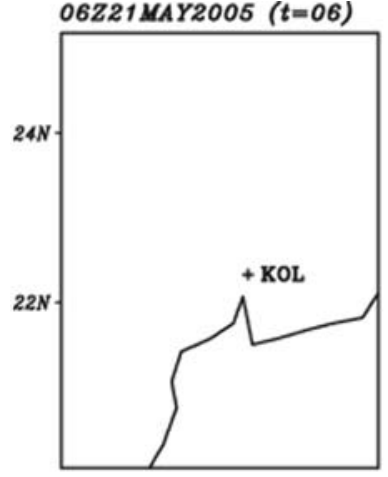

O6Z22MAY2005 $(t=30)$

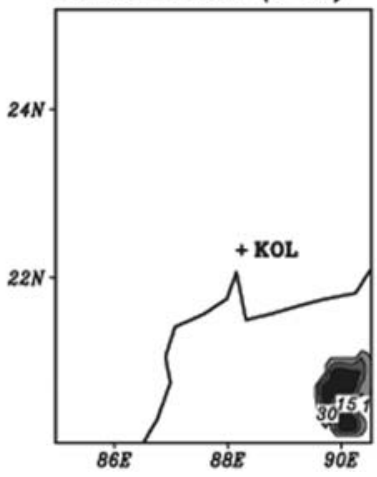

$12 Z 21$ MAY2005 $(t=12)$

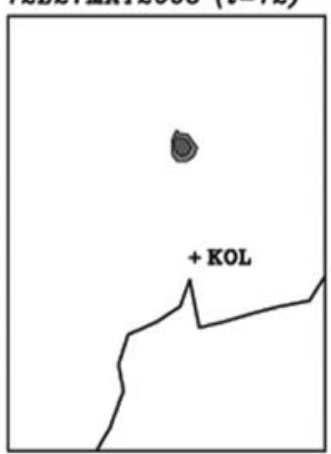

12Z22MAY2005 $(t=36)$

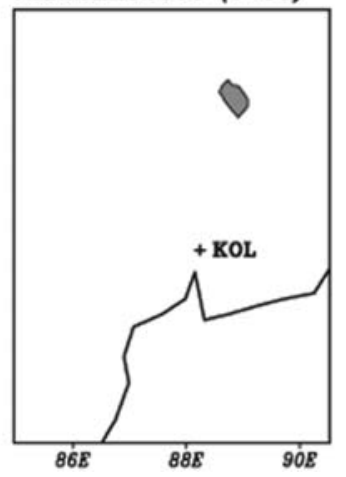

18Z21 MAY2005 $(t=18)$

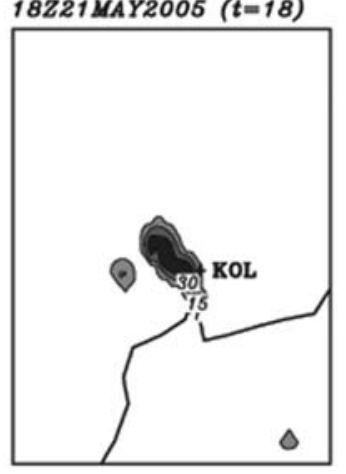

18Z22MAY2005 $(t=42)$

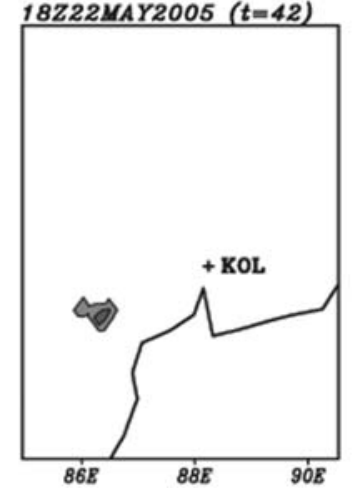

OOZ22MAY2005 $(t=24)$

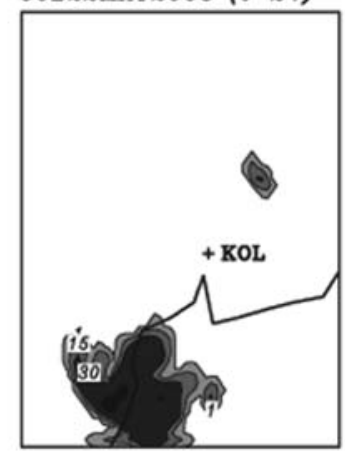

OOZ23MAY2005 $(t=48)$

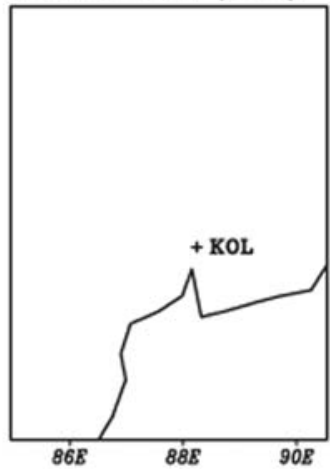

Figure $9(\mathbf{a}-\mathbf{c}) . \quad$ Composite reflectivity at 6 - $\mathrm{h}$ intervals simulated by the experiment (a) CTRL_GSFC, (b) 3DVAR_NoDWR and (c) 3DVAR_DWR based on initial condition at 0000 UTC, 21 May 2005.

and 1736 UTC, 7 June 2005. The radar reflectivity on 6 June shows that cloud clusters occurred northwest part of Kolkata. The radar images at 1236 UTC 7 June show that the major cloud clusters are seen over the north and northwest of Kolkata radar site.

\subsubsection{Simulated rainfall}

Figure 11(a) illustrates 6 -h accumulated rainfall obtained by TRMM during 0000 UTC, 6 June to 0000 UTC, 8 June 2005. Most of the rainfall occurred between 1200 and 1800 UTC, 7 June. The rainbands initially observed northwest of Kolkata move southeastwards between 0600 and 1800 UTC, 7 June and propagates like a typical Norwester. Major rainfall of about $8-16 \mathrm{~cm}$ was observed between 1200 and 1800 UTC, 6 June.

Figure 11(b, c and d) shows the simulated 6hourly rainfall from the three experiments. All the three experiments predict major rainfall between 1200 and 1800 UTC, 6 June 2005. However, the TRMM observations (figure 11a) do not show as much rainfall as simulated, the reflectivity fields (figure 10) do show a lot of echo over the region during this period. Although the CTRL_GSFC and 3DVAR_NoDWR experiments predict rainbands of 4-8 cm during 0600-1200 UTC, 7 June, the $3 \mathrm{DVAR} \_\mathrm{DWR}$ experiment more or less catches up the southeastward propagation of rainbands as observed in the TRMM rainfall. All three experiments predict rainfall over Kolkata during 12001800 UTC, 7 June. The 3DVAR_DWR experiment is able to produce a small rainfall patch over southwest of Kolkata during the period, whereas these southwest rainbands are absent in the other two experiments. From the analysis, it is clear that, all the experiments overpredict rainfall on 6 June and underestimate rainfall on 7 June when compared with TRMM observations.

\subsubsection{Reflectivity}

In this section, we shall examine the reflectivity fields simulated by the model and those observed by the DWR. Figure 10 presents PPI(Z) echoes observed by the DWR for the period 00 UTC, 6 June to 00 UTC, 8 June 2005. The reflectivity fields are instantaneous values. Only the frames corresponding to the highest echoes are shown in the 6-h intervals for the period. The diagram (figure 10) shows group of echoes around Kolkata region on 6 and 7 June. The convective cells traveled from north-northwest to south as seen in the time sequence of the radar echoes (not shown for brevity). The simulated reflectivity fields are shown in figure 12 for the three experiments. 
(a) PPI (Z) $1312 Z 060605$

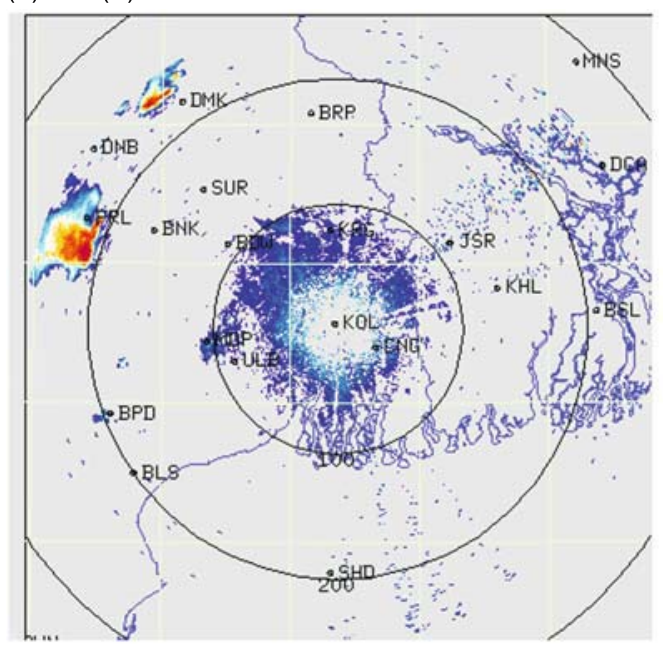

(c) MAX (Z) $1235 Z 070605$

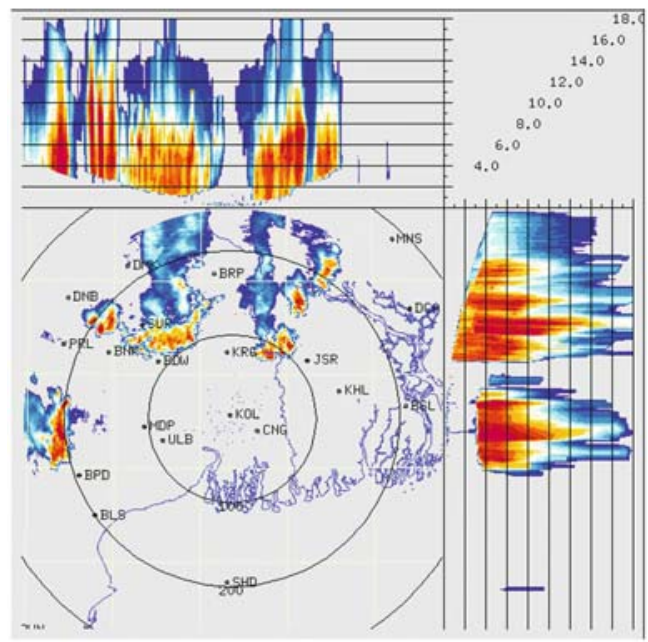

(b) PPI (Z) $1912 Z 060605$
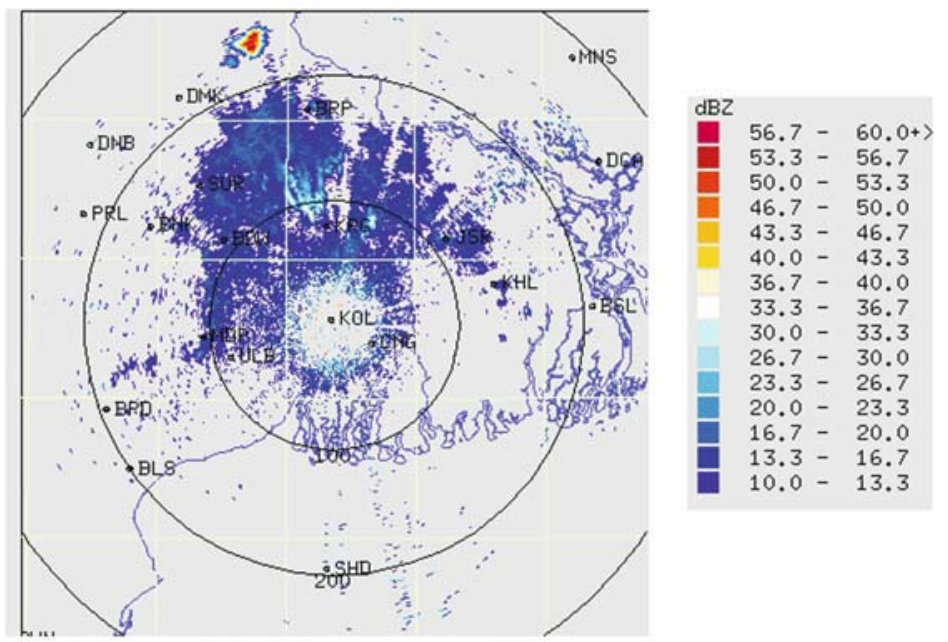

(d) MAX (Z) $1755 Z 070605$
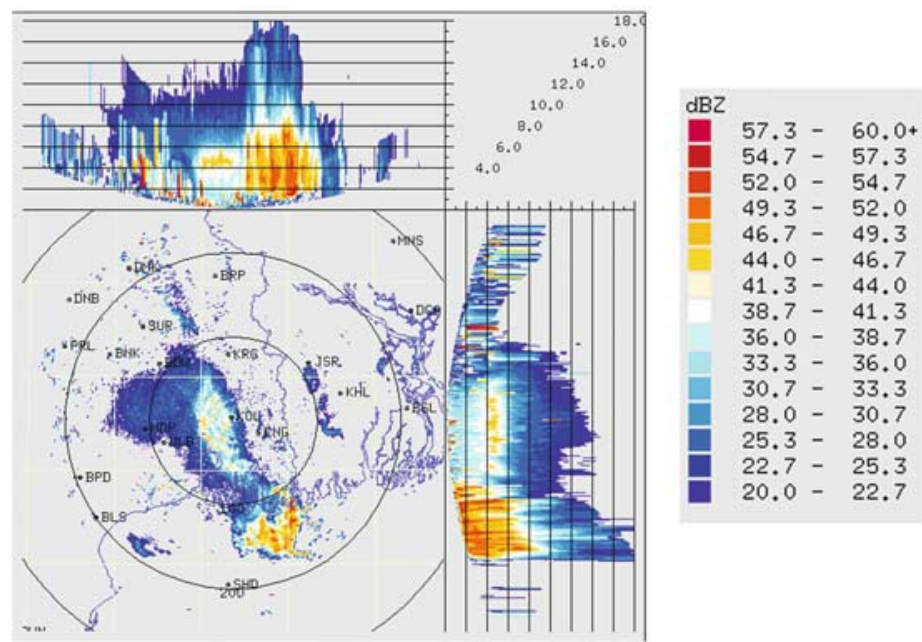

Figure 10. Reflectivity, PPI (Z) at (a) 1312 and (b) 1912 UTC, 6 June and MAX (Z) at (c) 1235 and (d) 1755 UTC, 7 June 2005.

All three simulations do produce reflectivity between 1200 and 1800 UTC of 6 and 7 June around Kolkata region corresponding to the observed echoes by the DWR. However, there is a difference of 6 hours between the locations of maximum echoes simulated by the 3DVAR experiments on 6 June. It may also be kept in mind that the echoes observed by the DWR are up to a range of about $200 \mathrm{~km}$ from its position, whereas the simulated echoes are shown over a much larger region.

\section{Simulation of the convection events around Chennai}

In the previous section, numerical simulations were carried out for three episodes of heavy rainfall with different synoptic settings. In this section, we have considered heavy rainfall produced by a northsouth trough and organization of precipitation bands associated with the movement of the trough.

\subsection{Brief description of the convective events (30 April-4 May 2005)}

A lot of convective activities occurred during 30 April to 4 May 2005 over the east coast of India off Tamil Nadu and adjoining coastal Andhra Pradesh. Several spells of thunderstorms were reported over the region during the period under the influence of a cyclonic circulation extending up to $1.5 \mathrm{~km}$ above sea level over south Tamil Nadu and its neighbourhood during 2-4 May. A northsouth trough extending up to $0.9 \mathrm{~km}$ was seen from the northeastern states to south peninsula during first half of the week from 28 April to 4 May. The trough oscillated from central India to south peninsula in the second half of the week. Maximum temperatures were above normal by $2-3{ }^{\circ} \mathrm{C}$ 
(a) TRMM
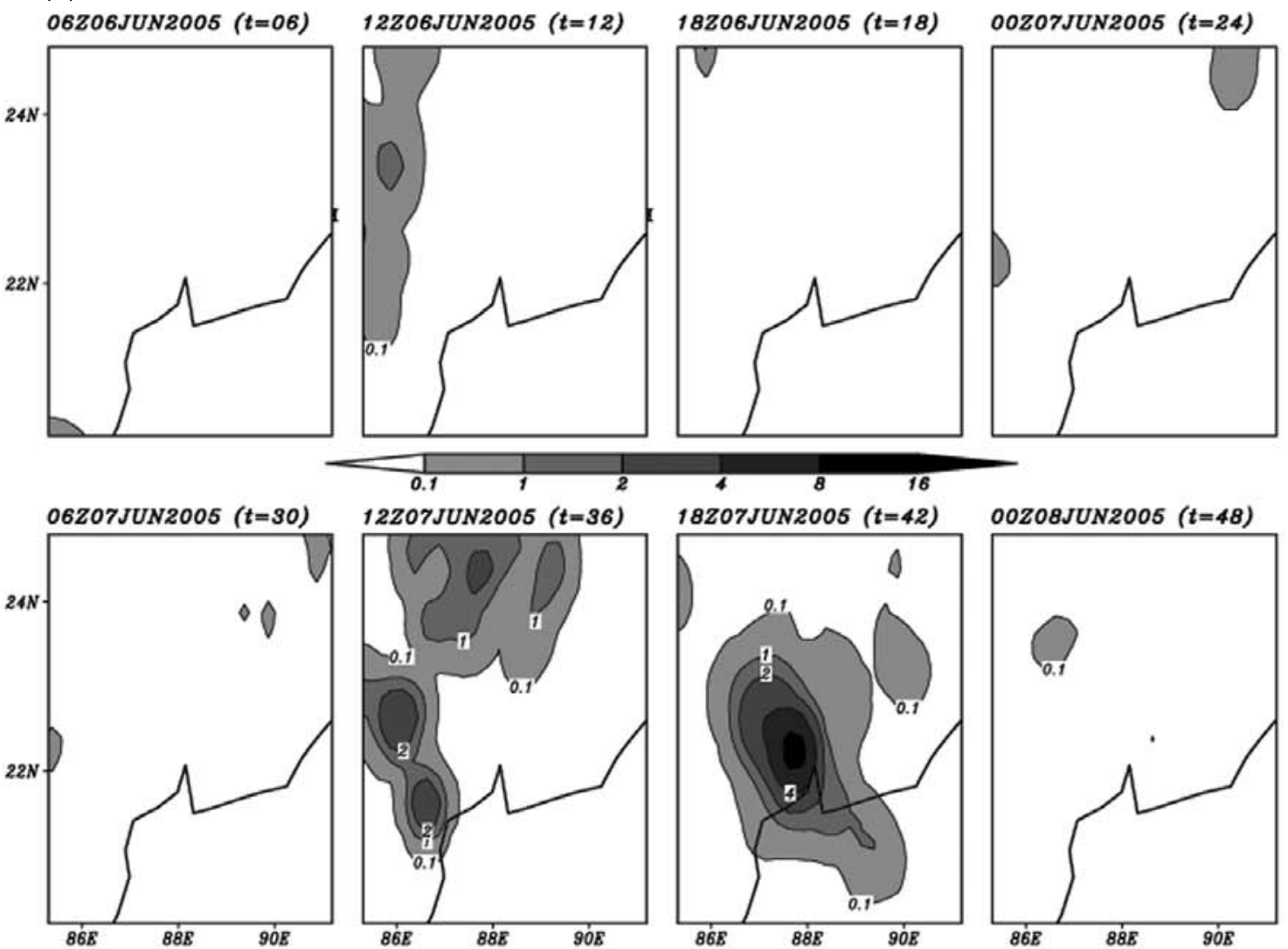

(b) CTRL_GSFC

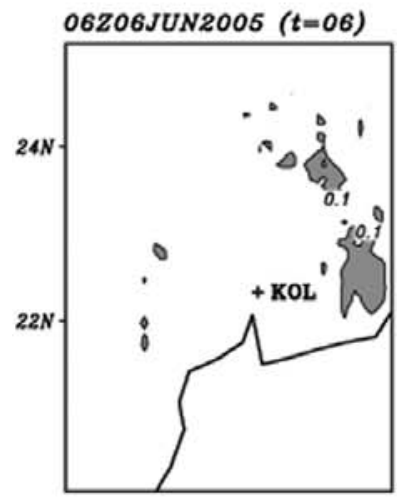

$12 Z 06 J U N 2005(t=12)$

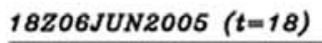

00Z07JUN2005 $(t=24)$
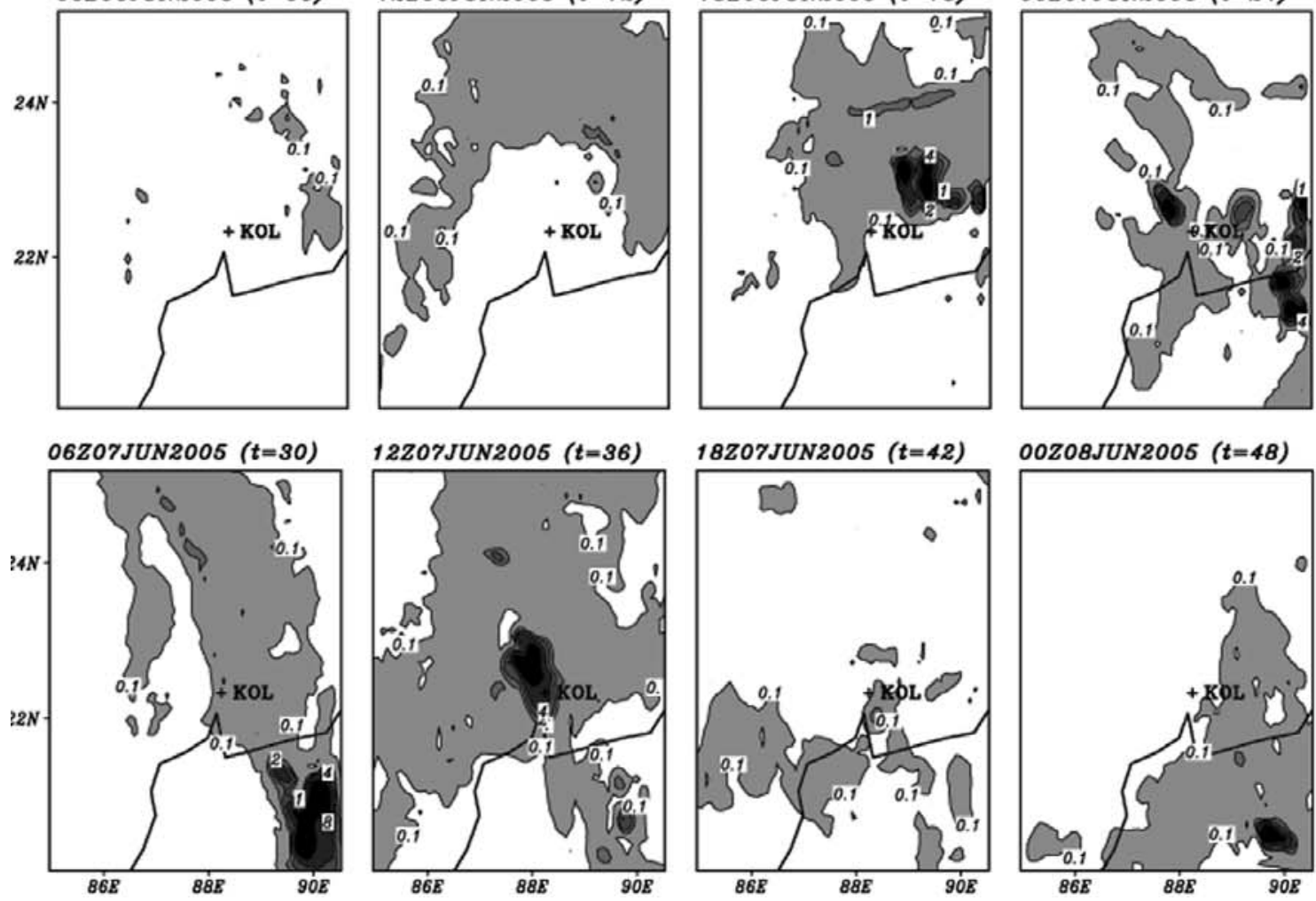

Figure 11. (Continued) 
(c) 3DVAR_NoDWR

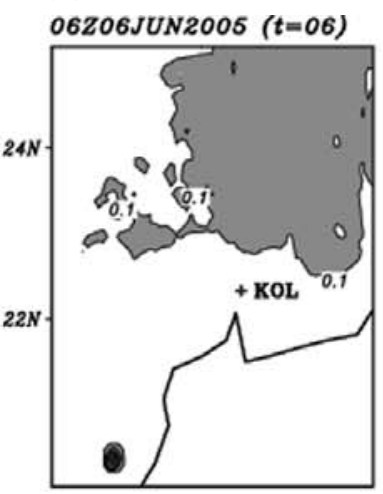

06Z07JUN2005 ( $t=30)$

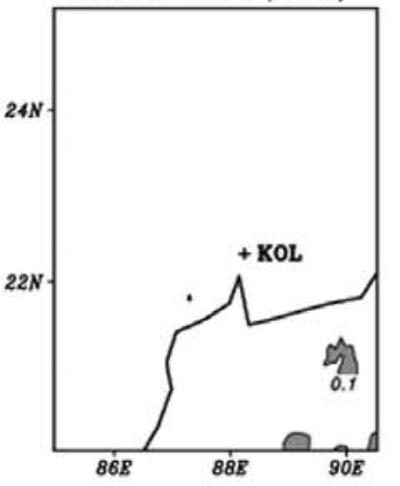

(d) 3DVAR_DWR
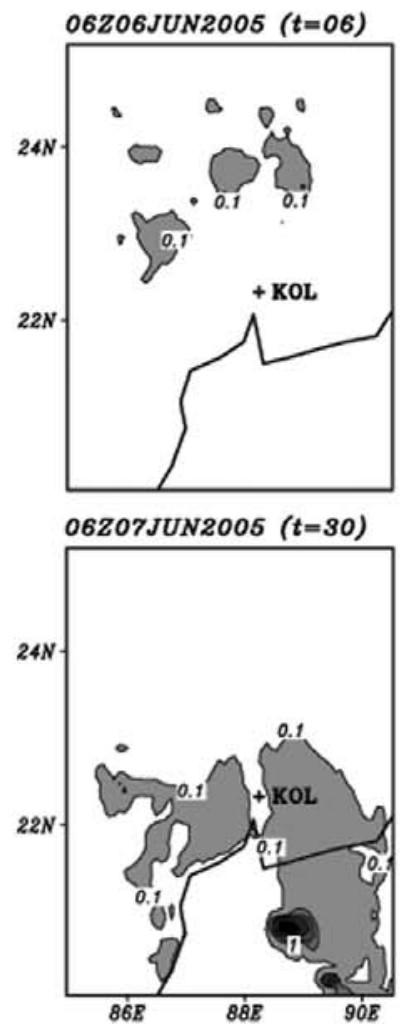

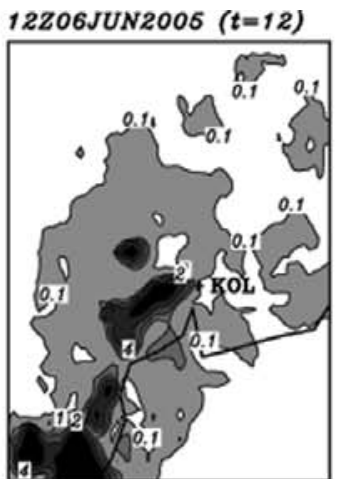

$12 Z 07 J U N 2005(t=36)$
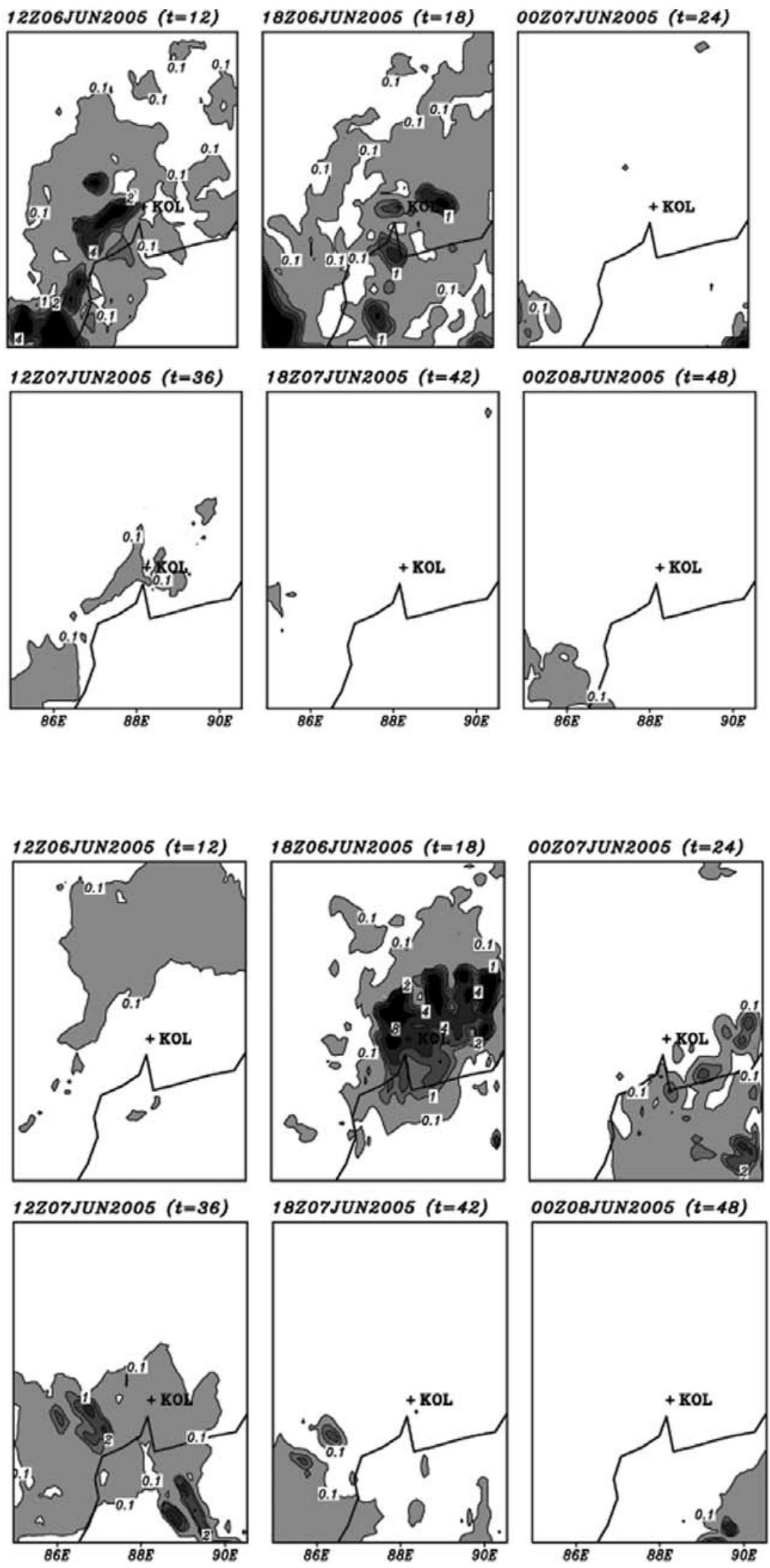

Figure 11(a-d). Six-hourly accumulated precipitation (cm) from (a) TRMM, (b) CTRL_GSFC, (c) 3DVAR_NoDWR and (d) 3DVAR_DWR experiment based on initial condition of 00 UTC, 6 June 2005. 
(a) CTRL_GSFC
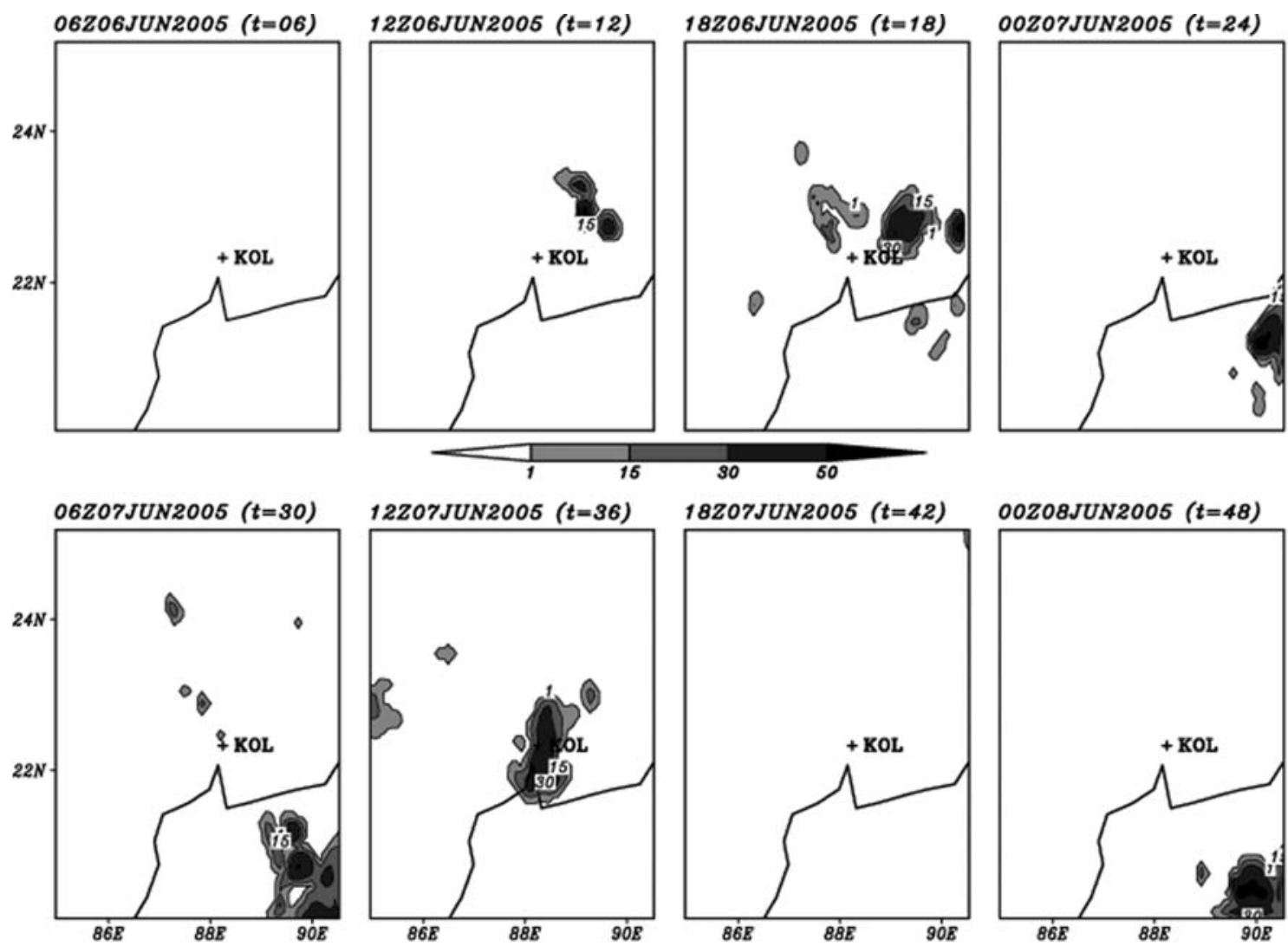

(b) 3DVAR_NoDWR
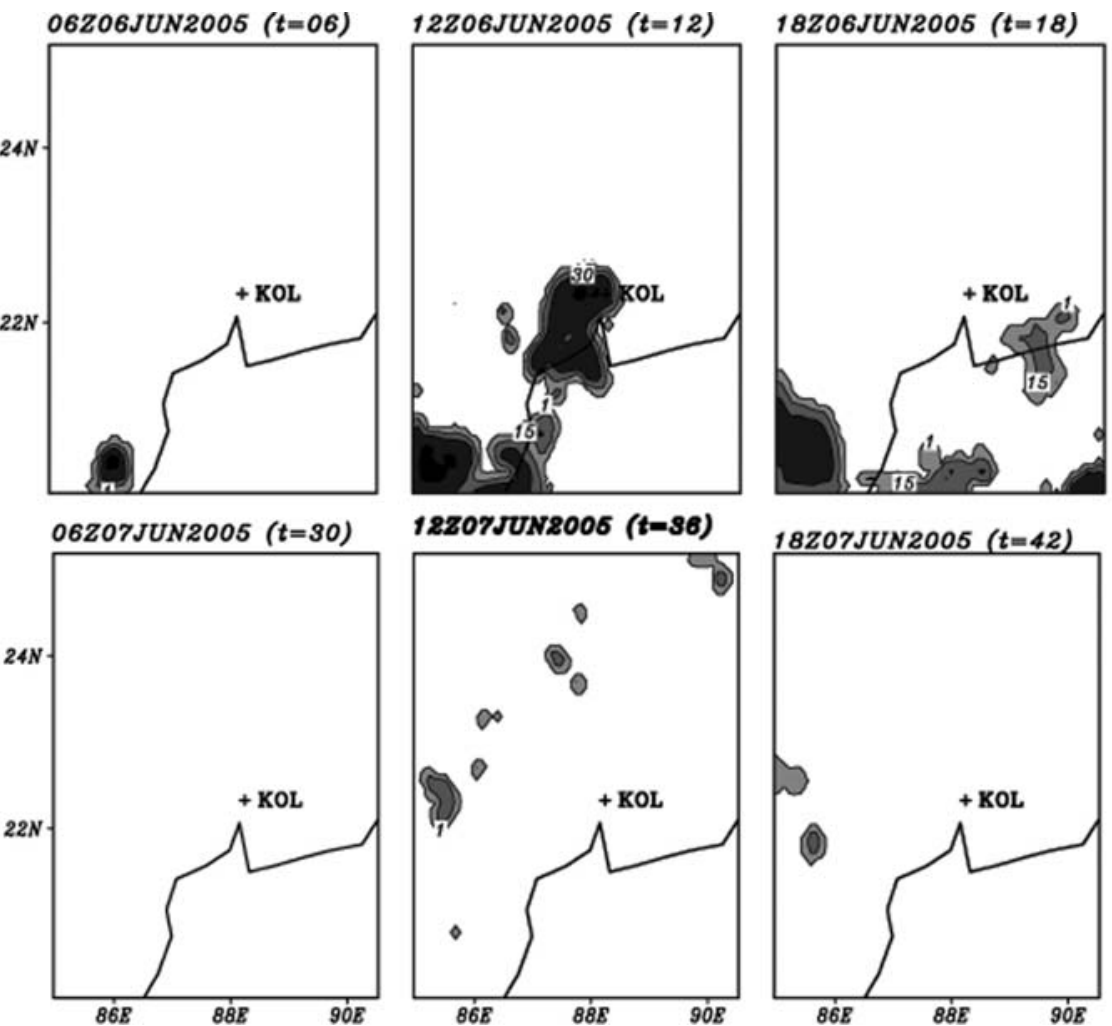

OOZ07JUN2005 $(t=24)$

12Z07JUN2006 (t-s6)
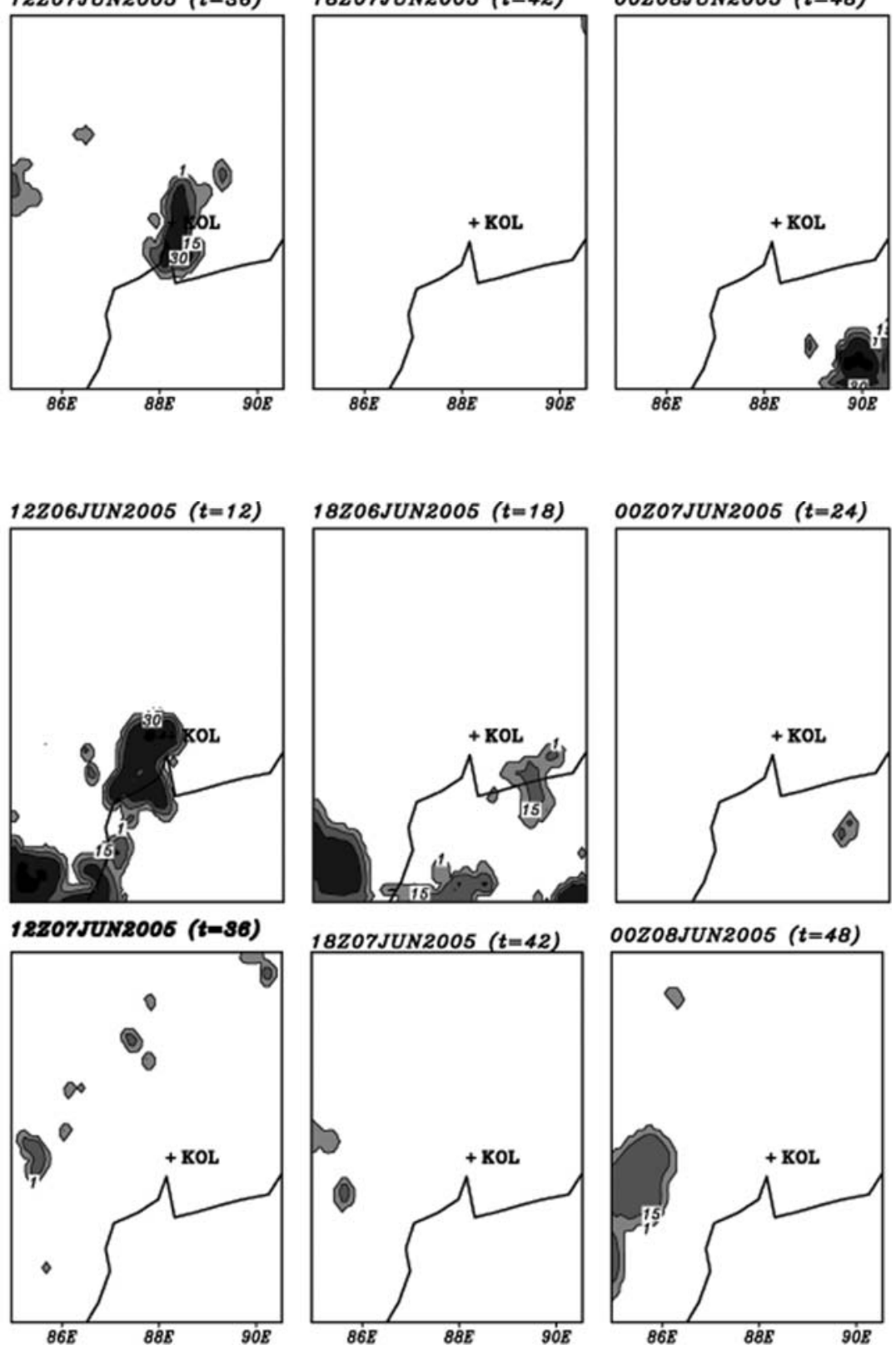

Figure 12. (Continued)

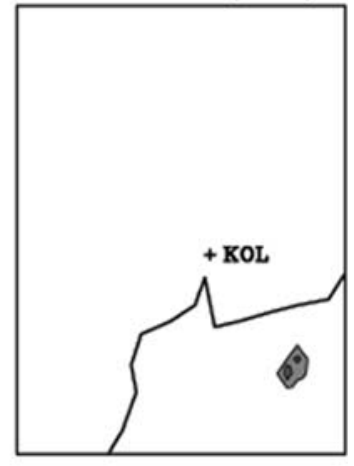

OOZOBJUN2005 $(t=48)$

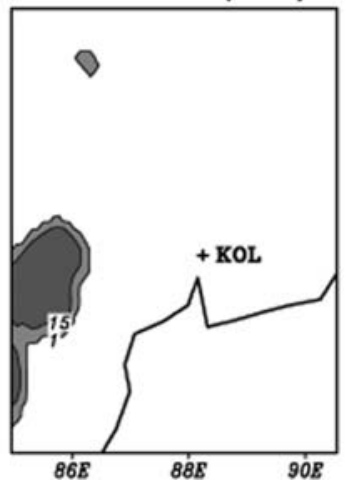


(c) 3DVAR_DWR
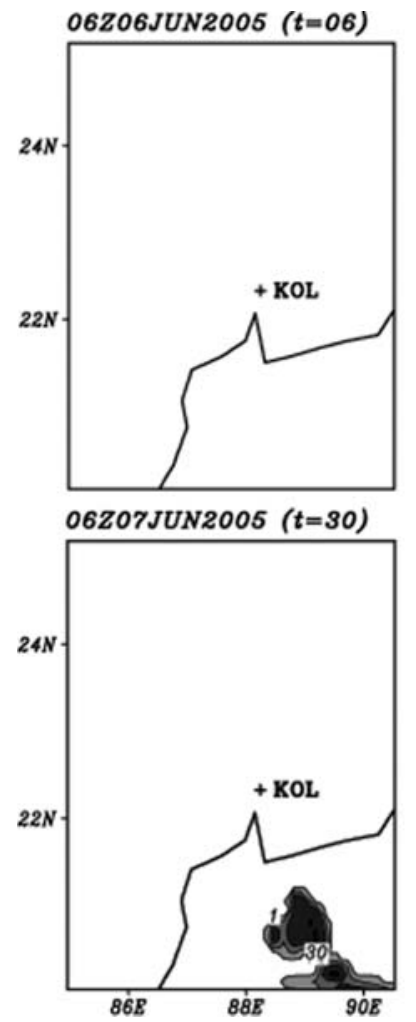
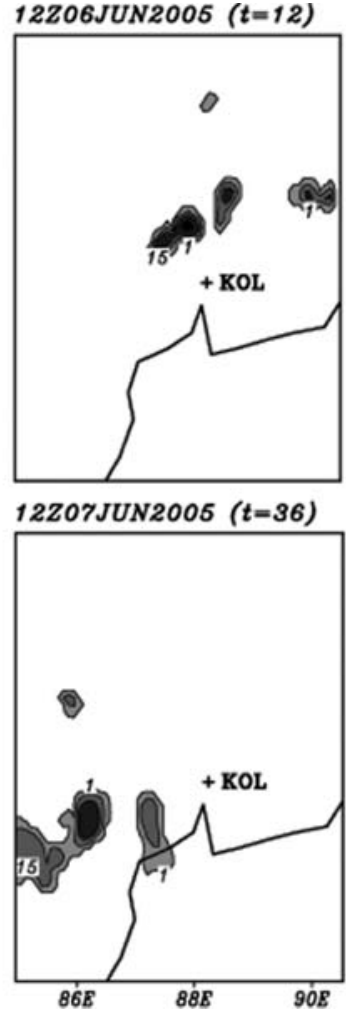

18Z06JUN2005 $(t=18)$

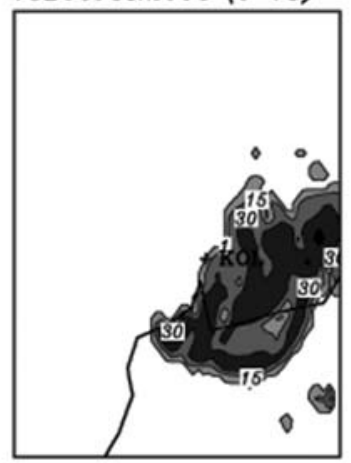

$18 Z 07$ JUN2005 $(t=42)$
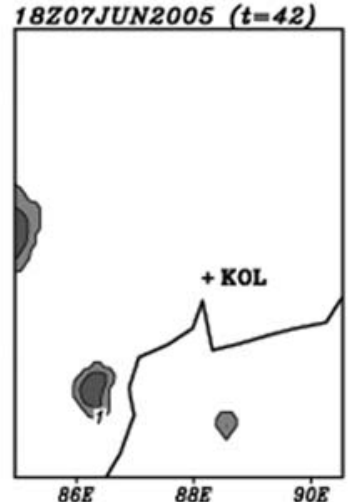

00Z07JUN2005 $(t=24)$

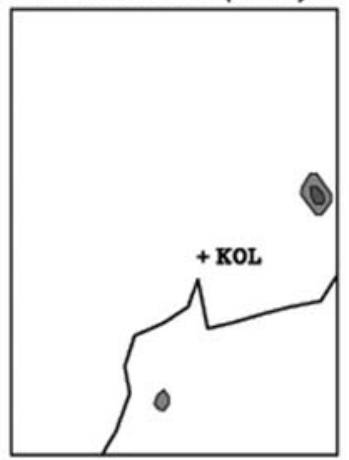

$00 Z 08 J U N 2005(t=48)$

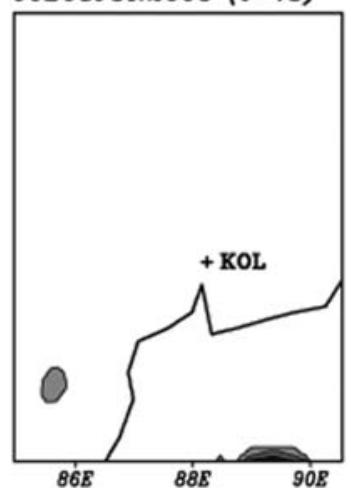

Figure 12(a-c). Composite reflectivity at 6 -h intervals simulated by the experiment (a) CTRL_GSFC, (b) 3DVAR_NoDWR and (c) 3DVAR_DWR based on initial condition at 0000 UTC, 6 June 2005.

over south peninsula on many days of the week. A major amount of rainfall reported over the coastal region during the periods is summarized in table 3.

The 6-hourly accumulated precipitation from TRMM in figure 13 shows the presence of a major rainfall band $(>1 \mathrm{~cm})$ over coastal regions of Tamil Nadu, Andhra Pradesh and the adjoining sea almost everyday from 0600 UTC of 30 April to 1800 UTC, 4 May 2005. Two regions of organized convection are seen over southwest and northeast of Chennai and the adjoining area during 06001800 UTC, 30 April. About 2-4 cm of rainfall is observed over Chennai and the adjoining area during 1800 UTC, 1 May and 0000 UTC, 2 May. During $0600-1800$ UTC on 2 May, the organization of rainbands is almost similar to that on 30 April. The rainbands originated northeast of Chennai and coastal Andhra Pradesh shows a southeastward propagation during 0000-1800 UTC, 3 May. During 0000-1800 UTC, 4 May, major rainbands are observed over southwest of Chennai and the adjoining sea.

Figure 14 presents radar reflectivity, $\operatorname{MAX}(\mathrm{Z})$ during the period 30 April to 3 May at selected times. The reflectivity diagrams are shown corresponding to the maximum echo in horizontal and vertical direction at 6 -h intervals between 0600 UTC of 30 April and 1800 UTC of 3 May 2005.

\subsection{Simulated rainfall}

Accumulated rainfall from the simulations are compared with the TRMM observations during the period. Figure 15 presents 6 -h accumulated rainfall based on the initial conditions of 0000 UTC, 30 April for the three experiments. The CTRL_GSFC experiment predicts the precipitation bands over southwest of Chennai during 1200-1800 UTC, 30 April reasonably well, but fails to predict the rain patches over northeast of Chennai and adjoining coastal Andhra Pradesh. The 3DVAR_NoDWR experiment predicts maximum rainfall during 0000-1200 UTC, 30 April. The southwest rainband from 3DVAR_NoDWR experiment is more or less comparable with the observed rainfall from TRMM, but overpredicts the precipitation band over northeast of Chennai and underestimates the rainfall during 1200-1800 UTC, 30 April. The 3DVAR_DWR experiment predicts $4-8 \mathrm{~cm}$ of rainfall during 0000-1200 UTC, 30 April but is more over the sea. The position of the rainbands predicted by $3 \mathrm{DVAR} \_\mathrm{DWR}$ experiment during 1200-1800 UTC, 30 April is more or less comparable with the observations and shows better skill in predicting the southwest and northeast precipitation bands. The southeastward propagation of the rain patches is better 

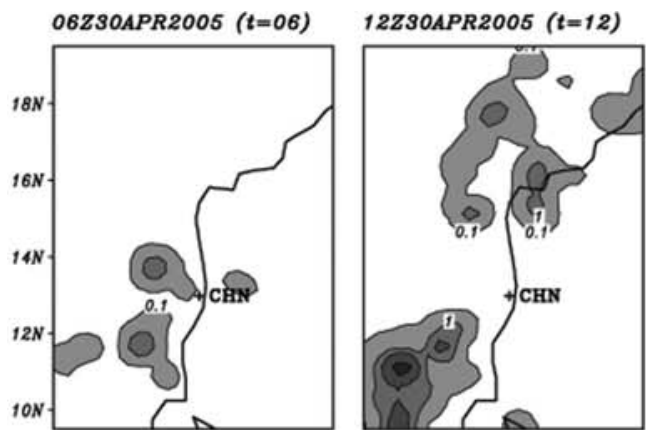

18Z3OAPR2OO5 $(t=18)$

O0Z01MAY2005 $(t=24)$
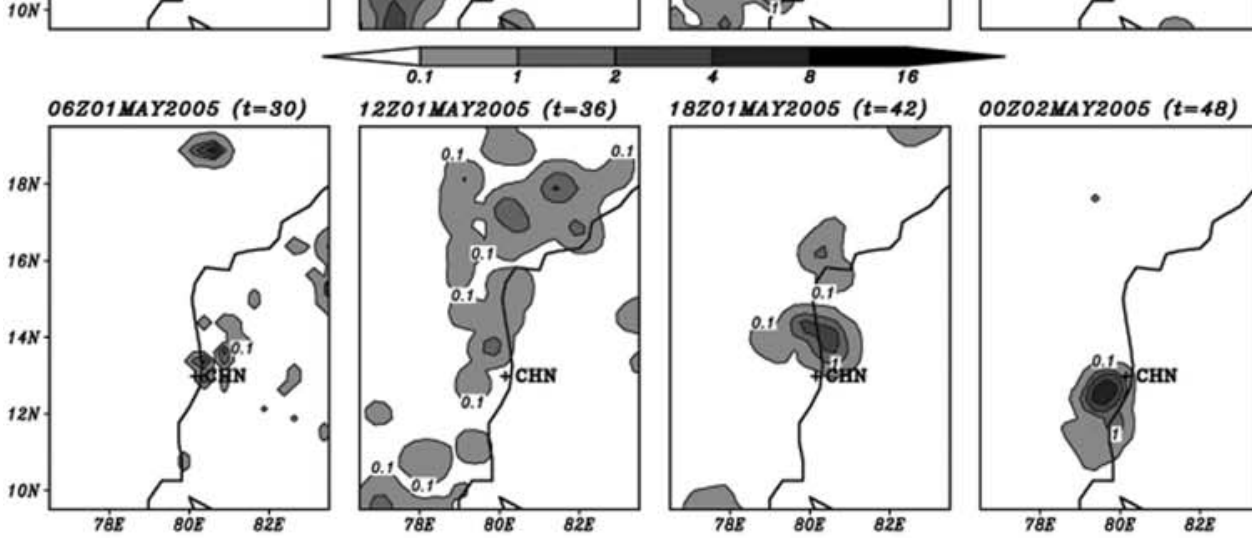

$18 Z 01$ MAY2005 ( $t=42)$

OOZ02MAY2005 $(t=48)$

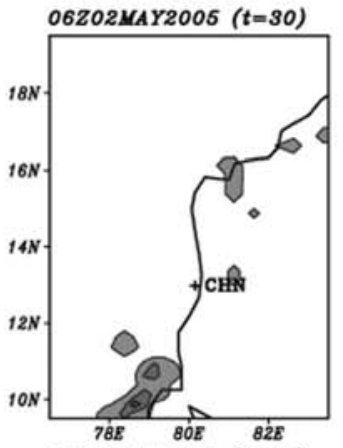

12Z02MAY2005 $(t=36)$
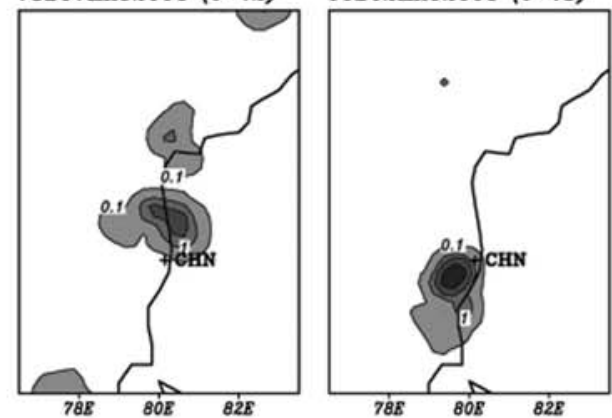

18Z02MAY2005 $(t=42)$
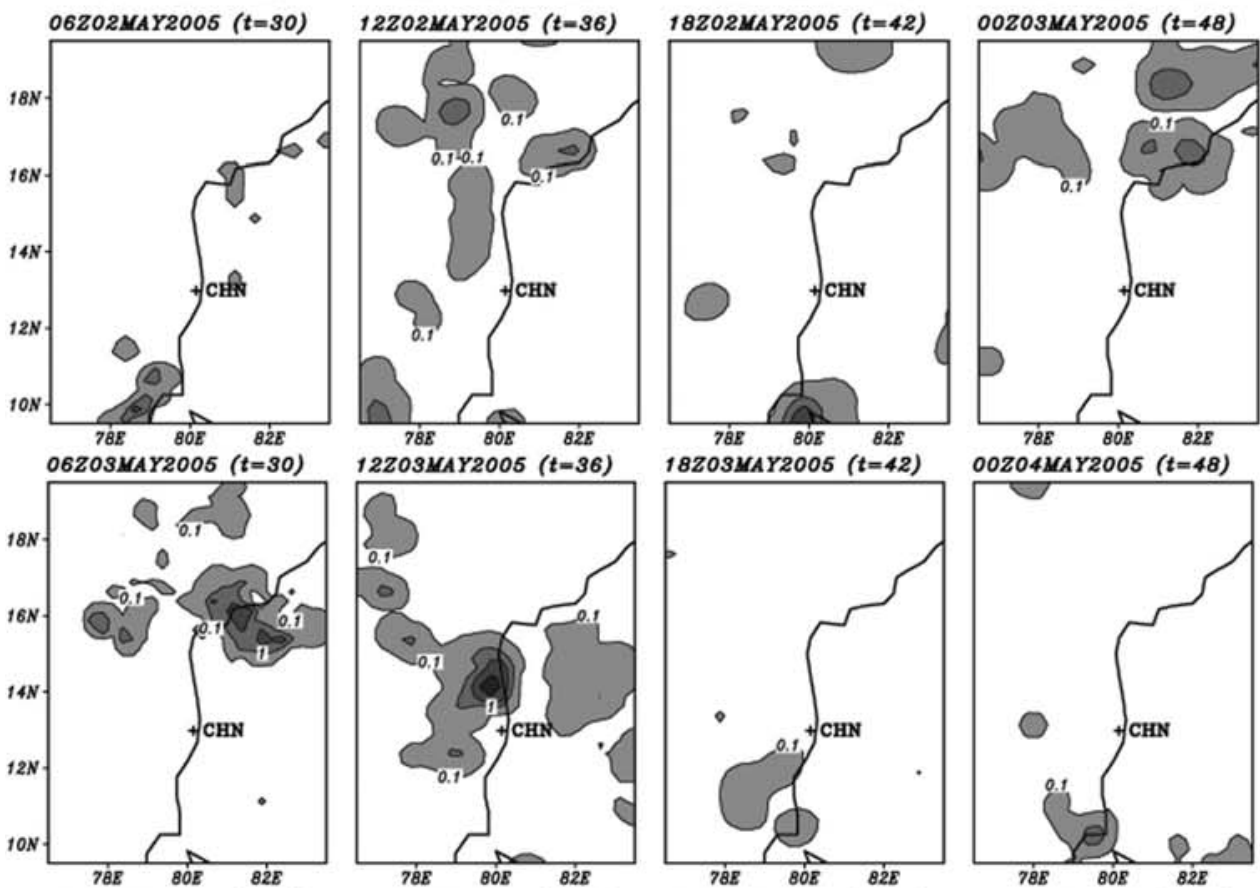

$00 Z 04 M A Y 2005(t=48)$
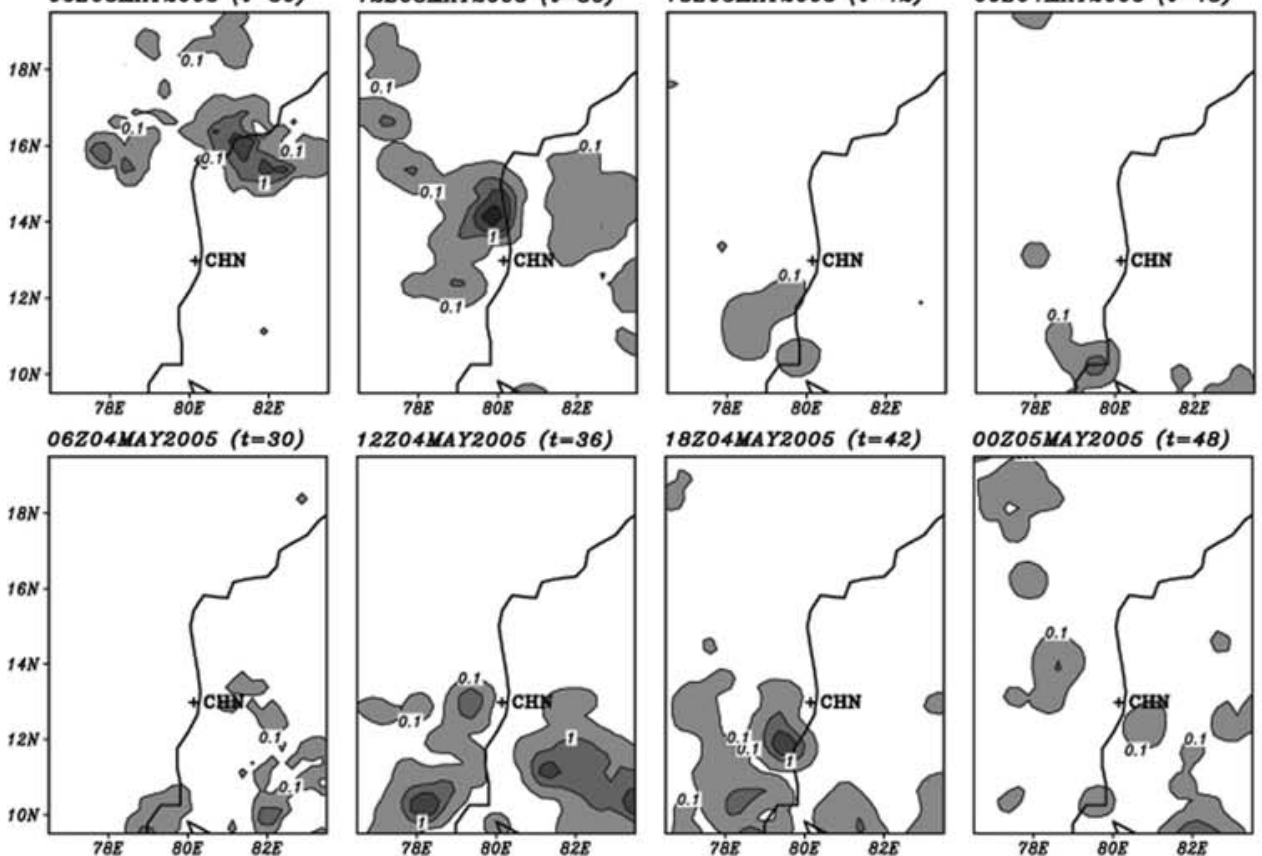

Figure 13. Six-hourly accumulated precipitation $(\mathrm{cm})$ from TRMM for the period 0600 UTC, 30 April-0000 UTC, 5 May 2005 around Chennai. 
(a) $0808 Z 300405$

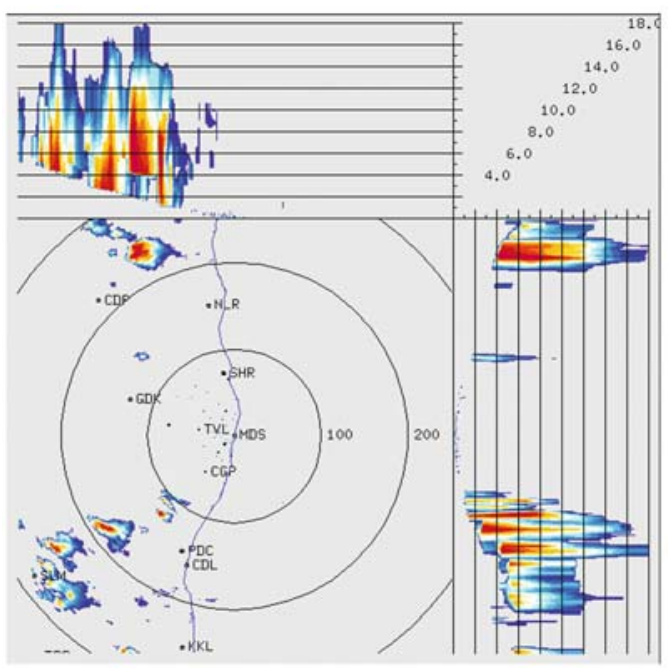

(c) $1208 Z 010505$

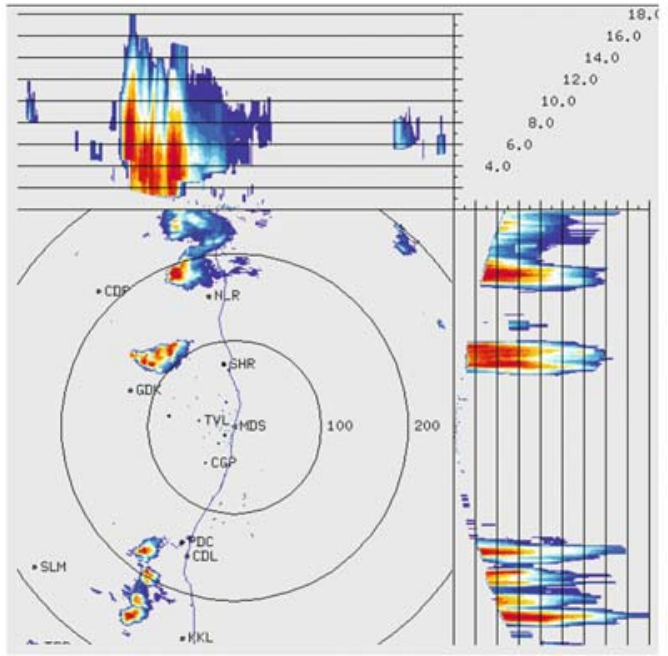

(e) $0808 Z 020505$

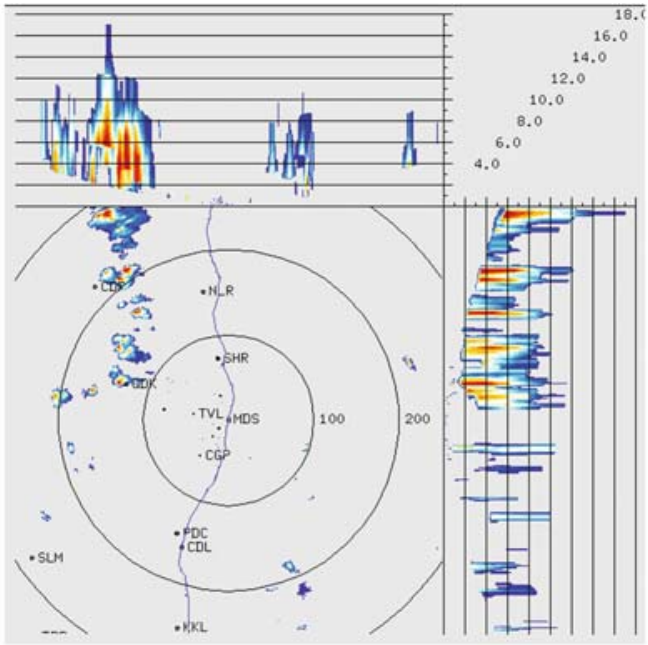

(b) $2308 Z 3040405$

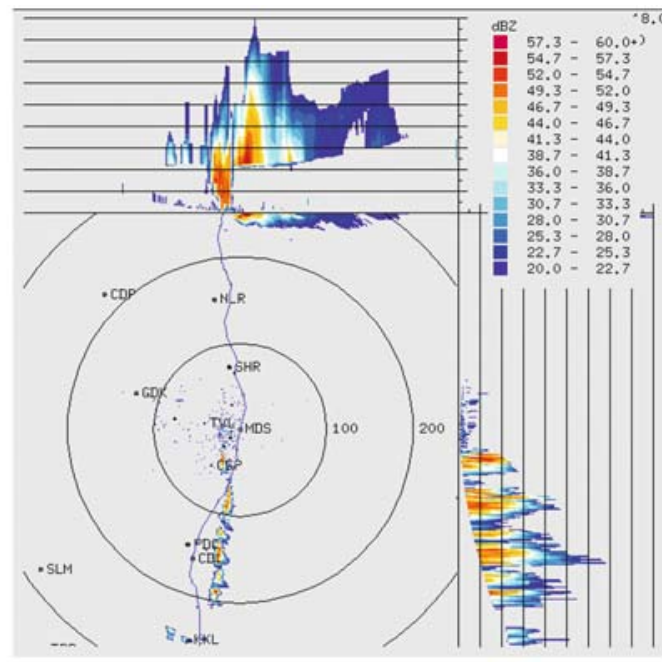

(d) $2008 Z 010505$

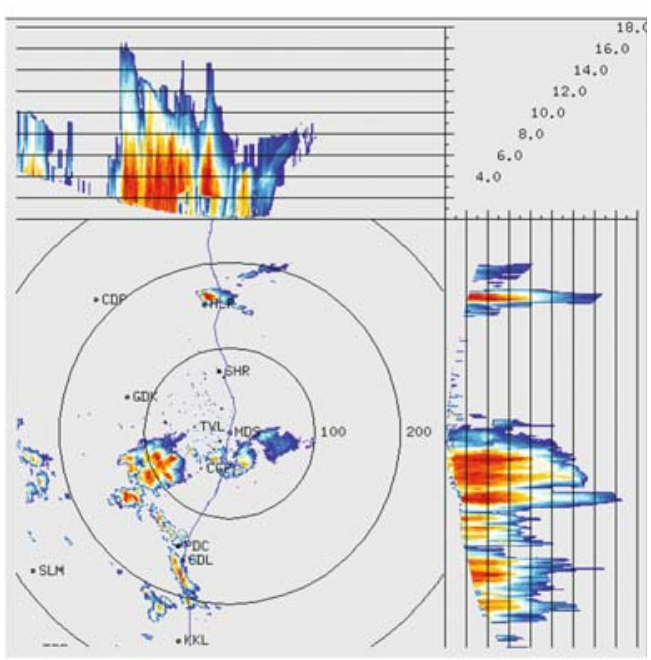

(f) $1208 Z 020505$

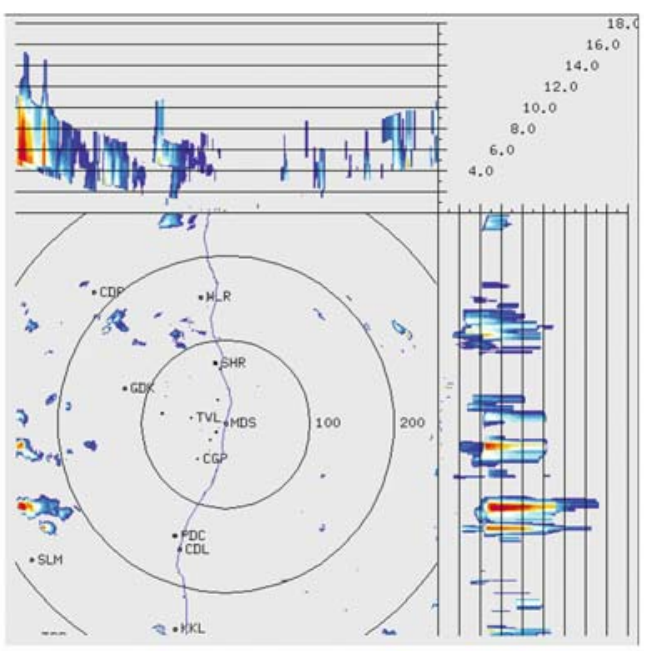

Figure 14. (Continued) 
(g) $0808 Z 030505$

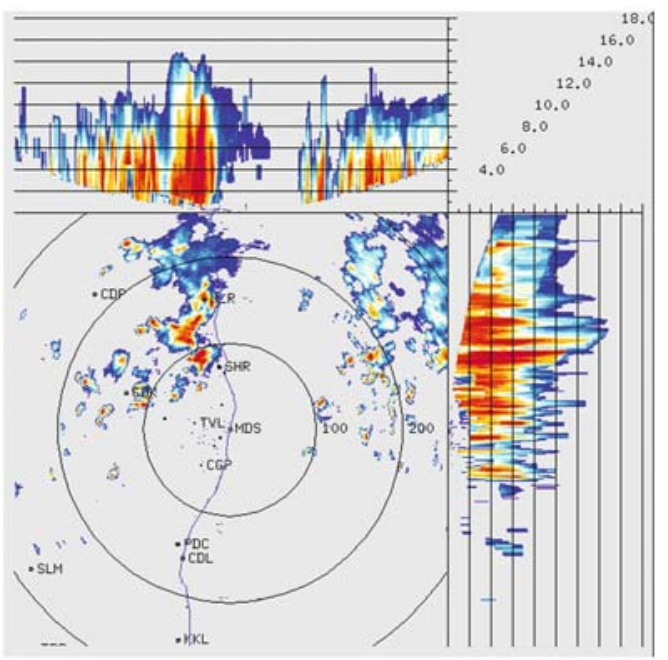

(h) $1708 Z 030505$

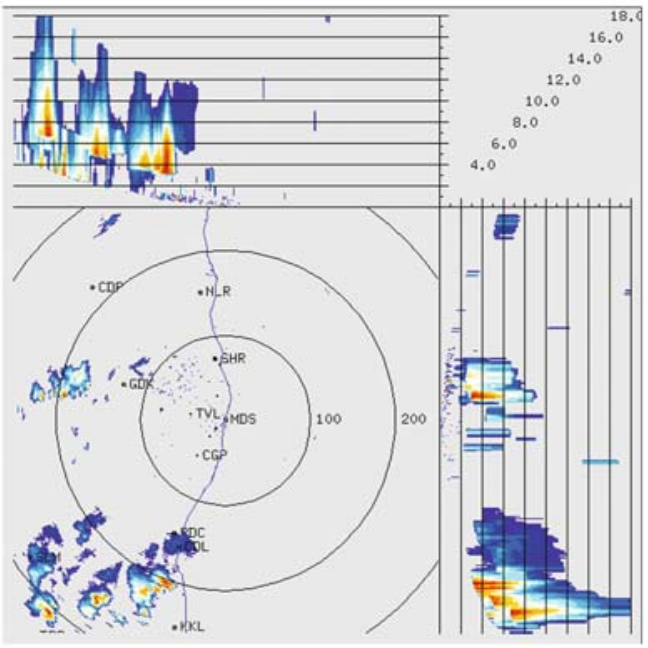

Figure 14(a-h). Reflectivity, MAX(Z) during 30 April-3 May 2005.

simulated in 3DVAR_DWR experiment. All the three experiments predict scattered precipitation clusters during 0600-1800 UTC, 1 May, while none of them are able to simulate the precipitation over Chennai during 1200 UTC, 1 May and 0000 UTC, 2 May. Comparison of the distribution and amount of rainfall from the above analysis reveals a fairly good correspondence between observations and simulations. The spatial distribution of simulated rainfall from CTRL_GSFC is as good as those obtained after data assimilation, but quantitative rainfall prediction is better when DWR winds are assimilated in the model.

Figure 16 shows 6 -h accumulated precipitation for the three experiments based on the initial condition of 0000 UTC, 1 May. The CTRL_GSFC predicts maximum rainfall during 1200-1800 UTC, 1 May. The rainfall pattern resulting from the CTRL_GSFC experiment is closer to the TRMM observations during 0600-1200 UTC, 1 May. The line of precipitation clusters along the coast is better reproduced in CTRL_GSFC experiment, but it overestimates the rainfall amount and predicts more widespread rain patches at 1800 UTC, 1 May. The control experiment, without data assimilation does not predict significant rainfall amount during 0000-1800 UTC, 2 May. The 3DVAR_NoDWR experiment predicts maximum rainfall in the domain during 0600-1200 UTC, 1 May. The assimilation without radar data predicts scattered rainfall over the sea. Unlike the rainfall distribution in CTRL_GSFC experiment, the 3DVAR_NoDWR experiment predicts better distribution as seen in the TRMM observation during 0000-1800 UTC, 2 May, however the quantity is underestimated. Furthermore, the rainfall forecast from 3DVAR_DWR experiment has a different distribution from the other two. As compared with the observations, the 3DVAR_DWR experiment predicts the northeast band during 0000-1200 UTC and the line structure not along the coast, but a little towards the sea. The assimilation experiment with radar wind data, 3DVAR_DWR more or less captures the rainfall around Chennai, but is shifted southeast of Chennai. An important result to be noted is that, the assimilation experiments underestimate the rainfall amount and delays the rainband development.

Accumulated rainfall from the simulation experiments based on the initial condition of 0000 UTC, 2 May is shown in figure 17. The control experiment, CTRL_GSFC predicts maximum rainfall of $4-8 \mathrm{~cm}$ during $1200-1800$ UTC, 2 May and the rainband predicted too farther north as compared to the TRMM observations. Scattered cloud clusters are produced from the CTRL_GSFC during 0600-1800 UTC on 3 May, but are underestimated as compared to the observations. The data assimilation experiment without radar data, 3DVAR_NoDWR experiment also predicts scattered rain patches, but the intensity is improved slightly from the CTRL_GSFC experiment. The assimilation experiments with radar data, 3DVAR_DWR also produced two rainbands during $0000-1800$ UTC on 2 May, but the position of the northeast band shifted farther north and the southwest band is almost close to the observations. The 3DVAR_DWR experiment predicts the northeast and southwest rainbands reasonably well during 00001800 UTC. The rainfall intensity forecast from the 3DVAR_DWR experiments more or less close to the TRMM observations during 0000-1800 UTC, 3 May 2005 and that from 3DVAR_NoDWR is close to observations during 0600-1800 UTC, 2 May. 
(a) CTRL_GSFC

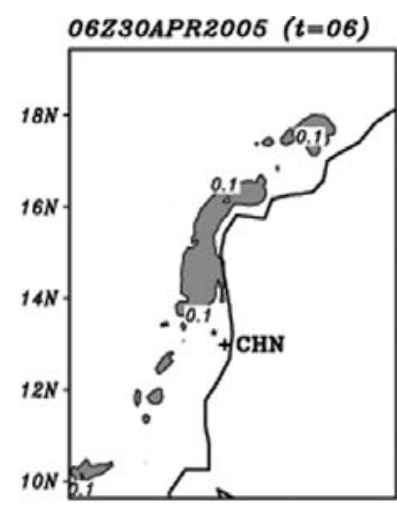

12Z3OAPR2005 $(t=12)$
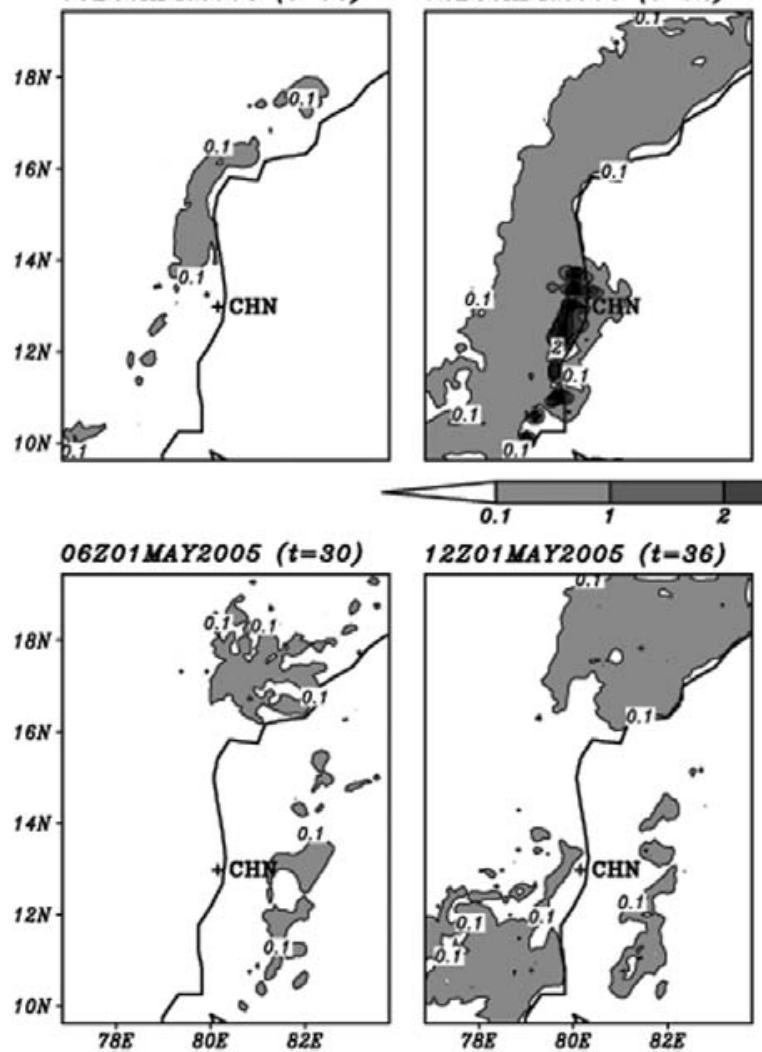

(b) 3DVAR_NoDWR
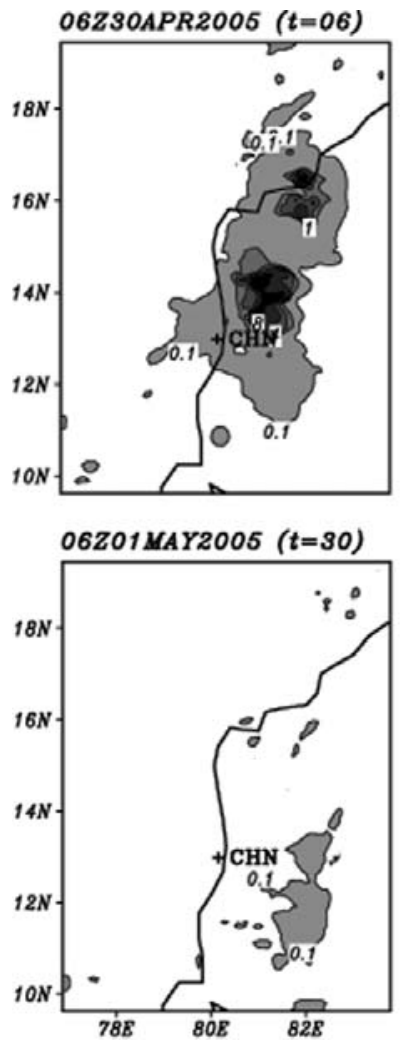

12Z30APR2005 $(t=12)$

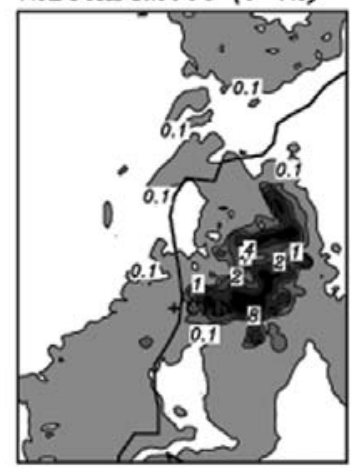

12Z01MAY2005 ( $t=36)$

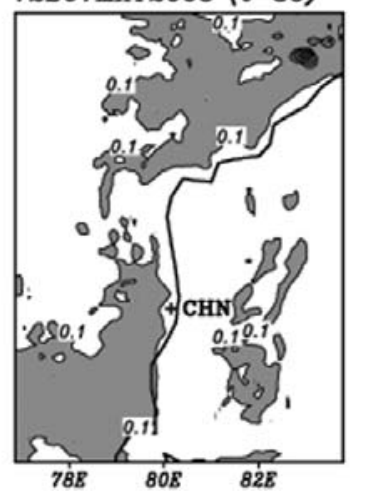

18Z30APR2005 $(t=18)$

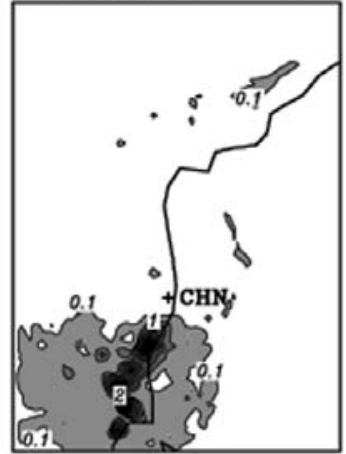

$00 Z 01$ MAY2005 $(t=24)$

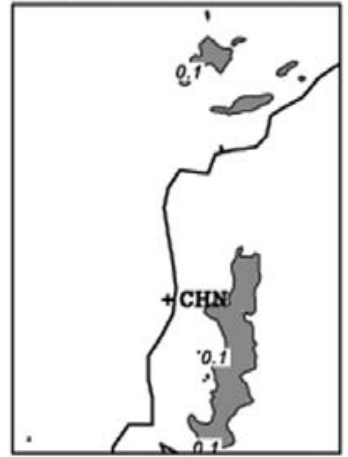

$18 Z 01$ MAY2005 $(t=42)$

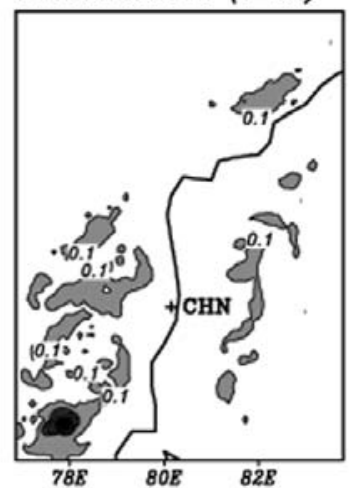

OOZO2MAY2005 $(t=48)$

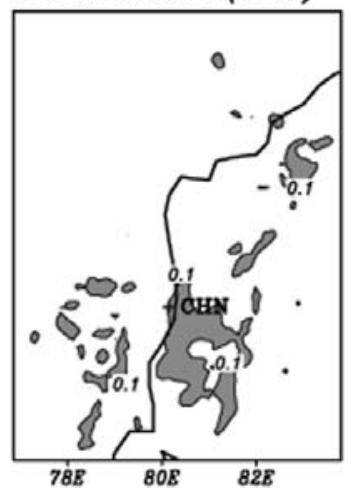

00Z01MAYZ005 $(t=24)$

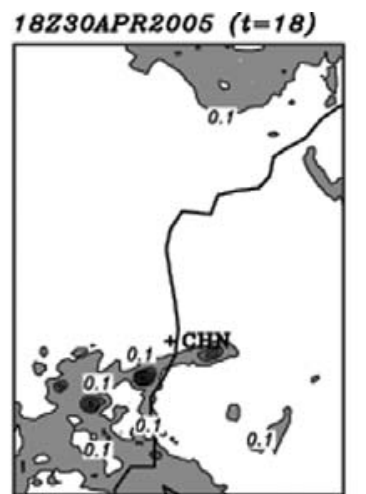

18Z01MAY2005 ( $t=42)$

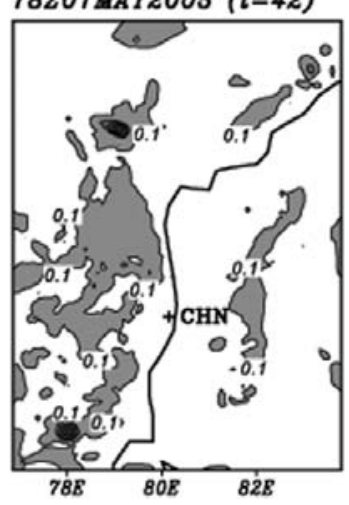

OOZO2MAY2005 ( $t=48)$

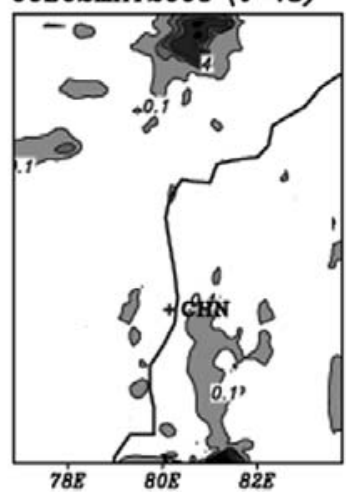

Figure 15. (Continued) 
(c) 3DVAR_DWR

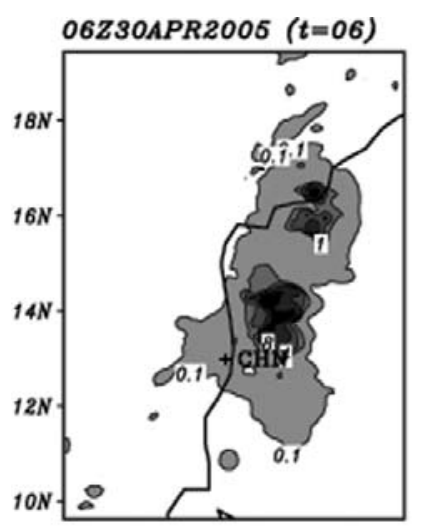

06201 MAY2005 $(t=30)$

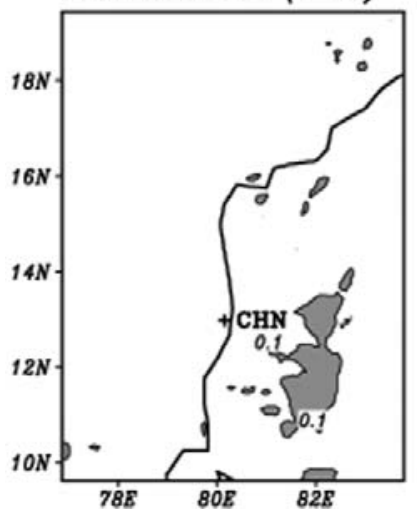

12Z3OAPR2005 ( $t=12)$

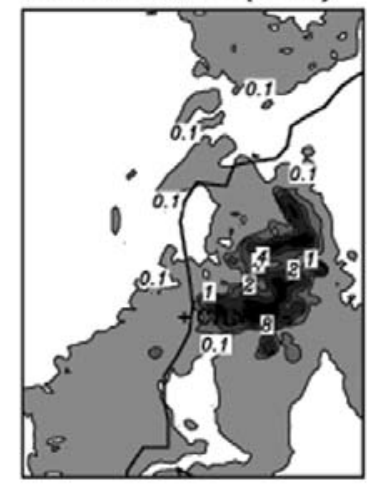

$12 Z 01$ MAY2005 $(t=36)$

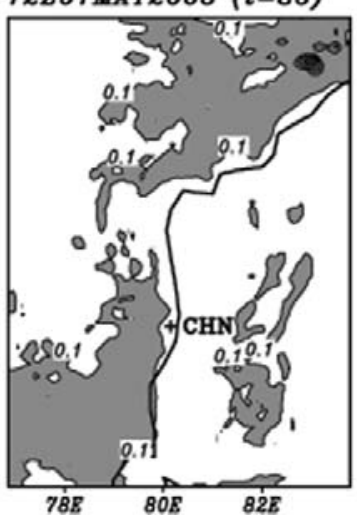

18Z30APR2005 $(t=18)$

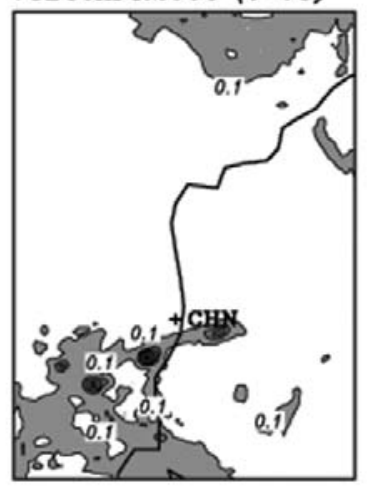

18Z01MAY2005 ( $t=42)$

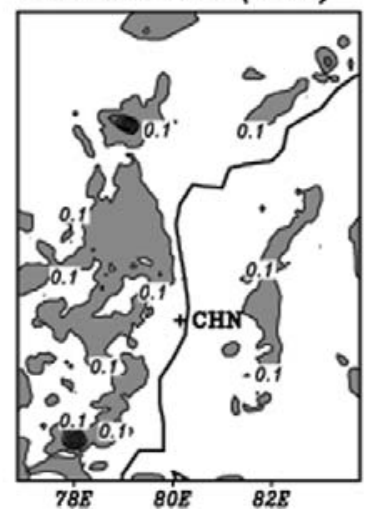

OOZ01MAY2005 ( $t=24)$

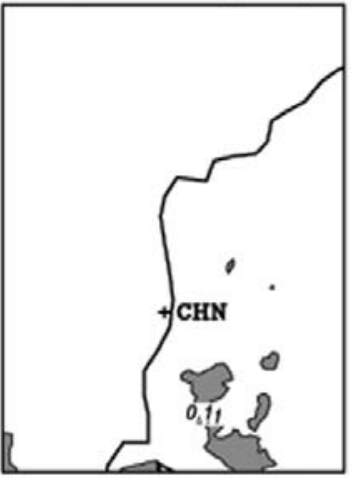

OOZO2MAYZOOS $(t=48)$

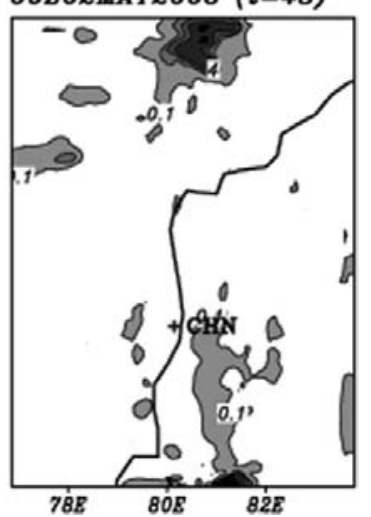

Figure 15(a-c). Six-hourly accumulated precipitation $(\mathrm{cm})$ from the (a) CTRL_GSFC, (b) 3DVAR_NoDWR and (c) 3DVAR_DWR experiment based on initial condition of 00 UTC, 30 April 2005.

Figure 18 shows simulated rainfall for the three experiments, based on the initial condition of 0000 UTC on 3 May. The control simulation without data assimilation predicts northeast rainbands during 0000-0600 UTC, 3 May reasonably well. Organization of rainbands during 0600-1200 UTC, 3 May is scattered and shifted farther northeastwards as compared to the observations and overpredicts the rainfall south of Chennai during 1200 UTC, 3 May and 0000 UTC, 4 May. Without data assimilation, the CTRL_GSFC experiment produced single rainbands during 0600-1800 UTC, 4 May over southwest of Chennai. Both the assimilation experiments and CTRL_GSFC experiment shows the similar organization of rainbands during the 48-h forecast period, while the CTRL_GSFC experiment overestimates the rainfall. The rainfall amount from the assimilation experiments is closer to the TRMM observations. An important result from the radar data assimilation experiment is the generation of new rainbands southeast of Chennai and adjoining Bay of Bengal region during 06001200 UTC on 4 May, which is not seen in the other two experiments.

\section{Summary and concluding remarks}

An attempt has been made here to initialize a storm-scale numerical model using retrieved wind fields from single Doppler weather radar and to forecast the thunderstorm evolution and structure. This study focuses on the impact of Doppler Weather Radar (DWR) and other conventional and non-conventional data in simulating the intense convective events over Chennai and Kolkata. Three strong convective events each over Chennai and Kolkata have been considered for the present study.

The model forecast of precipitation has been verified by calculating the ensemble equitable threat scores for all seven cases considered for the present study. The ETS of precipitation forecast has been calculated using 6 -h accumulated precipitation from merged rainfall analysis obtained from TRMM satellite. The figure 19(a) and (b) presents the 6 -h rainfall verification of the ETS averaged for the seven cases with thresholds of $10 \mathrm{~mm}$ and $20 \mathrm{~mm}$ respectively. For 12 hours, the results indicate that the assimilation of Doppler radar data 
(a) CTRL_GSFC
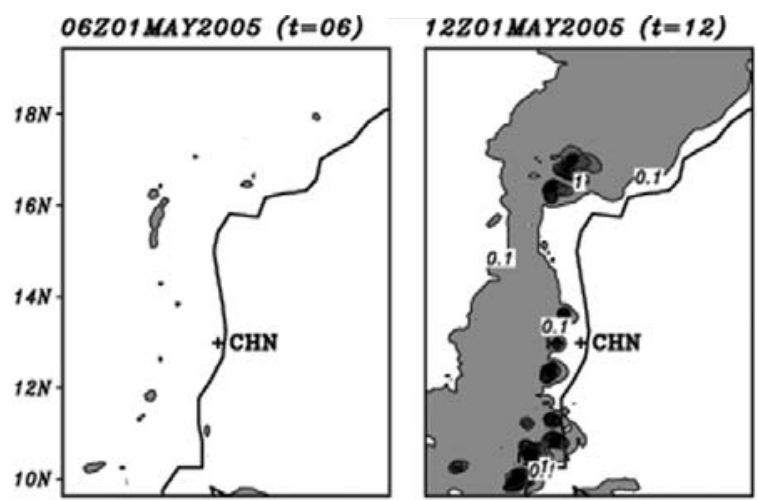

18201 MAY2005 $(t=18)$
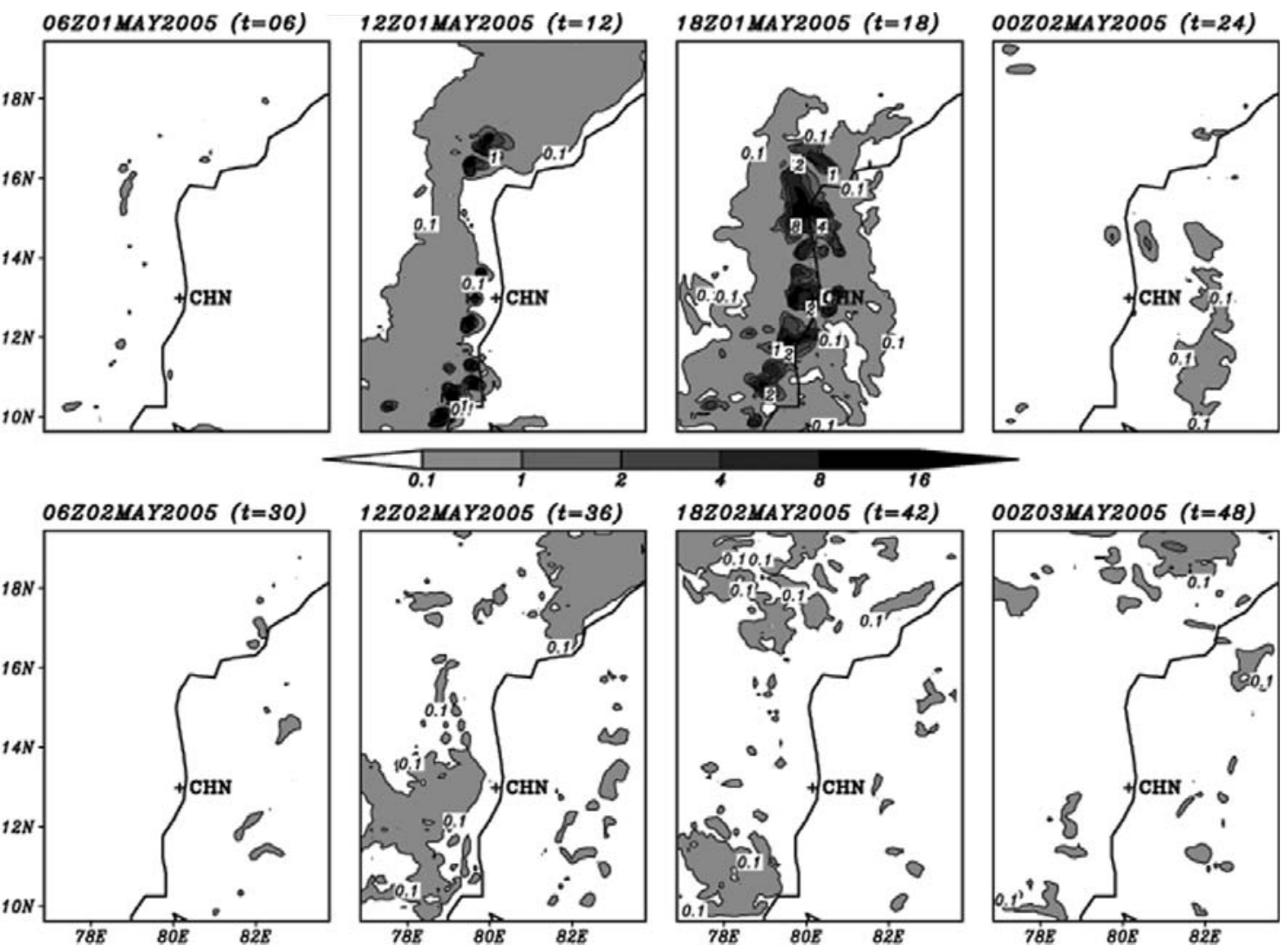

(b) 3DVAR_NoDWR
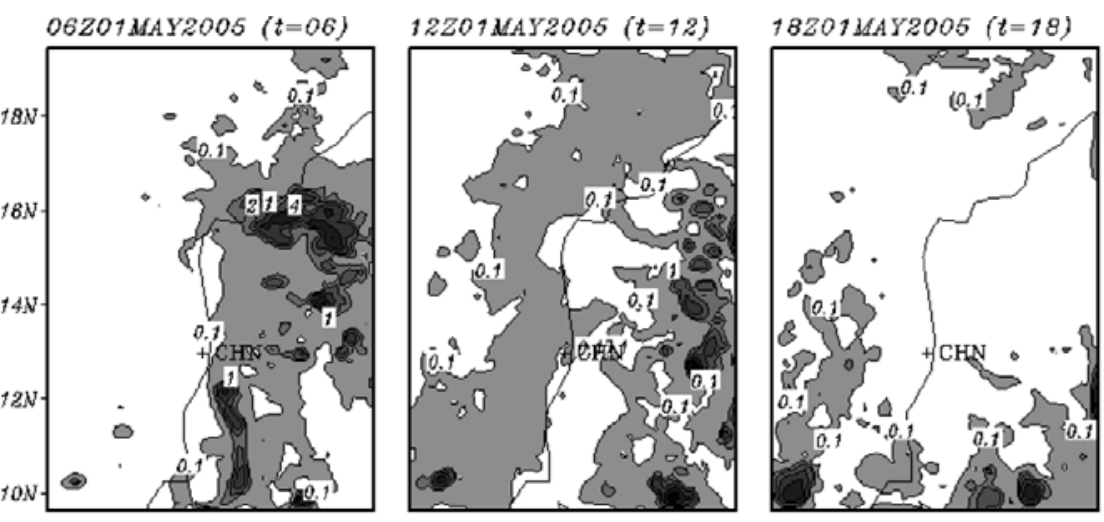

$00 Z 023 A A Y 2005(t=24)$
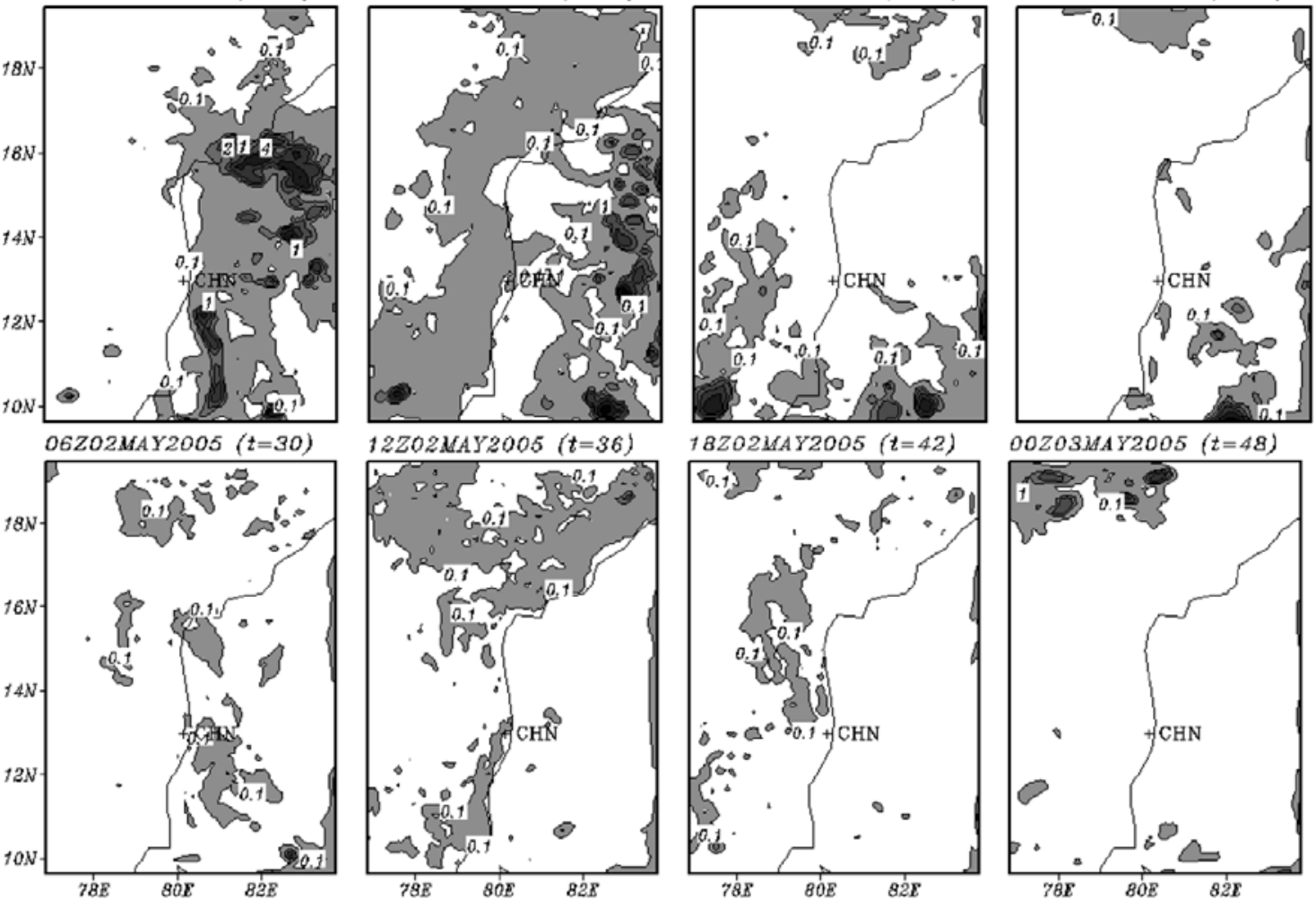

OOZ03MAY2005 $(t=48)$

Figure 16. (Continued)

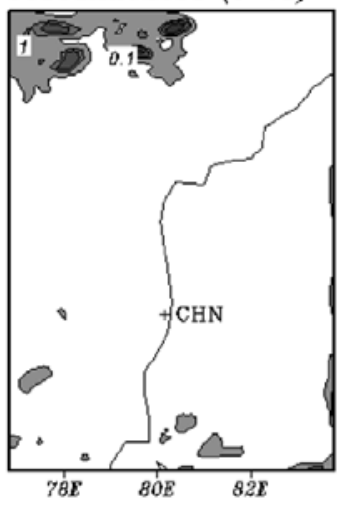


(c) 3DVAR_DWR
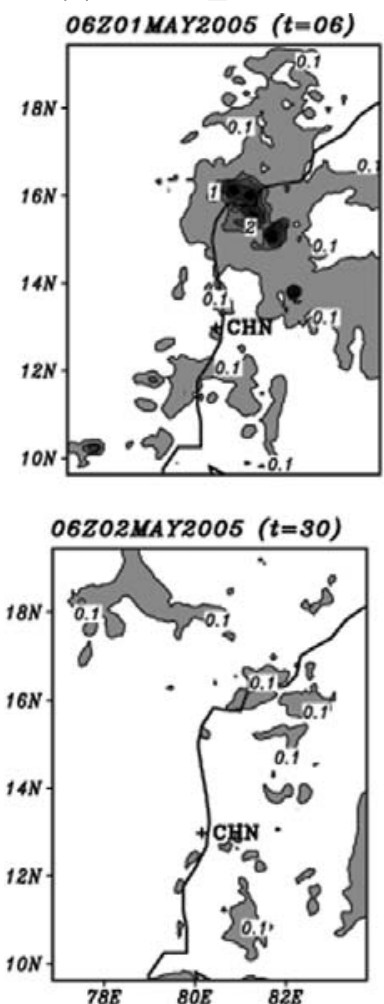

$12 Z 01$ MAY2005 $(t=12)$

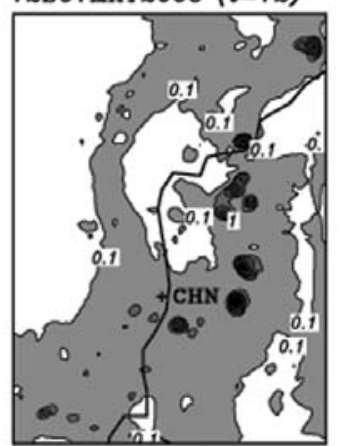

12Z02MAY2005 ( $t=36)$

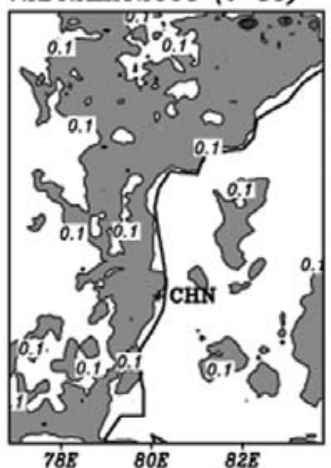

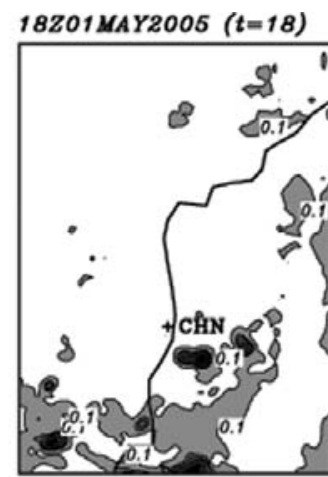

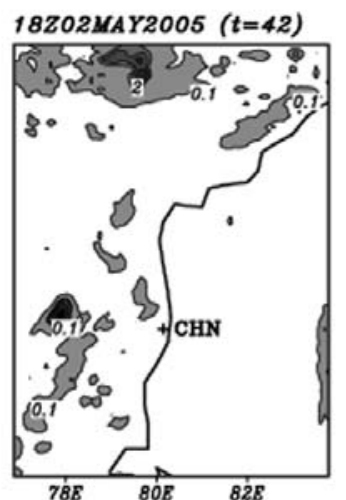

DOZ02MAYZOO5 $(t=24)$
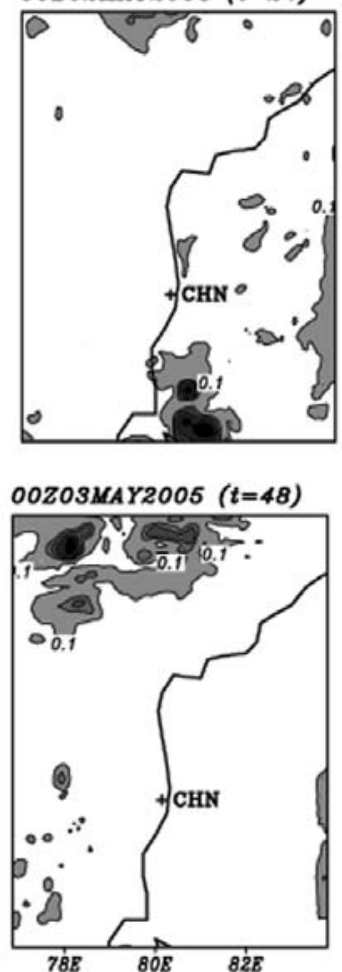

Figure 16(a-c). Six-hourly accumulated precipitation $(\mathrm{cm})$ from the (a) CTRL_GSFC, (b) 3DVAR_NoDWR and

(c) 3DVAR_DWR experiment based on initial condition of 00 UTC, 1 May 2005.

(a) CTRL_GSFC

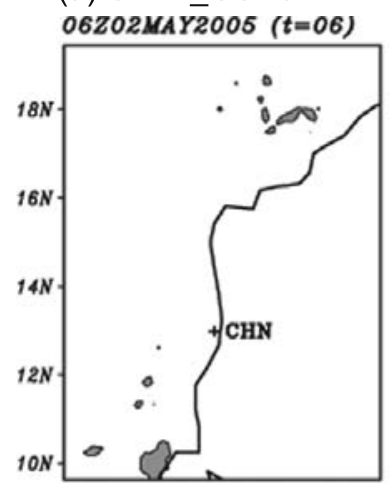

12Z02MAY2005 $(t=12)$
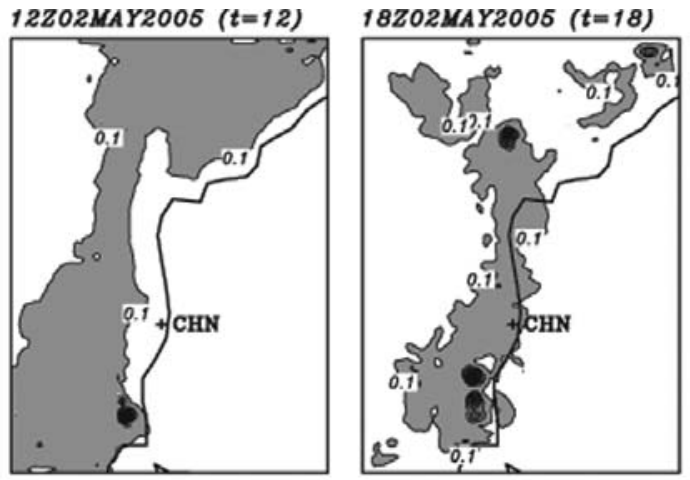

OOZO3MAY2005 $(t=24)$
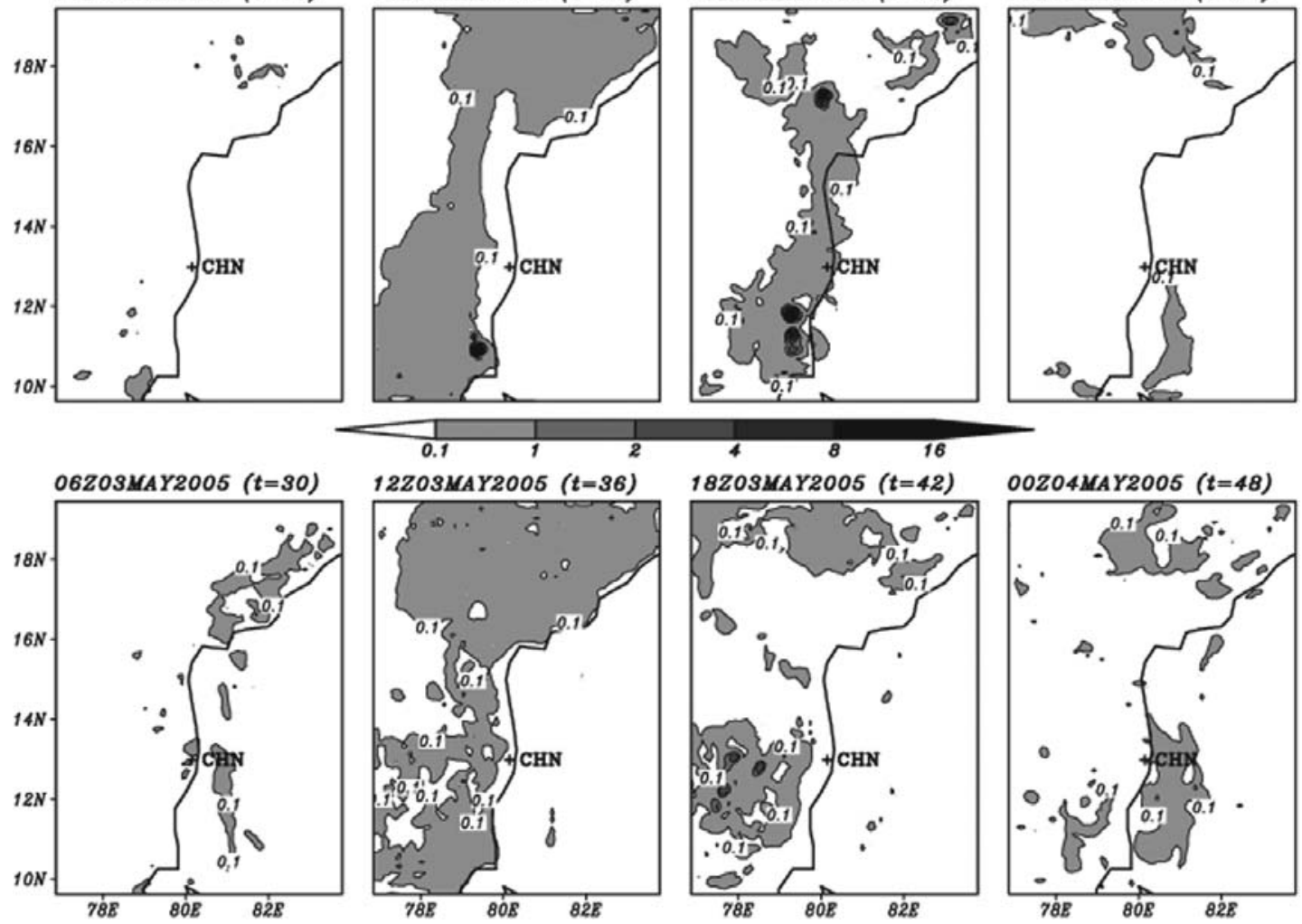

Figure 17. (Continued) 
(b) 3DVAR_NoDWR
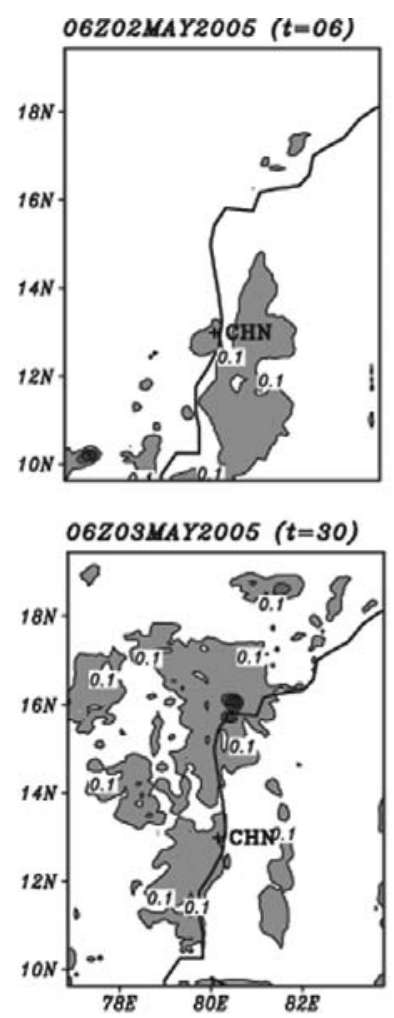

(c) 3DVAR_DWR
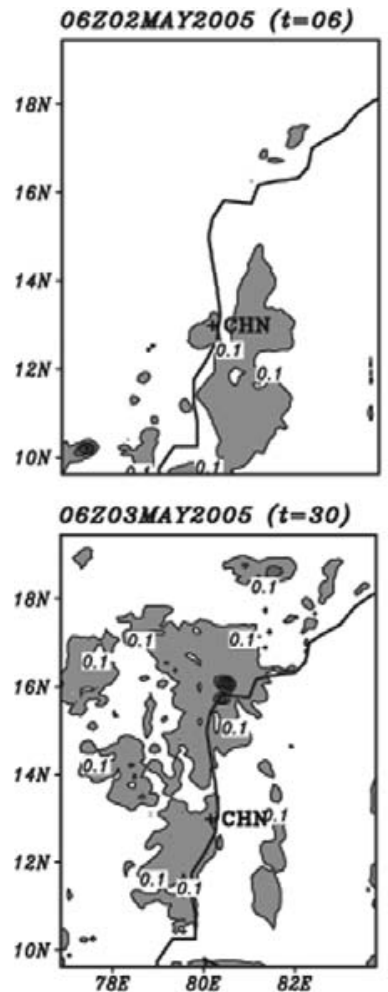
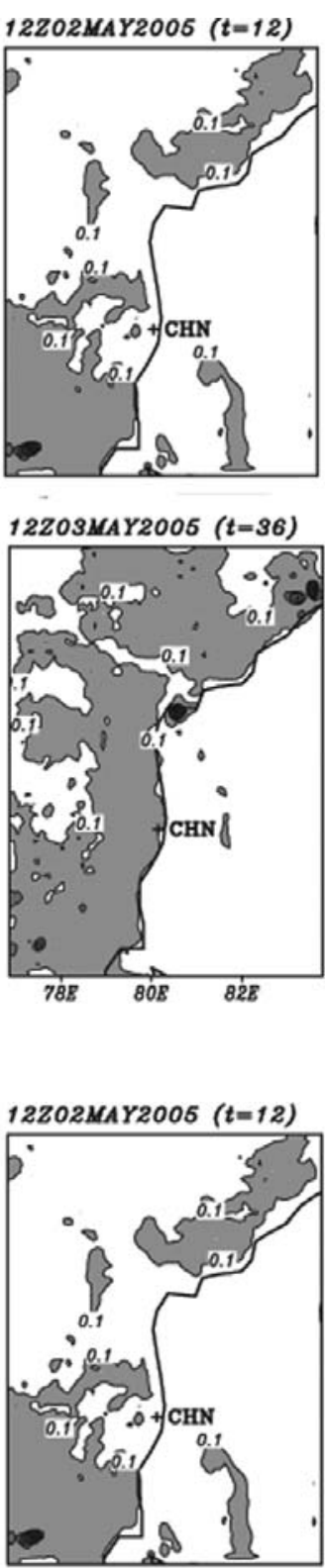

$12 Z 03 M A Y 2005(t=36)$

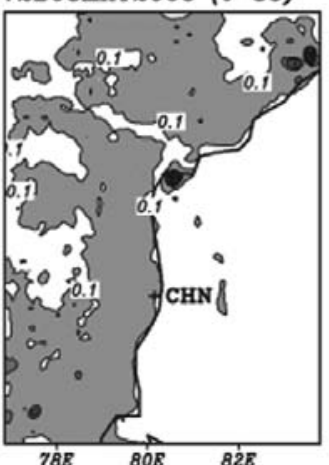

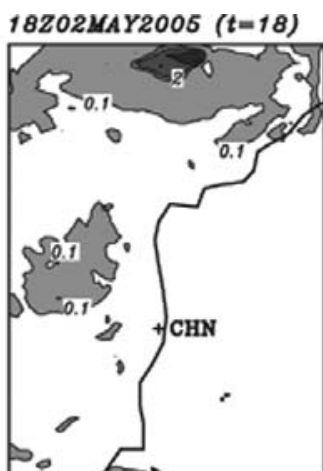

18Z0SMAYZOOS $(t=42)$
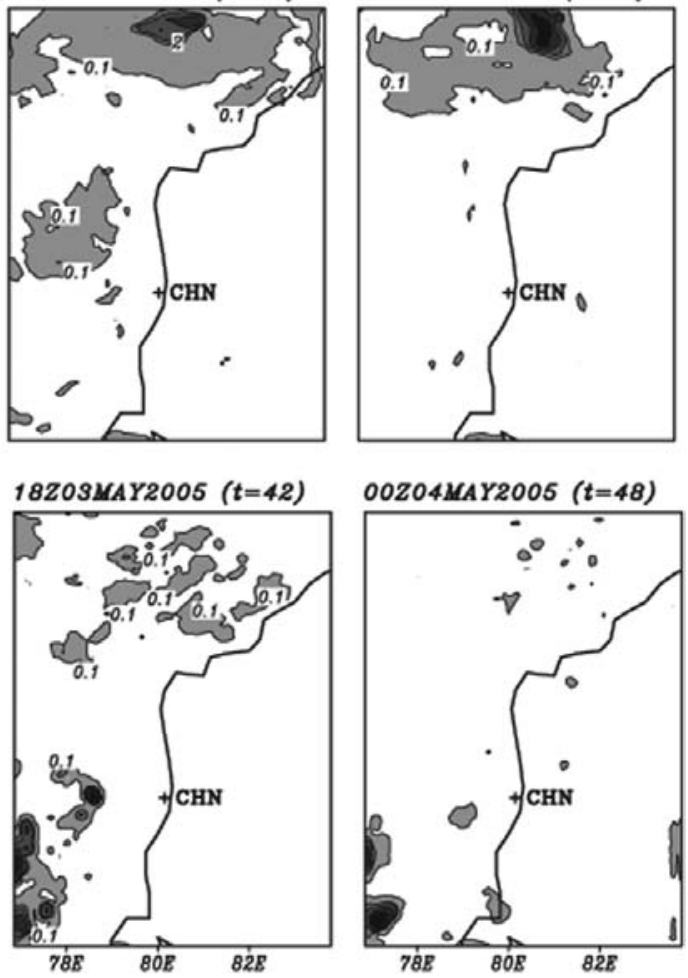

OOZ0SMAY2005 $(t=24)$
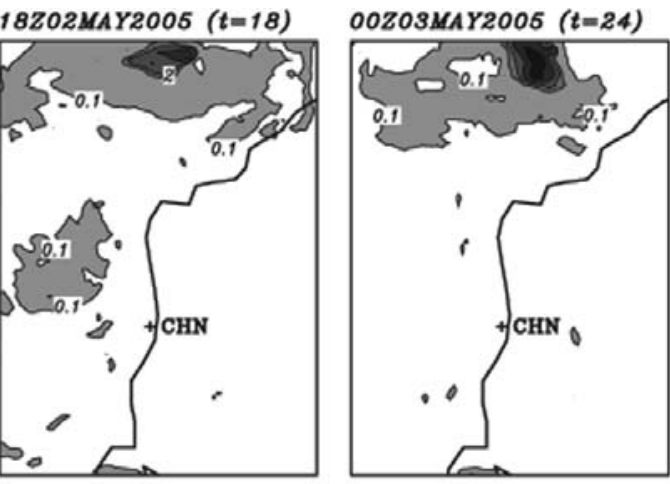

18Z03MAY2005 $(t=42)$

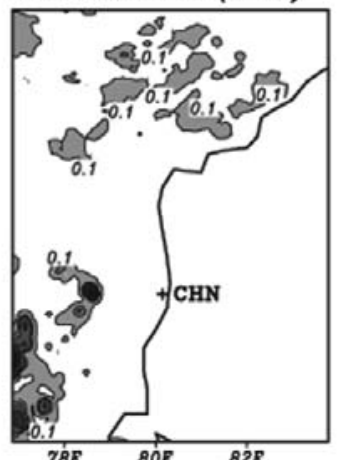

OOZ04MAY2005 $(t=48)$

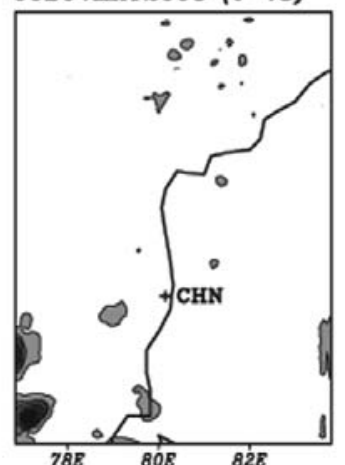

Figure 17(a-c). Six-hourly accumulated precipitation (cm) from the (a) CTRL_GSFC, (b) 3DVAR_NoDWR and (c) 3DVAR_DWR experiment based on initial condition of 00 UTC, 2 May 2005. 
(a) CTRL_GSFC
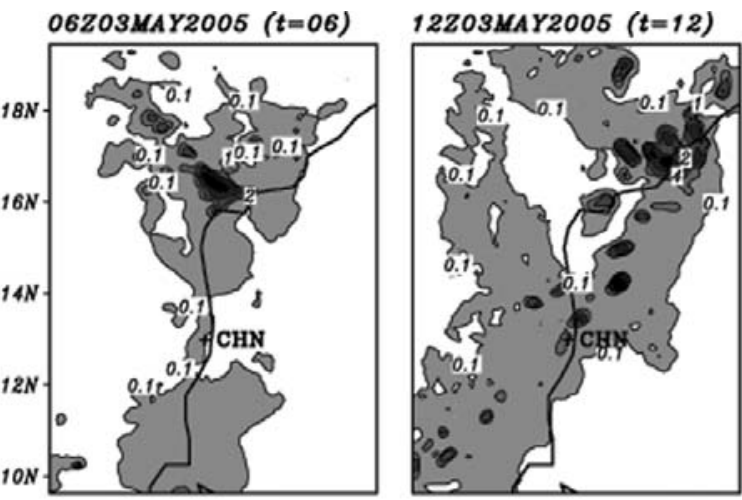

18Z03MAY2005 $(t=18)$

$00 Z 04 M A Y 2005(t=24)$
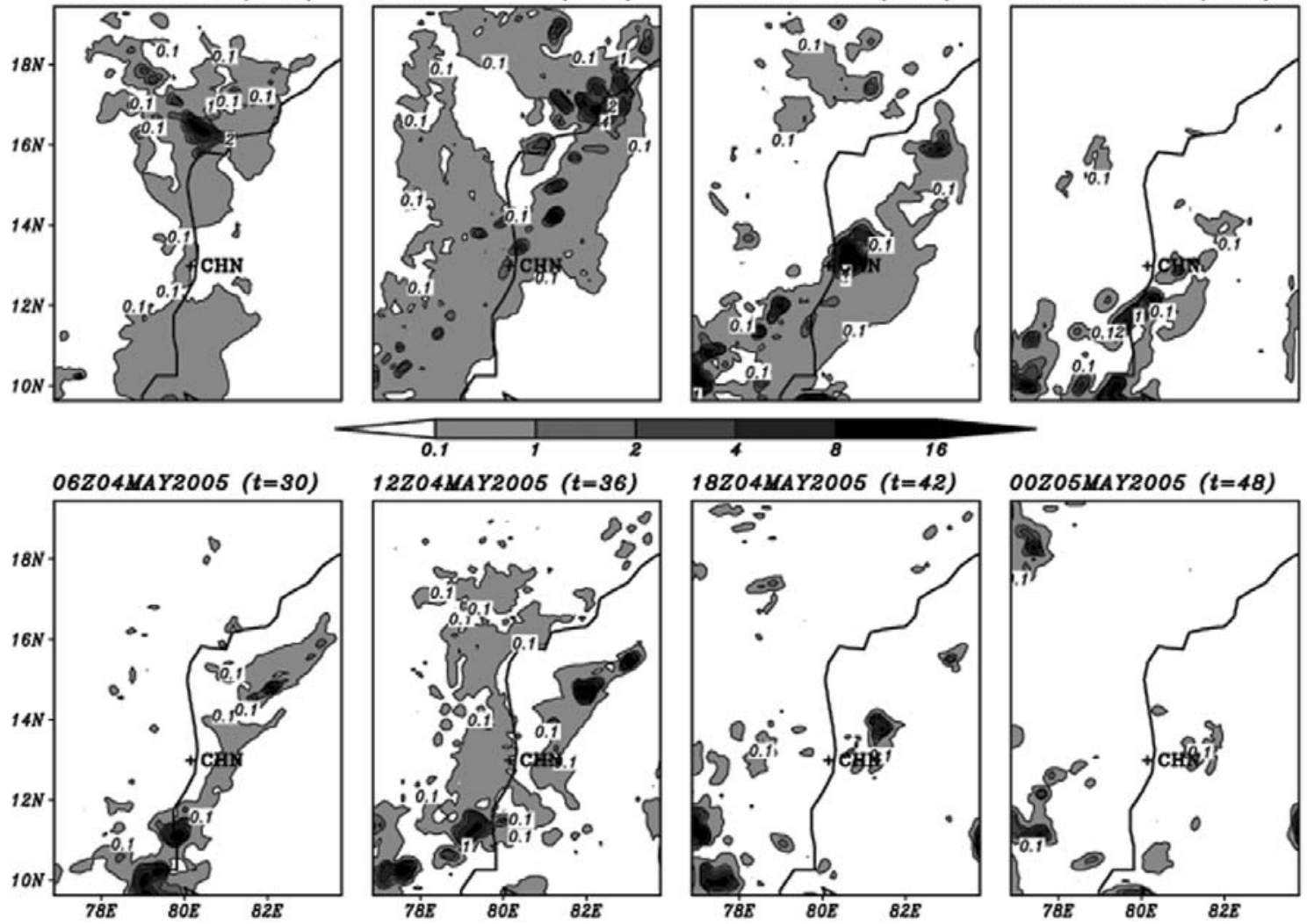

(b) 3DVAR_NoDWR
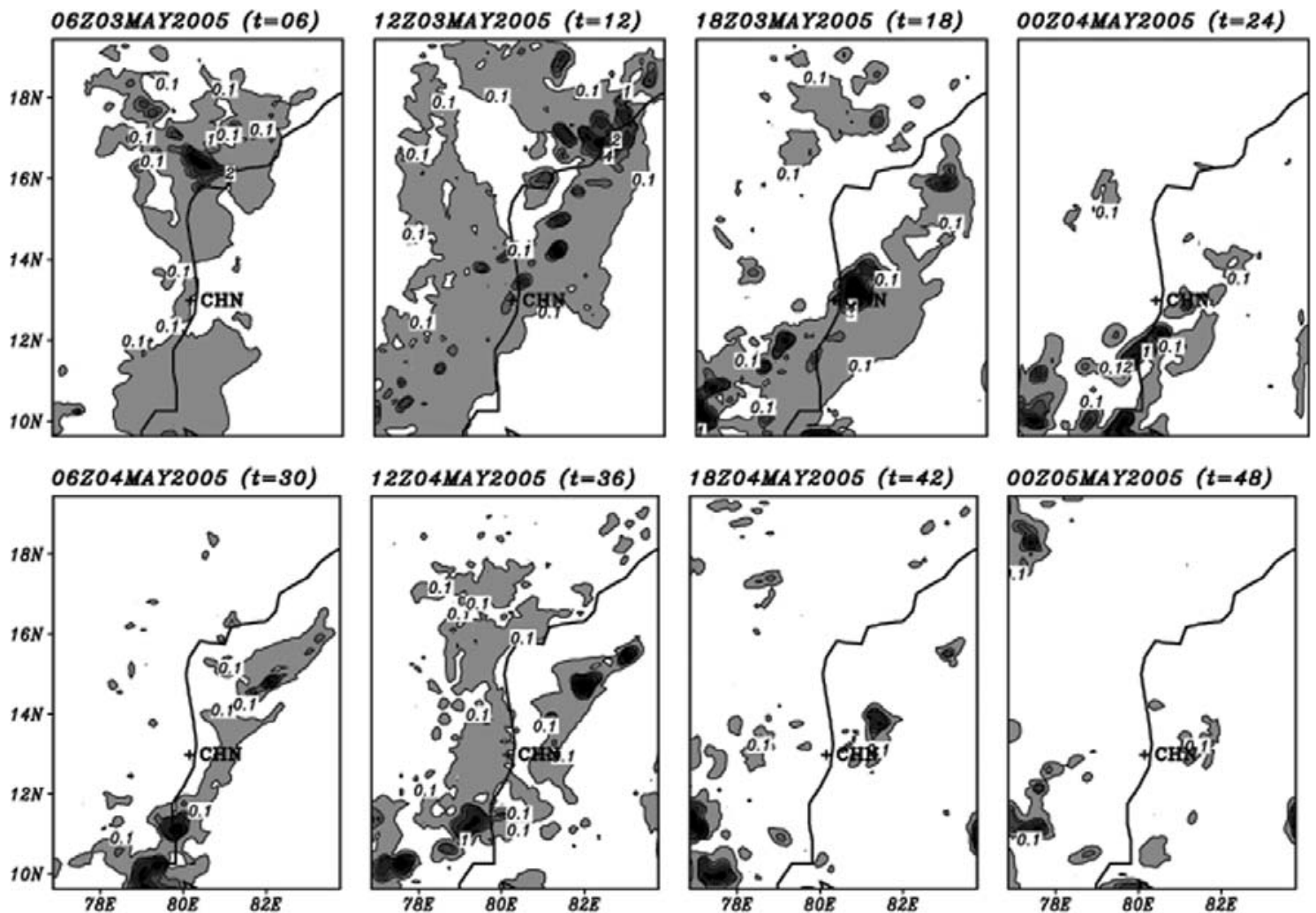

OOZ05MAY2005 $(t=48)$

Figure 18. (Continued)

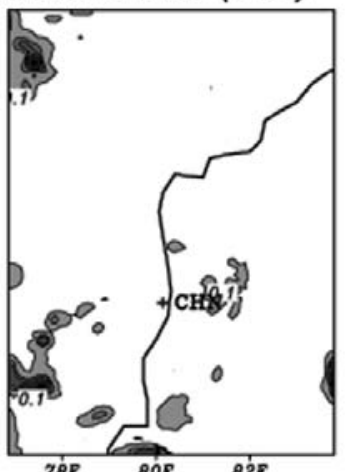


(c) 3DVAR_DWR
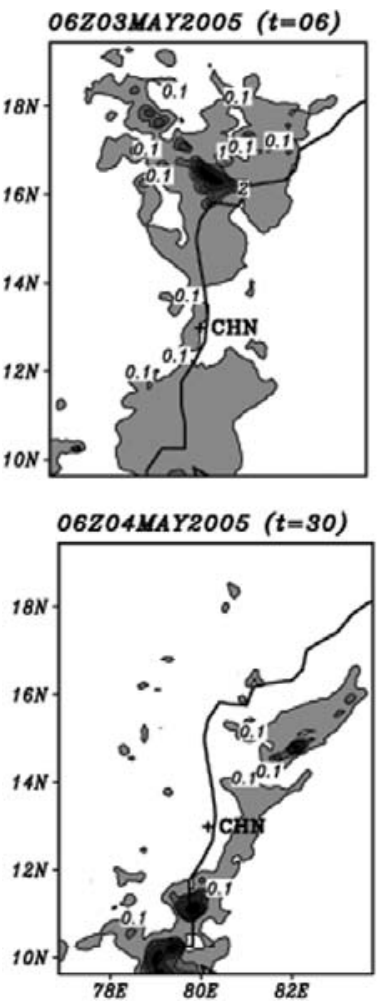
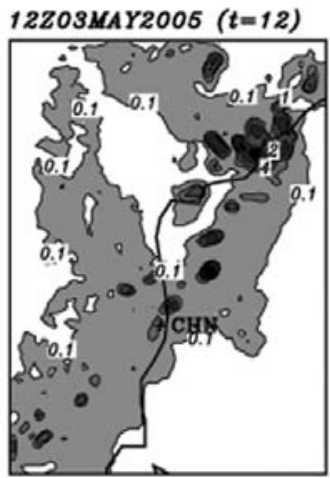

$12 Z 04$ MAY2005 ( $t=36)$

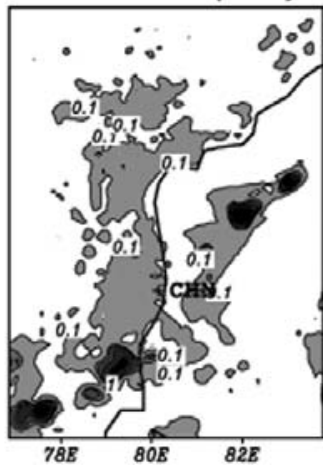

$18 Z 03 M A Y 2005(t=18)$

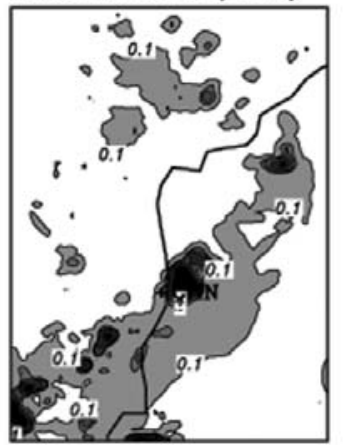

$18 Z 04$ MAY2005 $(t=42)$

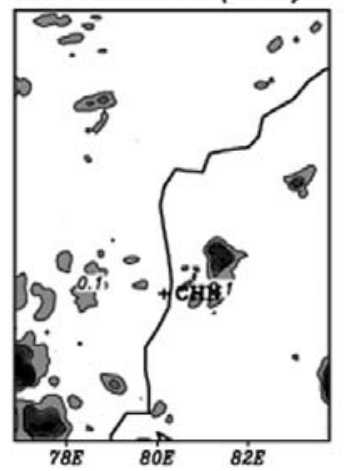

$00 Z 04 M A Y 2005(t=24)$

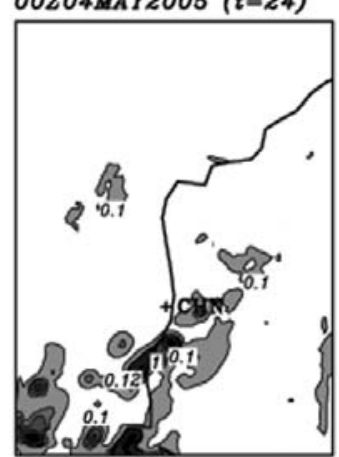

OOZ05MAY2005 $(t=48)$

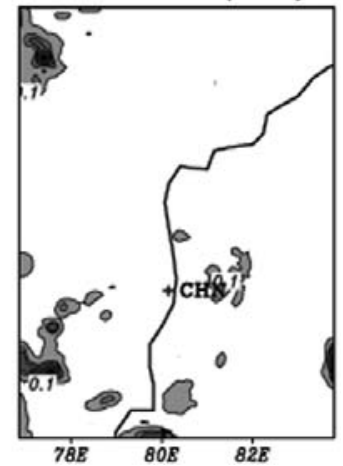

Figure 18(a-c). Six-hourly accumulated precipitation ( $\mathrm{cm}$ ) from the (a) CTRL_GSFC, (b) 3DVAR_NoDWR and (c) 3DVAR_DWR experiment based on initial condition of 00 UTC, 3 May 2005.

(a)

Threshold $=10 \mathrm{~mm}$

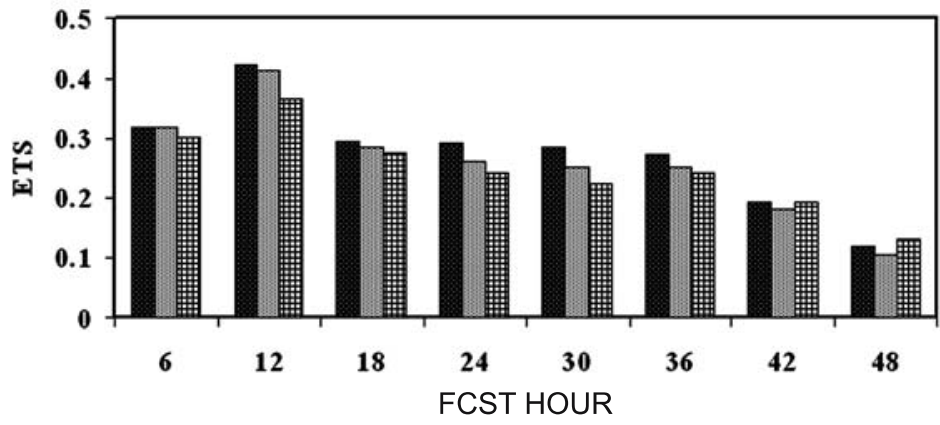

IDVAR_DWR G3DVAR_NoDWR 田CTRL_GSFC

(b)

Threshold $=20 \mathrm{~mm}$

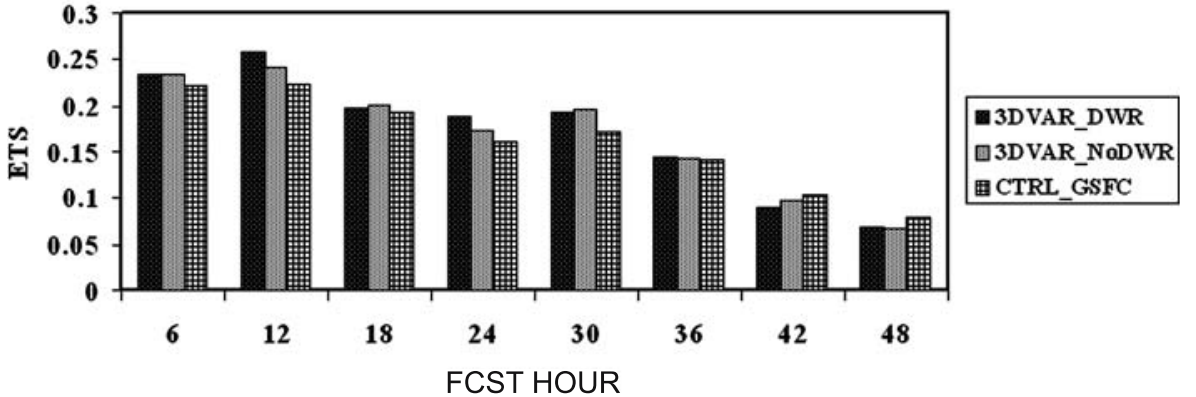

Figure 19. Equitable threat scores with a threshold of (a) $10 \mathrm{~mm}$ and (b) $20 \mathrm{~mm}$ for the three experiments. 
has a positive impact on the short range rainfall forecast. Significant improvements in the precipitation forecast appeared in the first 12-h forecast period. The ETS score decreases after 12-h forecast and remains more or less constant till 36$\mathrm{h}$ and thereafter ETS decreases considerably. The 3DVAR experiments produce higher scores as compared to the CTRL_GSFC experiments. The difference between the two assimilation experiments 3DVAR_DWR and 3DVAR_NoDWR are statistically less significant for both the precipitation thresholds. It may be kept in mind that the DWR wind fields are available only in one of the four assimilation cycles.

This work is a first attempt in utilizing IMD Doppler radar data in a numerical model for the prediction of rainfall associated mesoscale convective systems. The main purpose of assimilating the DWR wind data is to improve wind fields such as convergence in the initial condition for the prediction of intense convective events. The 3DVAR_NoDWR and 3DVAR_DWR experiment predicts the intensity and organization of rainbands convincingly well. The results from this study shows the positive impact of the assimilation of Doppler radar wind observations on the short range QPF. However, ETS from the 3DVAR_DWR and 3DVAR_NoDWR experiments are less significant and reveals the need to directly assimilate the reflectivity data in the regional assimilation system.

\section{Acknowledgements}

Results presented in this paper are based on the collaborative works between the National Center for Medium Range Weather Forecasting (NCMRWF), India Meteorological Department (IMD) and Cochin University of Science and Technology. We thank Mr. Prashant Mali and Dr. L Harendu Prakash for their initial help in reading the DWR data and graphic display of wind fields. We thank Dr. A K Bohra, Head, NCMRWF for providing the necessary facilities to carry out this work. Thanks are also due to Dr. B Lal (Director General of Meteorology, IMD), Dr. R C Bhatia (Additional Director General of Meteorology, IMD) for their help and support. The first author gratefully acknowledges Council of Scientific and Industrial Research (CSIR) for providing Junior Research Fellowship. We are grateful to the reviewers for their valuable comments that helped to improve the quality of the paper.

\section{References}

Barker D M, Huang W, Guo Y R and Al Bourgeois 2003 A Three Dimensional Variational (3DVAR) Data Assimilation System for Use with MM5, NACR Technical Note, NCAR/TN-453+STR, p. 68.

Barker D M, Huang W, Guo Y R and Xiao 2004 A three dimensional variational (3DVAR) Data Assimilation System with MM5: Implementation and initial results; Mon. Weather Rev. 132 897-914.

Das Gupta M, George J P and Das S 2005 Performance of MM5-3DVAR system over Indian sub-continent; Proceedings of International Conf. on MONEX and its legacy, 3-7 February 2005, Delhi.

Dudhia J, Gill D, Manning K, Wang W and Bruyere C 2002 PSU/NCAR Mesoscale modeling system (MM5 version 3) tutorial class notes and user's guide; Available from National Center for Atmospheric Research, Boulder, Colorado, USA, June 2002.

Grell G A, Dudhia J and Stauffer D R 1994 A description of the fifth-generation Penn State/NCAR Mesoscale model (MM5); NCAR technical note, NCAR/TN-398+STR, p. 117.

Hong S Y and Pan H L 1996 Non-local boundary layer vertical diffusion in a medium-range forecast model; Mon. Weather Rev. 124 2322-2339.

Houze R A Jr 1982 Cloud clusters and large-scale vertical motions in the Tropics; J. Meteor. Soc. Japan 60 396-410.

Ide K, Courtier P, Ghil M and Lorenc A C 1997 Unified notation for data assimilation: Operational, sequential and variational; J. Meteor. Soc. Japan 75 181-189.

Lorenc A C 1986 Analysis methods for numerical weather prediction; Q. J. R. Meteorol. Soc. 112 1177-1194.

Maddox R A 1980 Mesoscale convective complexes; Bull. Amer. Meteor. Soc. 108 1374-1387.

Mapes B and Houze R A Jr 1993 An integrated view of the 1987 Australian monsoon and its mesoscale convective systems. II: Vertical structure; Q. J. R. Meteorol. Soc. $119733-754$.

Nakazawa T 1988 Topical Super clusters within intraseasonal variations over western Pacific; J. Meteor. Soc. Japan 66 823-839.

Parish D F and Derber J C 1992 The National Meteorological Center's Spectral Statistical Interpolation Analysis System; Mon. Weather. Rev. 120 1747-1763.

Scott A and Houze R A Jr 1995 Melting and freezing in a mesoscale convective system; $Q$. J. R. Meteorol. Soc. 121 $55-77$.

Tao W K, Simpson J and McCumber M 1989 Ice-water saturation adjustment; Mon. Weather. Rev. 117 231-235.

Tao W K, Sui C H, Ferrier B, Lang S, Scala J, Chou M D and Pickering K 1993 Heating, moisture and water budgets of tropical and midlatitude squall lines: comparison sand sensitivity to longwave radiation; J. Atmos. Sci. $\mathbf{5 0}$ 673-690. 